\title{
INTERNATIONAL BANK FOR RECONSTRUCTION AND DEVELOPMENT
}

INTERNATIONAL DEVELOPMENT ASSOCIATION

INTERNATIONAL FINANCE CORPORATION

MULTILATERAL INVESTMENT GUARANTEE AGENCY

COUNTRY PARTNERSHIP FRAMEWORK

FOR

THE KINGDOM OF BHUTAN

FOR THE PERIOD FY2021-24

\section{Bangladesh and Bhutan Country Management Unit South Asia Region \\ The International Finance Corporation \\ Asia \& Pacific Region \\ The Multilateral Investment Guarantee Agency}

The date of the last Performance and Learning Review was May 17, 2017.

This document is being made publicly available prior to Board consideration. This does not imply a presumed outcome. This document may be updated following Board consideration and the updated document will be made publicly available in accordance with the Bank's policy on Access to Information. 


\begin{tabular}{|l|l|l|l|}
\hline & \multicolumn{1}{|c|}{ IDA } & \multicolumn{1}{c|}{ IFC } & \multicolumn{1}{c|}{ MIGA } \\
\hline Vice President: & Hartwig Schafer & Alfonso Garcia Mora & Ethiopis Tafara \\
Director: & Mercy Tembon & Mengistu Alemayehu & Merli Baroudi \\
Task Team Leaders: & Yutaka Yoshino & Wendy Jo Werner & Persephone Economou \\
& $\begin{array}{l}\text { Anne-Katrin Arnold } \\
\text { Tenzin Lhaden }\end{array}$ & Pia Trivedi & \\
\hline
\end{tabular}




\title{
ABBREVIATIONS AND ACRONYMS
}

\author{
CURRENCY EQUIVALENTS \\ Currency unit $=$ Ngultrum $(\mathrm{Nu})$ \\ US\$1 = Nu 73.95 (as of November 30, 2020)
}

FISCAL YEAR

July 1 -June 30

\begin{tabular}{|c|c|c|c|}
\hline ADB & Asian Development Bank & eGP & electronic government \\
\hline AMCHP & Accelerating Mother and Child & & \\
\hline \multirow[t]{2}{*}{ APA } & $\begin{array}{l}\text { Health Program } \\
\text { alternative procurement }\end{array}$ & FCDO & $\begin{array}{l}\text { Foreign, Commonwealth, and } \\
\text { Development Office }\end{array}$ \\
\hline & arrangement & FCS & Fragile and Conflict Situations \\
\hline ASAs & Advisory Services and Analytics & FDI & foreign direct investment \\
\hline BBIN & $\begin{array}{l}\text { Bangladesh, Bhutan, India, and } \\
\text { Nepal }\end{array}$ & FSAPP & $\begin{array}{l}\text { Food Security and Agricultural } \\
\text { Productivity Project }\end{array}$ \\
\hline CAD & current account deficit & $\mathrm{FY}$ & fiscal year \\
\hline \multirow[t]{2}{*}{ Cat DDO } & Catastrophe Deferred & FYP & Five Year Plan \\
\hline & Drawdown Option & G2P & government-to-people \\
\hline CEM & Country Economic & GDP & Gross Domestic Product \\
\hline \multirow[t]{2}{*}{ CLR } & $\begin{array}{l}\text { Memorandum } \\
\text { Completion and Learning }\end{array}$ & GAFSP & $\begin{array}{l}\text { Global Agriculture and Food } \\
\text { Security Program }\end{array}$ \\
\hline & Review & GNH & Gross National Happiness \\
\hline \multirow[t]{2}{*}{ CMAW } & Creating Market Advisory & GNI & Gross National Income \\
\hline & Window & GST & Goods and Services Tax \\
\hline $\mathrm{CO}_{2}$ & carbon dioxide & $\mathrm{HCl}$ & Human Capital Index \\
\hline COP21 & $21^{\text {st }}$ Conference of Parties & ICT & information and \\
\hline CPF & Country Partnership Framework & & communications technology \\
\hline CPS & Country Partnership Strategy & IT & information technology \\
\hline CRR & cash reserve ratio & IDA & International Development \\
\hline CSIs & cottage and small industries & & Association \\
\hline DFAT & Department of Foreign Affairs & IDA-19 & 19th IDA Replenishment \\
\hline DPC & $\begin{array}{l}\text { and Trade } \\
\text { Development Policy Credit }\end{array}$ & IFC & $\begin{array}{l}\text { International Finance } \\
\text { Corporation }\end{array}$ \\
\hline DPF & Development Policy Financing & IMF & International Monetary Fund \\
\hline DRF & Disaster Risk Financing & IFMIS & Integrated Financial \\
\hline DRM & Disaster Risk Management & & Management Information \\
\hline DSA & Debt Sustainability Analysis & & System \\
\hline ECCD & early childhood care and & IPF & Investment Project Financing \\
\hline & ppment & IT & information technology \\
\hline ECB & external commercial borrowing & ITES & IT-enabled service \\
\hline ECP & Economic Contingency Plan & JICA & $\begin{array}{l}\text { Japan International } \\
\text { Cooperation Agency }\end{array}$ \\
\hline
\end{tabular}




\begin{tabular}{|c|c|c|c|}
\hline JSDF & Japan Social Development Fund & SOE & state-owned enterprise \\
\hline LDC & Least Developed Country & TA & technical assistance \\
\hline MAPS & Methodology for Assessing & TF & trust fund \\
\hline Mbps & $\begin{array}{l}\text { Procurement System } \\
\text { megabits per second }\end{array}$ & TVET & $\begin{array}{l}\text { technical and vocational } \\
\text { education }\end{array}$ \\
\hline $\mathrm{MCH}$ & maternal and child health & UNFCCC & United Nations Framework \\
\hline MIGA & Multilateral Investment & & Convention on Climate Change \\
\hline & Guarantee Agency & UNICEF & United Nations Children's Fund \\
\hline MSMES & $\begin{array}{l}\text { micro, small, and medium } \\
\text { enterprises }\end{array}$ & WBG & World Bank Group \\
\hline NDC & $\begin{array}{l}\text { Nationally Determined } \\
\text { Contribution }\end{array}$ & & \\
\hline NKRA & National Key Results Area & & \\
\hline NPL & non-performing loan & & \\
\hline NPRP & $\begin{array}{l}\text { National Preparedness and } \\
\text { Response Plan }\end{array}$ & & \\
\hline ODA & Official Development Assistance & & \\
\hline PEF & $\begin{array}{l}\text { Pandemic Emergency Financing } \\
\text { Facility }\end{array}$ & & \\
\hline PEFA & $\begin{array}{l}\text { Public Expenditure Fiduciary } \\
\text { Assessment }\end{array}$ & & \\
\hline PER & Public Expenditure Review & & \\
\hline PFM & Public Financial Management & & \\
\hline PFM & public financial management & & \\
\hline PFM-MDF & $\begin{array}{l}\text { Public Financial Management } \\
\text { Multi-Donor Fund }\end{array}$ & & \\
\hline PforR & Program-for-Results & & \\
\hline PLR & $\begin{array}{l}\text { Performance and Learning } \\
\text { Review }\end{array}$ & & \\
\hline PPA & Performance and Policy Action & & \\
\hline PPG & public and publicly guaranteed & & \\
\hline REDD+ & $\begin{array}{l}\text { Reducing Emissions from } \\
\text { Deforestation and Forest } \\
\text { Degradation Readiness }\end{array}$ & & \\
\hline RETF & recipient executed trust fund & & \\
\hline RMA & Royal Monetary Authority & & \\
\hline RWCAR & $\begin{array}{l}\text { risk-weighted capital adequacy } \\
\text { ratio }\end{array}$ & & \\
\hline SCD & Systematic Country Diagnostic & & \\
\hline SDFP & $\begin{array}{l}\text { Sustainable Development } \\
\text { Finance Program }\end{array}$ & & \\
\hline SLR & statutory liquidity ratio & & \\
\hline SMES & small and medium enterprises & & \\
\hline
\end{tabular}




\section{TABLE OF CONTENTS}

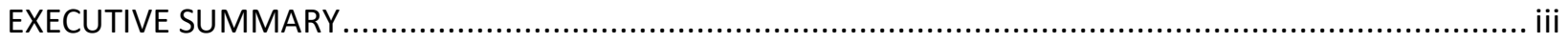

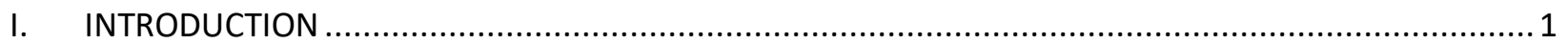

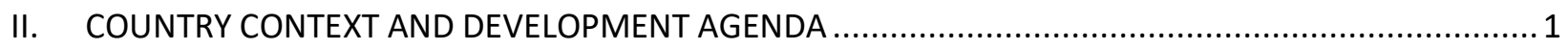

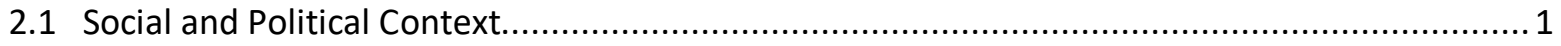

2.2 Recent economic developments and macroeconomic outlook ........................................ 2

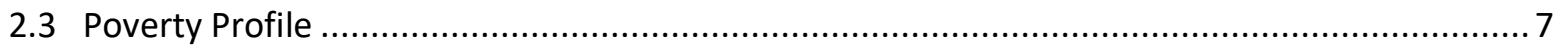

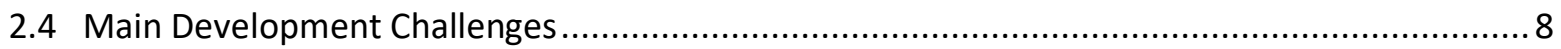

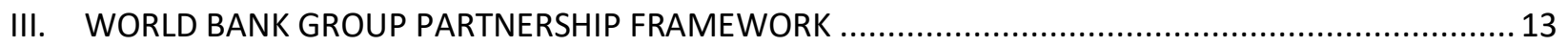

3.1 The Government's Program and Medium-Term Strategy................................................. 13

3.2 Lessons from the Completion and Learning Review for the FY15-FY19 CPS.......................... 14

3.3 The Proposed Country Partnership Framework ......................................................... 16

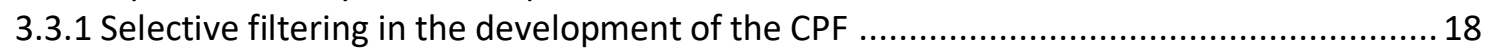

3.4 Focus Areas and Objectives of the Country Partnership Framework ................................... 21

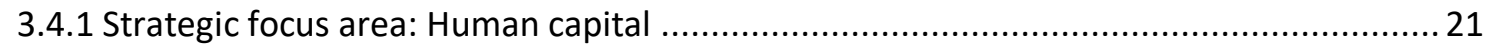

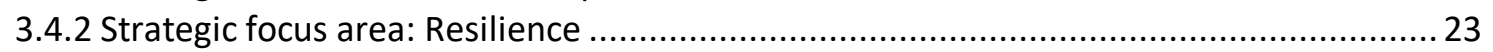

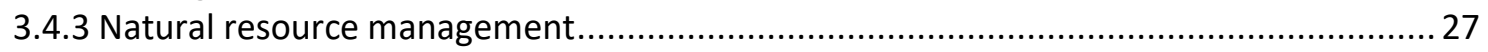

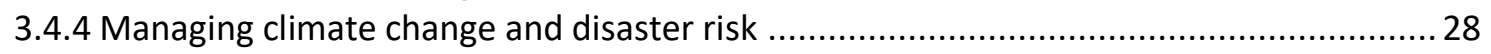

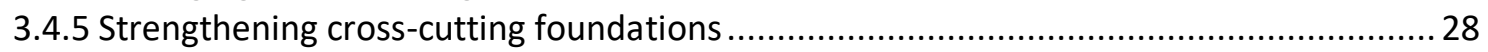

3.5 Implementing the Country Partnership Framework ...................................................... 30

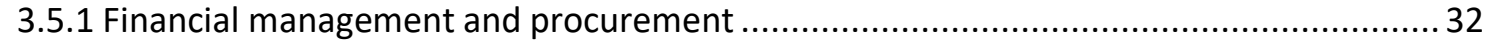

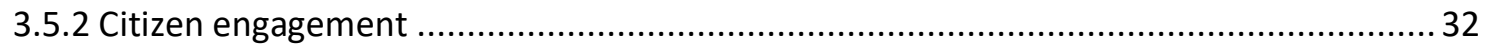

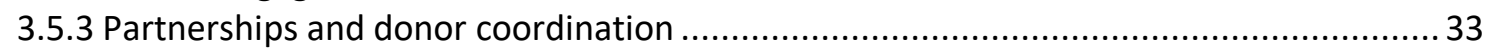

IV. MANAGING RISKS TO THE COUNTRY PARTNERSHIP FRAMEWORK PROGRAM.............................. 34

\section{TABLES}

Table 1. Selected economic and financial indicators in Bhutan, FY16/17-23/24............................... 6

Table 2. Development challenges and priorities identified by the 2020 Systematic Country Diagnostic .... 8

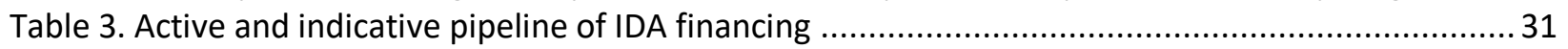

Table 4. Pipeline of World Bank Group advisory services and analytics ............................................ 31

Table 5. Evaluation of risks of the Country Partnership Framework..................................................... 34

\section{FIGURES}

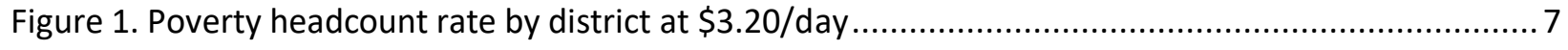

Figure 2. NKRA under Bhutan's 12th Five-Year Plan ..................................................................... 14

Figure 3. Strategic focus areas, objectives, cross-cutting foundation, and implementation approach ..... 17

Figure 4. The Country Partnership Framework at the intersection of selectivity criteria ....................... 19

Figure 5. Linkages Country Partnership Framework, Systematic Country Diagnostic, gvt. priorities ........ 19

\section{BOXES}

Box 1. Gross National Happiness (GNH) in practice - Bhutan's unique approach to development............2

Box 2. Bhutan's response to the COVID-19 pandemic and World Bank Group support for its efforts ...... 10

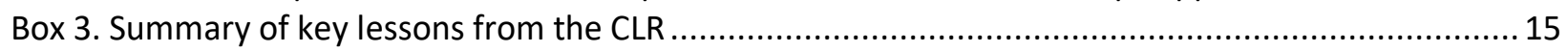

Box 4. Summary of findings from the 2019 Bhutan Country Opinion Survey ..................................... 16

Box 5. Potential benefits of regional cooperation for Bhutan ......................................................... 21

Box 6. Developing a vibrant but sustainable forest sector in the Republic of Korea ............................. 27

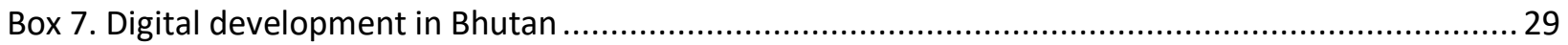




\section{ANNEXES}

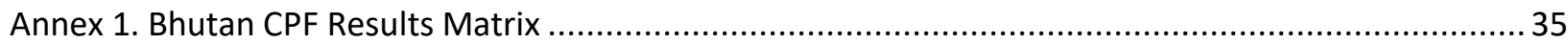

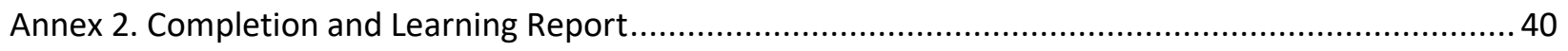

Annex 3. Selected Indicators of Bank Portfolio Performance and Management ...................................61

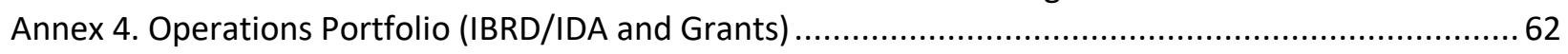

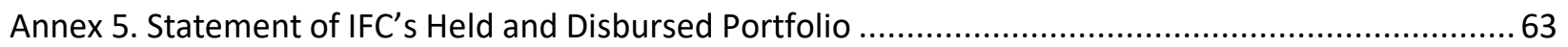




\section{FY21-24 COUNTRY PARTNERSHIP FRAMEWORK FOR}

\section{THE KINGDOM OF BHUTAN}

\section{EXECUTIVE SUMMARY}

i. Bhutan has unique geographical, historical, and cultural characteristics. A small, landlocked country nestled in the Himalayas, Bhutan has steep mountains, deep valleys, and scattered settlements. Nearly half the country's land area is protected to preserve biodiversity. With forest coverage exceeding 70 percent, Bhutan is the world's only country with negative carbon emissions. The country's constitution stipulates that 60 percent of all land must be covered by forests at any time. This constitutional requirement is indicative of Bhutan's commitment to preserving its unique natural, cultural, historic, and religious characteristics.

ii. The country's unique philosophy is expressed by Bhutan's Gross National Happiness (GNH) as the guiding principle of development. Coined in 1972 by its fourth king, Jigme Singye Wangchuck, GNH stands for "development with [...] fundamental values of kindness, equality and humanity and the necessary pursuit of economic growth." ${ }^{1}$ Self-sufficiency, preservation, and conservation of the environment and culture remain at the heart of Bhutan's approach to development.

iii. The philosophy of preservation and conservation has been coupled with rapid development progress and economic growth in the last decade. Much of the growth has been driven by public sectorled hydropower development and the sale of electricity to neighboring India. Since the early 1980s, real Gross Domestic Product (GDP) has grown at an average annual rate of 7.5 percent, making Bhutan one of the fastest-growing countries in the world. With Gross National Income (GNI) per capita of US\$2,970 in 2018, the country is approaching the threshold for upper-middle-income countries. From 2007 through 2017, Bhutan reduced poverty by two-thirds, from 36 percent to 12 percent, based on the $\$ 3.20 /$ day poverty line. Hydropower projects have helped the government create fiscal space for investing in human and physical capital, allowing Bhutan to significantly improve services, education, and health. Access to electricity has become almost universal.

iv. Despite impressive economic progress, Bhutan's private sector remains nascent and unable to create competitive jobs. Supporting the development of a robust private sector will require addressing issues of access to finance, improving skills mismatches, developing a startup ecosystem, improving connective infrastructure, and lifting regulatory bottlenecks. A paradigm shift of treating the private sector as a contributor and a partner in development rather than a beneficiary of development is urgently needed.

v. Dependence on hydropower makes Bhutan's economy highly vulnerable to macroeconomic volatility and climate shocks. Delays in hydropower plant construction limit electricity generation, which adversely affects exports, growth, and revenues. Hydropower investments have generated a large external deficit, which has been financed by borrowing from India. This borrowing has led to large accumulation of external debt (105 percent of GDP in 2018/19) and Bhutan's external debt distress risk has remained moderate only because of special financing arrangements with India. A regional dialogue

\footnotetext{
${ }^{1}$ Bhutan Foundation (2020). About Bhutan: Land of the Thunder Dragon. https://bhutanfound.org/about-us/about-bhutan/
} 
on cross-border electricity exports in South Asia has been evolving and efforts are needed to diversify export markets and financing sources beyond India.

vi. Bhutan has made significant progress improving human capital but still has a long way to go to realize its full potential. Human capital includes the health, education, and skills that an individual accumulates throughout their life to reach their potential. Building human capital is critical for countries to compete in the economy of the future. A child born today in Bhutan will be only 48 percent as productive in adulthood as she could have been with a complete education and better health care. Some estimates show that GDP per worker could be as much as 2.2 times higher if the quality and quantity of human capital were improved. Investments in human capital are also essential for the development of a vibrant private sector through a larger, better-educated and young workforce that can be employed in productive jobs and, thereby, earn higher incomes and catalyze economic growth.

vii. The COVID-19 pandemic and resulting global economic downturn will likely create substantial development challenges in Bhutan. Although Bhutan has a relatively small number of COVID-19 cases, the pandemic's significant disruptions of domestic production, tourism, and other services are expected to slow growth in FY20 and beyond. Job losses from the pandemic may also have negative social impacts. Given Bhutan's existing high levels of malnutrition, food security needs to be monitored closely, especially in remote areas.

viii. Bhutan is at a crossroads: It can maintain the current pattern of development-with rising inequality-or develop a vibrant private sector to generate jobs and diversify the economy, building resilience to future external shocks. The public sector, the largest formal employer, employs about 20 percent of the workforce and the hydropower sector employs less than 1 percent. Establishing an enabling environment for the private sector is critical to create more jobs, particularly for youth and in rural areas. Bhutan relies heavily on state-owned enterprises (SOEs) to provide essential goods and services because the domestic market is small and the private sector embryonic. Structural reforms are needed to create incentives for private sector investments, including in sectors with high potential for job creation, such as cottage and small industries (CSIs), agribusiness and tourism. To facilitate private investments, physical and digital infrastructure is needed to improve connectivity within the country and with neighbors, and to bring Bhutan's local producers into regional and global value chains.

ix. Supporting development in Bhutan means maintaining a balance between the country's constitutional commitment to cultural preservation and environmental conservation and the need for a diversified economy and strong private sector. A successful development model will integrate the country's unique philosophy by promoting diversification, self-reliance, and private sector growth with an emphasis on equity and resilience. An outward-oriented growth model, led by the private sector and global integration, faces inherent tensions with the country's cautious, state-managed approach to development. A nuanced, long-term approach to private sector growth can allow for slow adaptation that does not contradict the country's philosophy.

$x$. The overarching priority of this Country Partnership Framework (CPF) is job creation. The government recognizes the urgency to create high-quality jobs that keep young people employed in the country and allow Bhutan to benefit from the demographic dividend. Approaching jobs in a holistic manner-from both the supply and the demand side-will allow the World Bank Group (WBG) to provide support to Bhutan in a manner that responds to the government's priorities, draws on the WBG's comparative advantage, and respects Bhutan's commitment to preservation and conservation. 
xi. This CPF presents an integrated framework of WBG support to help Bhutan achieve inclusive and sustainable development through private sector-led job creation. It has two strategic focus areas: human capital and resilience, particularly economic and environmental resilience for job creation, with support for both the supply side and the demand side of jobs. The Framework seeks to achieve its objectives by: (a) catalyzing existing government initiatives and the private sector; (b) creating sustainable impact by supporting programs with clear, measurable outcomes; and (c) optimizing WBG engagement by diversifying and targeting the instruments used to support Bhutan.

- Human capital. Human capital investments will strengthen the supply side of jobs and help mitigate challenges to human capital development caused by the COVID-19 pandemic. The WBG will help Bhutan unlock its human capital potential with a life-cycle approach that provides support to mothers and to children from early childhood through their entrance into the labor market.

- Economic resilience. The WBG will undertake a two-pronged approach to increase economic resilience. At a macro level, it will support government efforts to recover from the COVID-19 economic downturn and maintain macroeconomic stability through measures to address fiscal sustainability, policy reforms, and institutional development that can provide an enabling environment for private sector investment. At micro and sector levels, the WBG will intervene in areas with potential for private sector job creation, particularly in rural areas. Interventions will include support to develop CSIs and high-value agribusiness. Other interventions will increase improvements in financial inclusion through microfinance and digital financial services for underserved populations such as microenterprises, farmers, and rural households. The WBG will engage in reform dialogues in areas such as sustainable tourism and hydropower that hold potential for future private sector investments.

- Environmental resilience. Preservation of natural resources is integral to Bhutan's development philosophy and provides unique opportunities for growth, including for underserved populations. A shift from conservation and subsistence-based management to conservation and sustainableuse management-plus effective management of climate and natural disaster risks-would harness this potential while maintaining high forest cover and protected areas.

xii. As a landlocked economy with a small domestic market, Bhutan could significantly benefit from deeper regional integration with its neighbors. Removing barriers to cross-border trade such as transport infrastructure bottlenecks and policy and institutional constraints would help economic diversification and job creation. An ongoing regional dialogue about cross-border electricity exports could help Bhutan find new opportunities to diversify its electricity sales. This CPF leverages the WBG's regional programs in addressing these barriers to foster closer ties with neighboring countries.

xiii. The WBG's COVID-19 response for Bhutan is fully integrated in this CPF. It is fully aligned with the WBG COVID-19 Crisis Response Approach Paper (June 2020). ${ }^{2}$ Through its strategic focus on human capital, this CPF will support Bhutan's efforts to strengthen its health system and pandemic preparedness. A strategic focus on resilience will help accelerate economic recovery by fostering private sector job creation and economic diversification.

\footnotetext{
${ }^{2}$ World Bank Group "Saving Lives, Scaling-up Impact and Getting Back on Track: World Bank Group COVID-19 Crisis Response Approach Paper", June 2020.
} 


\section{INTRODUCTION}

1. The FY21-24 Country Partnership Framework (CPF) is underpinned by the Royal Government of Bhutan's 12th Five-Year Plan (FYP), which covers the period from 2018 through 2023 and is dedicated to creating a "just, harmonious and sustainable society through enhanced decentralization." The CPF builds on and expands the main findings from the review of the government's 11th FYP and the 2015 Gross National Happiness (GNH) Index; the current program of the World Bank Group (WBG) in Bhutan as well as the WBG's Twin Goals and comparative advantage; the Systematic Country Diagnostic (SCD) completed in 2020; lessons learned from the Completion and Learning Review (CLR) assessing the outcomes of the previous Country Partnership Strategy (CPS); the 2019 Country Opinion Survey; and consultations with stakeholders.

\section{COUNTRY CONTEXT AND DEVELOPMENT AGENDA}

\subsection{Social and Political Context}

2. Bhutan is a small, landlocked country deep in the eastern Himalayas between India and China. Over a horizontal distance of just 100-150 kilometers, the elevation rises from about 150 meters above sea level in the south to over 7,000 meters in the north. The country's population of about 735,000 is scattered across steep mountain slopes and valleys, many in remote and far-flung hamlets, making Bhutan one of the most sparsely populated countries in the world. With forest coverage exceeding 70 percent, Bhutan is the only country in the world that absorbs more greenhouse gas emissions than it produces.

3. Despite its location between two large regional powers, the country has preserved its political independence and rich cultural heritage throughout its history. Bhutan's political system evolved rapidly over the past decade, from an isolated absolute monarchy into a democratic constitutional monarchy, with a remarkable degree of stability and continuity. Having opened up to other countries only in the early 1970s, Bhutan maintains strong relations with neighboring India and enjoys good bilateral and multilateral relations with its diplomatic partners and neighboring countries. The current government, which assumed office on November 7, 2018, is the third elected government. The political environment is stable and Bhutan's governance track record is sound ${ }^{3}$. This has allowed the government to accelerate reform efforts.

4. Recent changes in the country's social fabric have opened opportunities to improve Bhutan's human capital. Human capital has developed unevenly as young Bhutanese migrate to the cities in search of better jobs and living conditions, breaking up the tradition of large extended families as the backbone of society. Gender inequalities have increased as educated women have less economic mobility than male peers. Spatial disparities also affect human capital development, as people and services are concentrated in Bhutan's capital, Thimphu. New sociocultural patterns, influenced by outside values, are transforming how people live, work, move, and relate to others.

5. Bhutan is the only country in the world with an approach to development that does not focus on economic growth and per capita income. Gross National Happiness (GNH) is central to the Bhutanese model, which pursues a harmonious balance of the spiritual, cultural, emotional, and material well-being

\footnotetext{
${ }^{3}$ Bhutan ranked 27th among 168 countries on Transparency International's 2015 Corruption Perception Index, and it exceeded 60 percentile ranking in four of the six dimensions of governance (government effectiveness, political stability and absence of violence, rule of law, and control of corruption) in the WBG's 2018 Worldwide Governance Indicators
} 
of society and nature (Box 1). Under this development paradigm, instead of pursuing purely economic growth, Bhutan seeks to maximize happiness as the guiding metric for development. The concept recognizes not only individuals' material needs but also their spiritual and emotional needs. The approach is grounded in four pillars: (a) sustainable and equitable socioeconomic development; (b) preservation and promotion of culture; (c) conservation and sustainable utilization and management of the environment; and (d) promotion of good governance. In July 2011, Bhutan's proposed General Assembly resolution, "Happiness: Towards a Holistic Approach to Development", was unanimously adopted by the 193 members of the United Nations, officially placing the GNH development philosophy in the global development arena.

Box 1. Gross National Happiness (GNH) in practice - Bhutan's unique approach to development To realize GNH principles in policy making, two institutions-the Center for Bhutan Studies and the GNH Center-have been established along with a measurement system, the GNH Index. GNH has four interdependent pillars that guide development in the nation: (i) equitable and sustainable socioeconomic development; (ii) preservation and promotion of culture; (iii) environmental conservation; and (iv) good governance. Starting with Bhutan's constitution, which explicitly defines the government's responsibility to "promote those conditions that will enable the pursuit of Gross National Happiness," all government policies, programming, and development activities undergo a GNH "filter" against the GNH Index, and their impact is assessed through the GNH Policy Screening Tool.

The GNH Index includes both conventional areas of socioeconomic concerns, such as living standards, health, and education, and Bhutanese values of cultural and psychological well-being. To measure impacts and calibrate policies and programming, the government has classified the four GNH pillars into nine domains, reflecting a holistic range of $\mathrm{GNH}$ values: psychological well-being, health, time use, education, cultural diversity and resilience, good governance, community vitality, ecological diversity and resilience, and living standards. All nine domains are equally weighted, as each domain is considered to be equal in terms of its importance to $\mathrm{GNH}$.

In 2009, the government introduced the GNH Policy Screening Tool. The tool monitors progress and ensures that new policies are fully aligned with GNH principles.

\subsection{Recent economic developments and macroeconomic outlook}

6. Bhutan's economy has been driven largely by hydropower, which has contributed to rapid growth through investments, exports, and government revenues. The state-led hydropower sector currently accounts for about 26 percent of GDP 4,28 percent of exports and 22 percent of domestic revenues. ${ }^{5}$ Most hydropower projects are financed by India and based on a special intergovernmental agreement under which all surplus hydroelectricity-nearly 70 percent of total generation-is exported to India at cost plus 15 percent. ${ }^{6}$ Meanwhile, hydro-related borrowings are part of the public debt stock but hydro-related

\footnotetext{
4 This figure includes electricity (12 percent) and construction (14 percent) sector activities, which are mainly related to hydropower production and construction (NSB 2019). Hydro exports and revenue shares are provided for 2018/19 (actuals).

${ }^{5}$ The government receives hydro-related revenues in the form of royalties, a one-time profit transfer when a project is handed over to the government of Bhutan, and corporate income taxes and dividends from the Druk Green Power Corporation Limited (DGPC), a state-owned enterprise.

${ }^{6}$ Most of the hydropower projects are financed through commercially priced loans and capital grants from India. The government of India covers both financial and construction-related risks to the projects and buys surplus electricity at a price reflecting cost plus a 15 percent net return. Debt service begins only after the projects are on-streamed. This arrangement has supported debt sustainability in Bhutan.
} 
spending is not included in the budget. The mega-hydropower projects have resulted in a savinginvestment imbalance, with high external deficits and debt.

7. Tourism is another important sector for Bhutan's development. Growth is supported by the services sector, mainly transport, communications, retail, hotels, and restaurants. Tourism is also the leading sector for foreign direct investment (FDI) in Bhutan. Tourism accounts for 42 percent of FDI, although the total volume of FDI in the country is significantly low, at about US\$6.5 million in 2017 and US\$24.5 million in 2018. ${ }^{7}$ The number of tourists rose almost threefold in less than a decade to 316,000 in 2019, of which about 243,000 came from neighboring countries such as India and Bangladesh.

8. The COVID-19 pandemic has profoundly affected the Bhutanese economy and is expected to have possibly long-lasting effects. Economic growth was slowing before the COVID-19 pandemic began (see Table 1) due to subdued performance in the hydropower and tourism sectors. Real GDP growth is expected to fall from an estimated 3.8 percent in FY2018/19 ${ }^{8}$ to 1.5 percent in $\mathrm{FY} 2019 / 20 .{ }^{9}$ This is significantly lower than the pre-COVID-19 forecast of 5.5 percent. ${ }^{10} \mathrm{~A}$ sharp drop in tourist arrivals in the second half of FY2019/20 has dampened tourism-related services growth and exports. Additionally, domestic containment measures, including school closures and social distancing, have significantly depressed consumption and services activities that require close human interaction. Manufacturing, construction and other non-hydro exporting industries have been adversely affected in the second half of FY2019/20 through disruptions to critical inputs, temporary export restrictions, foreign labor shortages and lower external demand, especially from India. In contrast, hydropower production and exports increased in FY2019/20 due to the on-streaming of the Mangdechhu Hydropower Project (720 megawatt), supporting industry sector growth. Nevertheless, growth is expected to remain subdued in the medium term given the uncertainties surrounding the pandemic.

9. Inflation accelerated in the wake of the COVID-19 pandemic, driven by food price inflation. Average inflation was low in FY2018/19, standing at 2.8 percent, reflecting a decrease in food prices. While inflation remained modest in the first half of FY2019/20, averaging 2.5 percent (year-on-year), it accelerated to 4.5 percent in June 2020. This was primarily due to an increase in local and imported food prices from India, with food price inflation accelerating to 9.2 percent (year-on-year) in April 2020, before slowing to 8.9 percent in June. Inflation is expected to remain elevated in the short term, mainly due to food price inflation, before moderating in the medium term. Monetary policy is anchored by the currency peg of the Bhutanese ngultrum to the Indian rupee at par value, contributing to price stability in the country. The Royal Monetary Authority (RMA) of Bhutan does not have an explicit inflation target and uses the cash reserve ratio (CRR) and the statutory liquidity ratio (SLR) to manage credit growth and interventions in the foreign exchange markets targeted at maintaining the exchange rate peg. RMA cut the CRR by 300 basis points in April 2020 to improve liquidity in the banking system and facilitate the implementation of monetary relief measures.

10. The economic downturn and heightened uncertainty have increased financial sector vulnerabilities. While financial soundness indicators improved by end-2019, with the non-performing loan (NPL) ratio decreasing from 18.4 percent in September 2019 to 10.9 percent in December, the NPL ratio rose back to

\footnotetext{
7 Deduced from Ministry of Economic Affairs, FDI Annual Bulletin 2019

8 The fiscal year is from July to June.

9 The growth forecast for 2019/20 is based on World Bank staff projections since no quarterly GDP estimates are available for Bhutan. National accounts estimates are available for 2018.

10 World Bank Bhutan Development Update, January 2020.
} 
19.5 percent as of March 2020, reflecting mid-year cyclical factors. ${ }^{11}$ Provisioning coverage ratio for NPLs are high, standing at 68.6 percent in December 2019. While the financial sector has adequate cushion to absorb potential losses given its capital adequacy (the risk weighted capital adequacy ratio (RWCAR) stood at 14.2 percent in December 2019), disruptions caused by COVID-19 to households and businesses could add more stress to the financial sector. The RMA has introduced a set of relief measures to address the impact of COVID-19, including a debt moratorium and an interest waiver (including for NPLs), the provision of working capital and loans for the tourism, manufacturing and wholesale trade sectors at concessional terms, and micro loans for the cottage and small industries (CSIs) sector. It will be important to ensure strong macro-prudential measures and close surveillance and supervision to maintain the stability of the financial sector.

11. While the economy's overall external balance has remained stable, COVID-19 is expected to sharply reduce exports and imports in line with weak foreign and domestic demand. The current account deficit (CAD) is estimated to have narrowed from 22.5 percent of GDP in FY2018/19 to 14 percent of GDP in FY2019/20, with the reduction in imports having a greater overall impact on the trade balance. While hydropower exports increased in line with higher production, exports of non-hydro goods and services have been severely impacted by the border closure and lower external demand. Meanwhile, goods imports declined as the pandemic curbed public investment projects and further delayed hydropower construction. The CAD is expected to remain narrow over the medium term as COVID-19 related disruptions weigh on exports and imports. International reserves are projected to remain adequate at 9.5 months of next year's imports of goods and services by end-2023/24.

12. The fiscal balance is expected to deteriorate as the government implements economic stimulus measures to lift the economy. The fiscal balance is estimated to have deteriorated from a surplus of 0.7 percent of GDP in FY2018/19 to a deficit of 3.1 percent of GDP in FY2019/20. This was due to a large increase in current spending, while total revenues also rose but to a lesser extent. Current spending has been driven by salary increases in the public sector, as well as higher government spending to fund public health measures (including stocking essential goods). Capital expenditures are believed to have remained subdued in FY2019/20 as the government strove to reduce non-priority spending. Hydropower revenues increased due to a one-off profit transfer from the commissioning of the Mangdechhu hydropower plant. This was partly offset by a decrease in non-hydro revenues as a result of the discontinuation of excise duty refunds from India and lower tourism receipts. The tax-to-GDP ratio is projected to have decreased from 15.4 percent of GDP in FY2018/19 to 13.4 percent of GDP in FY2019/20, its lowest level since 2008/09. Tax collection was low by international standards before the COVID-19 crisis, primarily because of a narrow tax base, widespread exemptions, and a limited share of the private sector in the economy. The fiscal deficit is projected to remain elevated in the medium term as growth and non-hydro revenues remain subdued and the government implements COVID-19 relief and recovery measures.

13. Public debt levels remain high, but risks are moderate, as most of the external debt is linked to hydropower project loans backed by an intergovernmental agreement with India. Public debt as a share of GDP is high, estimated at 109.1 percent as of June 2020. However, the 2018 Debt Sustainability Analysis (DSA) carried out jointly by the International Monetary Fund (IMF) and the World Bank assessed Bhutan

\footnotetext{
11 The financial sector experiences significant fluctuations in its NPL ratio for the following reasons (i) NPLs are written off periodically; (ii) financial instruments are not well aligned with borrowers' expected cash flow distribution; and (iii) there are seasonal repayments based on the borrowers' activities.
} 
to be at moderate risk of debt distress. ${ }^{12}$ Public and publicly guaranteed (PPG) debt stood at 109.1 percent of GDP as of June 2020, of which hydropower debt accounted for 75.5 percent (equivalent to 82.4 percent of GDP). Around 95 percent of PPG debt is external with a long-term maturity, of which the majority is linked to hydropower project loans from the Government of India. The hydropower debt is denominated in rupees, electricity export receipts are also in rupees and the Bhutanese currency is pegged at par with the rupee, thereby reducing exchange rate risks. Risks stemming from non-hydropower debt are low. The share of external non-hydropower debt, stood at 24.6 percent of GDP as of June 2020, owed mostly to the Asian Development Bank (ADB) and the International Development Association (IDA), on concessional terms. Domestic debt is modest (estimated at 2.2 percent of GDP). Total public debt-to-GDP ratio is expected to remain elevated due to low economic growth, before gradually declining in the medium term.

14. The government has outlined a Comprehensive National Response to COVID-19 to protect vulnerable households and minimize the impact on employment, growth, and financial stability. Health measures are aimed at containing the pandemic and strengthening healthcare system resilience. Social protection measures include an income support program targeted at vulnerable populations and measures to increase food security. The government also implemented a set of fiscal and monetary policy measures in March and June 2020 to provide immediate relief to affected households and businesses, including an interest waiver to all borrowers for the period April 2020 to March 2021. To support economic recovery and growth, the government is prioritizing the implementation of the Economic Contingency Plan (ECP) with a focus on agriculture and farm roads, tourism and construction, and bringing forward and reprioritizing the 12 th FYP activities. ${ }^{13}$

15. Although downside risks have increased significantly because of COVID-19, the government remains committed to maintain overall macroeconomic stability. Given the unpredictability of the pandemic's course, there is a high degree of uncertainty over Bhutan's growth forecast. The most acute risk to the outlook is a scenario of large-scale community transmission. This would trigger prolonged mobility restrictions and result in substantial societal and economic costs. Other domestic risks include lower-than-expected hydropower production and delays in the implementation of the goods and services $\operatorname{tax}$ (GST) and other revenue measures, which are critical to offset the decline in excise duties and grant financing in the medium to long term. Another risk is the materialization of financial sector contingent liabilities, which could strain government finances. On the external front, a protracted outbreak globally and in India could reduce economic growth further and delay the recovery, given significant tourism and trade linkages. The government has taken steps to reduce the economic risk from COVID-19 and begun mobilizing resources for a comprehensive economic support package. Apart from COVID-19, Bhutan's macroeconomic fundamentals have remained sound. Although external debt is high, the intergovernmental agreement with India guarantees returns and mitigates risks. The government remains committed to macro-fiscal prudence, as evidenced by its efforts to adopt fiscal stabilization measures, implement GST, improve spending efficiencies through strengthened public financial management, and maintain the currency peg to the Indian rupee.

\footnotetext{
12 The next joint IMF-World Bank DSA for Bhutan is scheduled for 2020.

13 IMF (2020). Policy Reponses to COVID-19 - Policy Tracker by Country. International Monetary Fund. https://www.imf.org/en/Topics/imf-and-covid19/Policy-Responses-to-COVID-19
} 
Table 1. Selected economic and financial indicators in Bhutan, FY16/17-23/24

$\begin{array}{cccccccc}\mathrm{FY} 16 / 17 & \mathrm{FY} 17 / 18 & \mathrm{FY} 18 / 19 & \mathrm{FY} 19 / 20 & \mathrm{FY} 20 / 21 & \mathrm{FY} 21 / 22 & \mathrm{FY} 22 / 23 & \mathrm{FY} 23 / 24 \\ \text { (act) } & \text { (act) } & \begin{array}{c}\text { (est) } \\ \text { (proj) }\end{array} & \begin{array}{c}\text { (proj) } \\ \text { (proj) }\end{array} & \begin{array}{c}\text { (proj) } \\ \text { (proj) }\end{array}\end{array}$

Real Economy: annual percent change, unless indicated otherwise

\begin{tabular}{|c|c|c|c|c|c|c|c|c|}
\hline Real GDP & 6.3 & 3.8 & 3.8 & 1.5 & 1.8 & 2.0 & 2.8 & 3.4 \\
\hline Agriculture & 3.6 & 3.7 & 3.8 & 2.5 & 3.1 & 3.5 & 4.0 & 4.0 \\
\hline Industry & 4.7 & $(1.2)$ & $(1.6)$ & 3.7 & 2.0 & 1.5 & 1.5 & 2.5 \\
\hline Services & 8.2 & 7.9 & 9.9 & $(0.6)$ & 1.3 & 2.2 & 3.6 & 4.0 \\
\hline GDP per capita (USD, nominal) & 3,094 & 3,348 & 3,294 & 3,163 & 3,423 & 3,571 & 3,749 & 3,926 \\
\hline GDP Deflator & 4.7 & 3.4 & 2.6 & 3.0 & 4.6 & 2.6 & 2.4 & 2.4 \\
\hline CPI (year-average) & 4.3 & 3.7 & 2.8 & 3.2 & 5.0 & 2.8 & 2.7 & 2.7 \\
\hline \multicolumn{9}{|c|}{ Fiscal Account: percent of GDP unless otherwise indicated } \\
\hline Revenues and Grants & 28.0 & 31.6 & 25.6 & 27.7 & 24.2 & 24.6 & 25.0 & 24.9 \\
\hline Hydropower & 4.4 & 5.1 & 4.3 & 7.0 & 7.0 & 5.9 & 5.9 & 5.9 \\
\hline Non-Hydropower & 15.1 & 17.5 & 15.4 & 13.9 & 10.3 & 11.8 & 12.3 & 12.3 \\
\hline Grants & 8.5 & 9.1 & 6.0 & 6.9 & 6.9 & 6.9 & 6.8 & 6.7 \\
\hline Expenditure & 32.8 & 34.5 & 25.0 & 30.8 & 30.9 & 29.9 & 29.3 & 28.9 \\
\hline Current expenditure & 15.8 & 16.8 & 15.7 & 20.5 & 20.5 & 20.3 & 19.8 & 19.6 \\
\hline Capital expenditure & 17.0 & 17.6 & 9.2 & 10.3 & 10.4 & 9.6 & 9.5 & 9.3 \\
\hline Fiscal Balance & $(4.8)$ & $(2.8)$ & 0.7 & (3.1) & $(6.7)$ & $(5.3)$ & $(4.3)$ & $(4.0)$ \\
\hline Primary Balance & (3.5) & (1.5) & 1.6 & (2.1) & $(5.6)$ & (3.7) & (2.7) & $(2.4)$ \\
\hline \multicolumn{9}{|c|}{ Balance of Payments: percent of GDP unless indicated otherwise } \\
\hline Current Account Balance & (23.9) & $(19.1)$ & $(22.5)$ & $(14.0)$ & $(13.8)$ & $(12.3)$ & $(12.1)$ & $(11.5)$ \\
\hline Merchandise Exports & 24.2 & 24.0 & 21.6 & 21.9 & 20.7 & 20.5 & 20.4 & 20.6 \\
\hline Hydropower & 8.5 & 6.8 & 6.2 & 9.5 & 9.6 & 9.1 & 8.6 & 8.1 \\
\hline Non-Hydropower & 15.7 & 17.2 & 15.5 & 12.4 & 11.1 & 11.4 & 11.8 & 12.5 \\
\hline Merchandise Imports & 44.8 & 41.1 & 38.6 & 30.5 & 26.1 & 25.3 & 25.2 & 25.0 \\
\hline $\begin{array}{l}\text { Foreign Direct Investment } \\
\text { Gross International Reserves (USD }\end{array}$ & $(1.1)$ & 0.2 & 0.5 & 0.2 & 0.2 & 0.2 & 0.2 & 0.3 \\
\hline millions) & 1,104 & 1,111 & 1,065 & 1,065 & 965 & 885 & 805 & 745 \\
\hline $\begin{array}{l}\text { Gross International Reserves } \\
\text { (months of next year's imports, } \\
\text { GNFS) }\end{array}$ & 10.5 & 11.3 & 14.1 & 15.5 & 13.8 & 11.9 & 10.3 & 9.5 \\
\hline Total Public Debt & 111.8 & 110.5 & 104.4 & 109.1 & 108.8 & 109.1 & 108.8 & 108.6 \\
\hline External Public Debt & 105.2 & 105.5 & 101.5 & 107.0 & 105.1 & 104.5 & 104.1 & 103.9 \\
\hline Hydro Debt & 81.3 & 80.6 & 77.7 & 82.4 & 80.9 & 80.5 & 80.1 & 80.0 \\
\hline Non-Hydro Debt & 23.8 & 24.9 & 23.9 & 24.6 & 24.2 & 24.0 & 23.9 & 23.9 \\
\hline Domestic Public Debt & 6.6 & 5.0 & 2.9 & 2.2 & 3.7 & 4.7 & 4.7 & 4.7 \\
\hline \multicolumn{9}{|l|}{ Other memo items: } \\
\hline GDP nominal in LCU (millions) & 152,322 & 163,449 & 176,404 & 182,012 & 193,846 & 202,959 & 213,715 & 226,320 \\
\hline $\begin{array}{l}\text { GDP nominal in USD (millions) } \\
\text { Exchange Rate (Nu/USD), FY }\end{array}$ & 2,293 & 2,511 & 2,500 & & & & & \\
\hline Average & 66.4 & 65.1 & 70.6 & & & & & \\
\hline
\end{tabular}

Source: $R G O B$ and WBG staff estimates.

Note: Figures are based on the May/June Macroeconomic Framework (MEF) and WBG staff estimation 


\subsection{Poverty Profile}

16. Bhutan has achieved impressive gains in reducing poverty, although progress on shared prosperity has recently slowed. The official national poverty rate declined significantly in 2007-17, from 23.2 percent to 8.2 percent. Extreme poverty ( $\$ 1.90$ per day) has been almost eradicated. However, growth in per capita consumption of the bottom 40 percent slowed in the five-year period ending in 2017 (2012-17), falling to 1.6 percent annually during that period, down from 6.5 percent annually during the previous period of 2007-12. At the same time, per capita consumption for the entire population grew 2.3 percent in 2012-17.

17. There is a substantial spatial variation in poverty rate within the country with poverty being almost exclusively rural. Poverty rates vary widely by district (Dzongkhag) (Figure 1(a)). While most districts have made steady progress in reducing poverty, as of 2017 it was still above 35 percent in Dagana and Zhemgang. Some of the districts with relatively high poverty rates are also geographically remote, making access to services and markets difficult. Most of the poor live in rural areas, are less educated, and work in agriculture. In 2017 the urban poverty rate was only 1.6 percent in 2017, in stark contrast to the 17.4 percent rate in rural areas, where over 90 percent of the poor live. Even among rural areas, there is a wide variation of poverty rates across the country at the block (Gewog) level (Figure 1 (b)). Almost 80 percent of the poor, compared to 60 percent of those not poor, have no education. About two-thirds of the heads of poor households work in agriculture, compared to only about a third of non-poor household heads.

\section{Figure 1. Poverty headcount rate}

(a) Urban and Rual Areas (at Dzongkhag level)

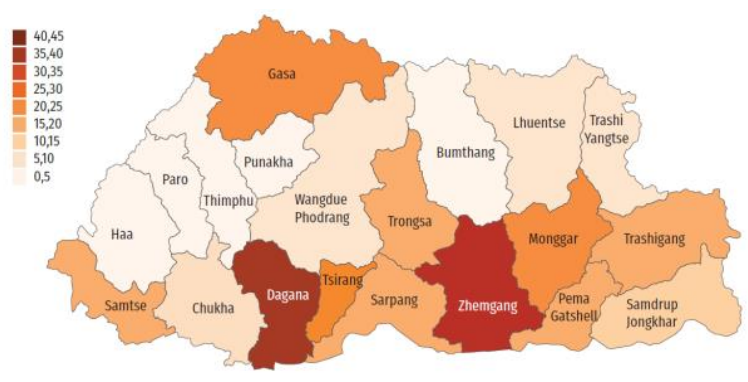

Source: Bhutan Systematic Country Diagnostic (2020); World Bank Poverty Assessment (2019) ${ }^{14}$

Note: Based on the international poverty line of $\$ 3.20 /$ day. (b) Rural Areas Only (at Gewog level)

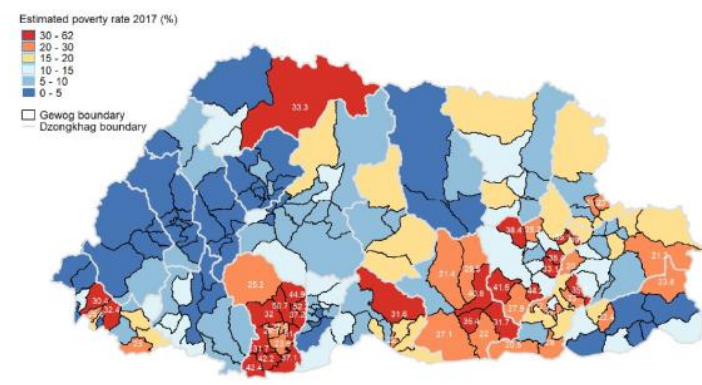

Source: National Statistical Bureau and World Bank (2019) ${ }^{15}$ Note: Based on the national poverty line.

18. Bhutan also made significant improvements in human development. Life expectancy has doubled. Almost 100 percent of Bhutan's children are enrolled in primary school, and the literacy rate improved from 55.5 percent in 2005 to 66 percent in 2017.

19. The COVID-19 pandemic will affect the welfare of Bhutan's people mainly through labor income, particularly in non-farm sectors and in urban areas. Poverty at $\$ 3.20$ per day is expected to remain almost

14https://openknowledge.worldbank.org/bitstream/handle/10986/33286/Bhutan-Systematic-Country-

Diagnostic.pdf? sequence=1\&isAllowed=y

15 National Statistical Bureau and the World Bank "Small Area Estimation of Poverty in Bhutan Poverty Mapping Report 2017"

(December 2019) http://www.nsb.gov.bt/publication/files/pub6gr5366qc.pdf 
unchanged at 10.8 percent in 2020, compared to 10.9 percent in 2019, reflecting lack of progress due to the pandemic. Most of the poor work in subsistence agriculture and their incomes are relatively shielded from supply chain disruptions and potential price shocks to staples. Nevertheless, reduced demand for agricultural exports could hurt agribusinesses and their employees. The economic impact is expected to be felt more broadly in urban areas where about 40 percent of households depend on tourism and traderelated activities and could continue to suffer from job or earnings losses. ${ }^{16}$ About 87 percent of nonhousehold establishments operate in trade, accommodations, and food services; and most are micro or small businesses. These enterprises, which have been the emerging backbone of the economy, could struggle to survive an extended economic crisis. Temporary cash support offered through the Druk Gyalpo's Relief Kidu is expected to help mitigate the impact of household earnings losses while financial mitigation measures aimed at businesses could help them meet debt payments for the time being.

20. Meanwhile, elevated food price inflation could threaten food security. Supply chain disruptions combined with an import ban on select food products in a context of high reliance on imports have been contributing to intermittent food shortages and elevated food prices in recent months. As a consequence, food prices continued to climb and increased by almost 15 percent year-on-year in July 2020. Meat consumption has grown rapidly in recent years and the rising demand has been met almost entirely by imports. Food security needs to be monitored closely, especially in remote areas with high levels of preexisting malnutrition. Ongoing efforts to increase domestic production of cereal and vegetables could help fill the shortage, mitigating food security and increasing the earnings of smallholder agricultural households.

\subsection{Main Development Challenges}

21. The $\mathbf{2 0 2 0}$ Systematic Country Diagnostic (SCD) identifies five major development challenges for accelerating poverty reduction and enhancing shared prosperity in Bhutan. It recognizes that Bhutan is a development success story in many respects but that spatial and gender disparities as well as youth unemployment remain challenges. It also identifies macroeconomic vulnerability; vulnerability to natural disasters; climate change, especially for the poor; and implementation gaps of policies as major challenges. The SCD proposes that five priority actions be taken to address these challenges (Table 2).

Table 2. Development challenges and priorities identified by the 2020 Systematic Country Diagnostic

\begin{tabular}{lr}
\hline Development challenge & \multicolumn{1}{c}{ Priority } \\
\hline Lack of job opportunities, & 1: Boost private sector development \\
especially for educated & - Improve regulatory capabilities and mutual trust with the private sector \\
youth & - Increase access to finance, initiate quick win projects for the private sector \\
& - Invest in connective transport infrastructure and information and \\
& communications technology (ICT); promote digital solutions in parallel \\
& - Harness the potential of the country's vast natural resources including \\
& agribusiness, step-up entrepreneurship and micro, small, and medium \\
& enterprises (MSMEs) development \\
\hline Macroeconomic & 2: Strengthen macro-fiscal stability \\
vulnerability & Strengthen domestic revenue mobilization \\
& Improve management of hydropower rents \\
\hline
\end{tabular}

\footnotetext{
${ }^{16}$ Estimate is based on data from the 2018 Labor Force Survey.
} 


\begin{tabular}{ll}
\hline $\begin{array}{l}\text { Remaining spatial and } \\
\text { gender inequality }\end{array}$ & $\begin{array}{r}\text { 3: Improve service delivery for equal opportunities } \\
\text { - Improve access to and the quality of basic services, and increase investment in } \\
\text { skill-based human capital } \\
\text { - Strengthen the social protection system }\end{array}$ \\
\hline $\begin{array}{ll}\text { Vulnerability to natural } \\
\text { disaster and climate change, }\end{array}$ & $\begin{array}{l}\text { 4: Enhance disaster and climate resilience } \\
\text { especially for the poor }\end{array}$ \\
$\begin{array}{ll}\text { - Promote sustainable management of water resources } \\
\text { Policy implementation gaps }\end{array}$ & $\begin{array}{l}\text { 5: Address implementation gaps } \\
\text { - Improve coordination within the government and address capacity constraints } \\
\text { - Strengthen statistical capacity }\end{array}$ \\
\hline Source: Bhutan Systematic Country Diagnostic ${ }^{17}(2020)$.
\end{tabular}

22. The COVID-19 pandemic has highlighted Bhutan's vulnerabilities and development challenges such as job creation, and shifted the focus to additional areas. The economic shock from the pandemic has affected labor market dynamics, creating shortages of foreign workers from India, due to the country's lockdown and border closure. The government is also concerned about the lack of job opportunities for returning students and workers from overseas. With the need to reinvigorate growth and create jobs, the government has increased its emphasis on strengthening the rural economy and elevated the importance of addressing financial sector vulnerabilities and economic diversification. Pandemic preparedness, prevention capacity, and food security have become more central development challenges (see Box 2).

23. To provide effective support to the country's efforts addressing the impacts of the COVID-19 pandemic, the WBG has made a number of adjustments to the country program during FY20: An emergency health operation was quickly prepared in April 2020 to help Bhutan prevent, detect, and respond to the COVID-19 pandemic and strengthen its public health preparedness. In order to provide additional fiscal space to the government as it undertakes necessary public health measures and economic stimulus programs, the World Bank prepared a Development Policy Financing (DPF) with Catastrophe Deferred Drawdown Option (Cat DDO) to help Bhutan undertake a comprehensive set of reforms to manage climate and disasters risks, including disease outbreaks. The Cat DDO was specifically intended to provide dedicated contingent financing to support the government respond to imminent or occurring natural disasters, including a public-health emergency event. The World Bank also worked closely with the government to ensure the delivery of the Third Strengthening Fiscal Management and Private Sector Employment Opportunities Development Policy Credit (DPC), which had already been programmed for FY20 ahead of the pandemic, and which helped provide fast budget support.

24. Bhutan's remote and sparse settlements slow the spread of communicable diseases but also make it more difficult for the government to deliver services. There has been significant progress in improving coverage, but the quality of basic services has failed to keep pace. Access to electricity is near universal, for example, but outages are frequent and widespread across the country. Most households have access to tap water, but it is not potable and water supply is intermittent. More than a fifth of children in Bhutan are stunted, and 27-36 percent of women and adolescent girls are anemic. Antenatal health coverage varies widely across areas of the country and socio-demographic groups.

\footnotetext{
17 World Bank (2020). Bhutan - Systematic Country Diagnostic (English). The World Bank. Washington, D.C.
} 
Box 2. Bhutan's response to the COVID-19 pandemic and World Bank Group support for its efforts

As of early December 2020, COVID-19 had not spread as far in Bhutan as it had in other countries in the region owing to the domestic pandemic mitigation measures. The government introduced travel restrictions and health-related measures starting early March including a three-week mandatory quarantine at designated facilities for everyone returning from abroad. Although there were confirmed cases of community transmissions, the recovery rate has been encouraging and no deaths have been recorded to date. However, given the potential difficulties of preventing and controlling the spread of the outbreak as well as the economic and social impacts, the government requested WBG support to mount an immediate response.

Bhutan has outlined a very comprehensive national response to COVID-19 including the development of a National Preparedness and Response Plan (NPRP) to improve the health sector's capacity to surveil, detect, control and prevent, respond to, investigate, and recover from the spread of COVID-19. The NPRP established teams for outbreak investigation and surveillance, clinical management, isolation and quarantine, and media and risk communication. It designated the National Referral Hospital in Thimphu for the isolation and treatment of cases. The national response also outlines measures to protect vulnerable households and to minimize impacts on employment, growth and financial stability. These measures include an income support program targeted at vulnerable populations and measures to increase food security and a set of fiscal and monetary policy measures to provide immediate relief to affected households and businesses, including interest waivers for debt/loans. An Economic Contingency Plan launched in July 2020 is also under implementation to support economic recovery and growth.

International borders remain closed since March 2020, except for the movement of essential goods from India. An unprecedented nationwide lockdown was announced on August 11, 2020 with all schools, institutions and commercial establishments remaining closed. During this period, the delivery of essential food supplies and emergency medical services was facilitated.

The WBG provided access to its COVID-19 fast-track facility to support Bhutan's emergency response with US\$5 million. The program supports Bhutan's efforts to prevent, detect, and respond to the threat posed by COVID19 and strengthen national systems for public health preparedness. It aims to reduce morbidity and mortality in the medium term and support systemic changes to the health system that strengthen human capital and build resilience against future public health threats. It is expected to significantly strengthen the ability of Bhutan's health system to deal with future disease outbreaks. This support complements the Bhutan Development Policy Financing (DPF) with Catastrophic Deferred Drawdown Option (Cat DDO) for US\$14.8 million, which includes action on "[endorsing] the Bhutan pandemic preparedness and response plan." It contributes to the human capital and resilience pillars of this CPF.

25. Fiscal revenues from hydropower have helped finance major investments in human capital that significantly improved service delivery and educational and health outcomes. Even with these investments, however, Bhutan has more work to do to realize its full human capital and growth potential. Gender disparities persist in access to economic opportunities, and the quality of jobs is lower among women. Female labor force participation declined in recent years, falling to 56 percent in 2018. Although this figure is higher than in most other South Asian countries, it is 14 percentage points lower than male participation, suggesting that women's opportunities and career choices are limited. Women are more likely to work in low-paying sectors and as unpaid family workers, which results in large earnings gaps (women's earnings average 75 percent of men's). Only some of this gap is attributed to differences in education and occupational segregation. Bhutan's law gives men and women equal rights, but traditional perceptions of gender roles remain a major barrier to gender equality. There is little formal support for female entrepreneurs, and the low literacy rate among rural women limits their access to information and markets. Challenges to human capital development are likely to be exacerbated through impacts of the COVID-19 pandemic and need to be mitigated to avoid loss of previous human capital gains. 
26. Utilization of recent human capital gains also remains a challenge. Close to 60 percent of Bhutanese workers are employed in subsistence agriculture limiting their ability to utilize increased human capital and convert it into increased productivity. This is especially true for women, who lag behind their male counterparts in terms of educational attainment, access to and enrollment in technical and vocational education and training (TVET), and employment outcomes, as reflected in lower wages and much higher proportion of employment as unpaid family workers. Educated young people are increasingly forced to leave the country to find economic opportunities elsewhere. At the same time, one of the major constraints for private sector development is the shortage of skilled labor. Despite rapid improvements in access to education, the general skill level is low. Potential employers find the technical and noncognitive skills of graduates inadequate. Secondary enrollment has been rising, but the transition to post-school opportunities is not smooth.

27. In the absence of a strong social protection system that is able to protect the population throughout the life cycle and to address income loses caused by economic and natural shocks, poor households are likely to be locked into a vicious cycle of suboptimal human capital investment. Poor households in Bhutan are not only less likely to invest in the human capital of their children, they are also more likely to resort to unproductive coping strategies in the event of natural disasters or economic shocks, such as withdrawing children from school and utilizing child labor in farm production or other household production and reducing nutritional intake. While schools for older students reopened in July 2020, primary grades are expected to remain closed this academic year. This requires more sustained focus on remote delivery, improved preparation of teachers to adapt to learning loss experienced by students, and further strengthening the resilience of the education system as a whole. Prolonged school closures increase the chances of intergenerational poverty traps and continued suboptimal investment in human capital.

28. Therefore, the combined effect of COVID-19 on health, education, and household welfare could lead to an increase in poverty, stunting and food insecurity, and worsened social development indicators such as maternal and child health $(\mathrm{MCH})$, educational achievement and learning poverty. These effects threaten gains from previous years. Globally, COVID-19 has had a direct negative impact on human capital stock, and an indirect impact on investment capacity for further human capital accumulation. The pandemic continues to have a profound impact on human capital gains, manifested through disrupted demand for and supply of health and education services, risks to child development, and household welfare losses linked to the economic shutdown and global recession that has had a spillover effect on the Bhutanese economy.

29. Slow improvements in shared prosperity, as manifested in spatial and gender disparities, are linked to the insufficient growth in jobs, particularly in rural areas. Total labor force participation in the economy has improved only slightly in recent years. More than half the workforce remains in agriculture, which is highly correlated with being poor. Productivity is low in subsistence farming, partly because many rural households rely on crops to mitigate food insecurity. Agricultural productivity improved notably in recent years, which helped reduce poverty; nevertheless, it remains low, at only 25 percent of overall productivity. Unemployment is low in rural areas, but disguised unemployment is likely to be high, as livelihoods are dominated by subsistence farm activities. Although earnings improved in recent years, farmers remain vulnerable to various risks stemming from price volatility, weather shocks, and wildlife predation.

30. Youth unemployment is a growing concern. Hydropower revenues have helped expand the public sector, including state-owned enterprises (SOEs) that are active in most key sectors and provide an array 
of essential services. Public sector jobs account for about half of nonagricultural jobs. Their attractiveness has led to the extensive queueing of educated urban youth, who often reject private sector job offers. Wage employment remains low and concentrated in urban areas. Youth unemployment is relatively high, especially in urban areas and among people with skills. The country is urbanizing rapidly, but because of its mountainous terrain, opportunities for agglomeration economies are limited while urban and rural areas are poorly connected economically.

31. The private sector is embryonic and has not been able to create enough good-quality jobs for young people entering the job market. Educated young people typically pursue careers in the public sector, which is unable to absorb all educated youth on the job market. The potential for the private sector to create jobs is likely to be highest in agriculture/agribusiness, forestry, and tourism, given the country's comparative advantage in natural assets. However, the business climate in these areas is not conducive for private sector growth. Bhutan's private sector will need improved financial infrastructure so that more firms have access to financial services. The World Bank Enterprise Survey data show that access to finance is the most binding business-related obstacle and that financial inclusion is among the lowest in the region. Investments in major connective and ICT infrastructure are needed to increase market access and growth and to improve the mobility of people and goods in the country. In addition, the regulatory environment needs to be more predictable.

32. The absence of a vibrant private sector is partly explained by the dominance of SOEs in Bhutan's economy. SOE contributions, through dividends and taxes, accounted for more than 40 percent of the government's revenues in 2016. Bhutan has 38 SOEs that are concentrated in the financial and energy sectors (especially hydropower), and operate in manufacturing and telecommunications. Under Bhutan's centralized SOE ownership, the Ministry of Finance is the sole shareholder of all SOEs. Most SOEs are profitable, but profits are driven largely by the energy and financial sectors and by lack of competition. Because of the small domestic market and nascent private sector, Bhutan relies heavily on SOEs to provide essential goods and services. Going forward, the Government must consider divesting its ownership in non-strategic SOEs and investing in new areas where the private sector is not well positioned.

33. Bhutan has significant potential to attract FDI, but a restrictive regime has constrained its ability to do so. FDI is important as a source of capital, technology transfer, and jobs. Bhutan's 2010 FDI Policy (and its 2012 amendment) prohibited FDI in certain sectors and imposed equity restrictions and minimum investment requirements. Investments in the information technology (IT) sector, for example, have been constrained by a minimum investment threshold of Nu 5 million, and investments in infrastructure have required a public-private partnership arrangement. FDI is also restricted by a cumbersome approval process that requires certification by various ministries and agencies.

34. Lack of economic diversification is a risk to long-term sustainability of growth. Bhutan relies heavily on hydropower generation for tax revenue and foreign exchange. With 85 percent of imports coming from India and the exchange rate pegged to the Indian rupee, Bhutan's inflation rate is closely linked to that of India, with a time lag. Major changes in economic conditions in India are thus likely to have spillover impacts on the Bhutanese economy.

35. Bhutan is subject to seismic and hydro-meteorological hazards-including earthquakes, landslides, forest fires, and windstorms-because of its location on the eastern edge of the Himalayas. Floods and landslides continue to pose major threats to people's lives, assets, and infrastructure every monsoon season. Climate change is increasing Bhutan's vulnerability, exposing it to new challenges, such as glacial lake outburst flooding. Climate change models indicate that Bhutan will experience rapid changes in 
weather patterns, with a temperature increase of over $1.9^{\circ} \mathrm{C}$ and a precipitation increase of more than 6 percent. Bhutan's 2011 Climate Change Vulnerability Assessment predicts a warming trend in annual temperature and high levels of variability and uncertainty in annual precipitation. These changes are expected to lead to shifts in seasonal stream flows, ecosystems, and distributions of species, depending on habitat changes. Climate change will also affect Bhutan's water resources, which need to be actively managed to meet population and production needs.

\section{WORLD BANK GROUP PARTNERSHIP FRAMEWORK}

\subsection{The Government's Program and Medium-Term Strategy}

36. Bhutan's 12th FYP for 2018-23 aims to create a "just, harmonious, and sustainable society through enhanced decentralization." The framework, which is guided by Bhutan's unique development philosophy of GNH, is implemented through 17 National Key Results Areas (NKRAs) (Figure 2). ${ }^{18}$

37. The 12th FYP presents several new features, including: (a) greater emphasis on intergovernmental coordination, consolidation, and collaboration to improve cross-sectoral programming, targeting, and the leveraging of scarce resources; (b) increased transfer of authority to local governments and the allocation of equal shares of capital resources to central agencies and local governments for more effective decision making and implementation closer to constituencies; and (c) the consolidation of actions around core flagship programs to ensure that critical issues such as youth unemployment, water security, and spatial disparities are addressed more coherently. Government priorities are reflected in the SCD focus areas and cross-cutting areas.

38. In addition to the NKRAs, the government developed nine cross-cutting flagship programs:

- screening for cancer

- growing organic

- managing waste and stray dogs

- providing reliable drinking and irrigation water

- digitalizing Bhutan

- redefining tourism

- ICT-izing schools

- footprints of National Day (an archive of priorities mentioned by the king in his National Day speeches )

- increasing economic diversification

These programs address specific, well-defined development issues that require multisectoral collaboration and coordination but could yield speedy results.

39. In response to COVID-19, the government announced an economic stimulus plan that includes fasttracking implementation of the $12^{\text {th }}$ FYP, with an emphasis on revitalizing the rural economy and creating employment opportunities. Focus sectors include tourism, agriculture, and infrastructure. The government said it recognized the need to transcend "business as usual" attitudes and practices, and aims

\footnotetext{
18 The CPF covers a period through FY24, which will be the first year of Bhutan's 13th Five-Year Plan. The PLR, currently anticipated
} for FY23, will take into account government plans for the new FYP and adjust country engagement as appropriate at that time. 
to minimize delays from bureaucratic processes. Details about this initiative are expected to be announced soon.

Figure 2. NKRA under Bhutan's 12th Five-Year Plan
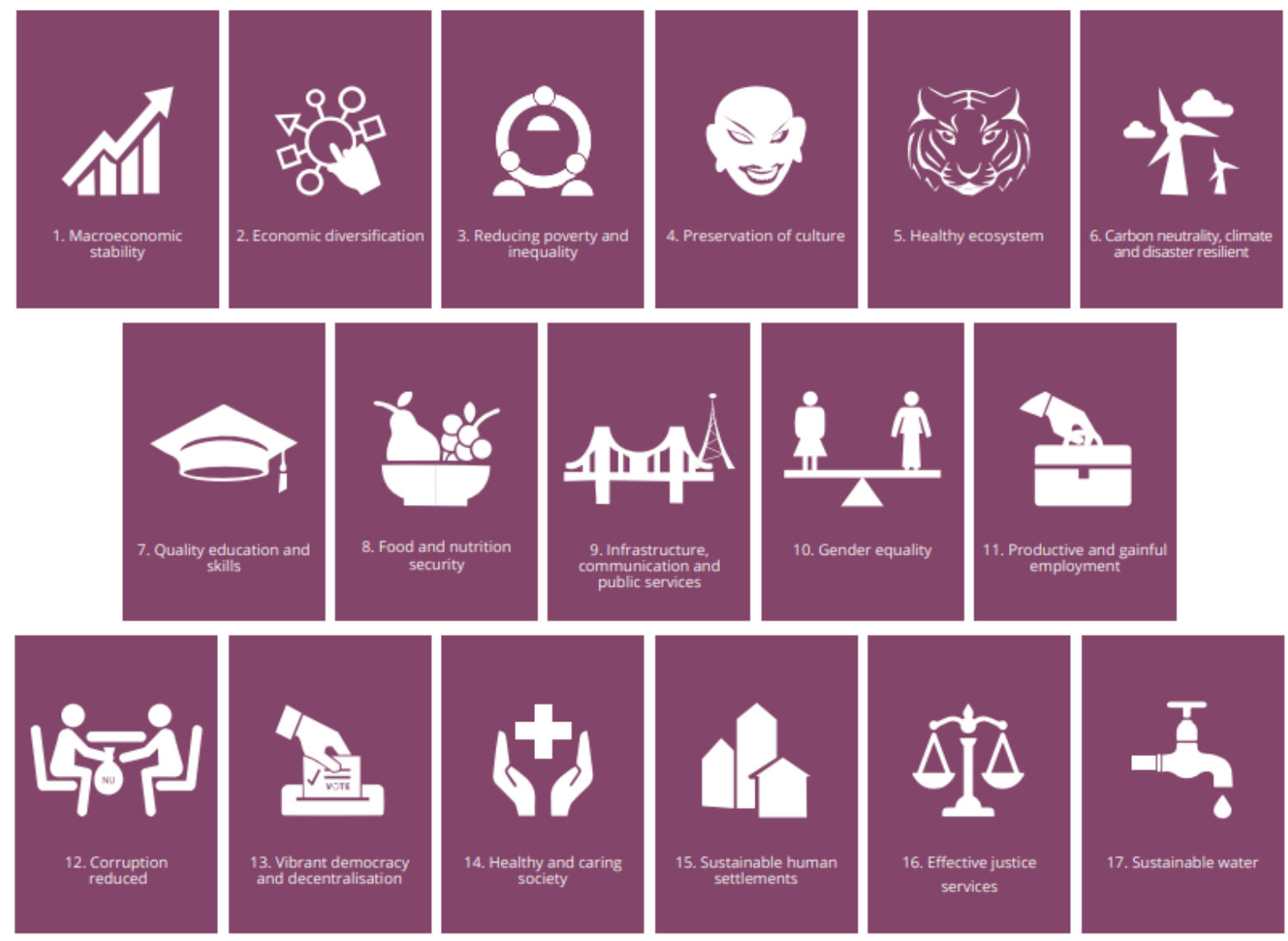

Source: Royal Government of Bhutan.

\subsection{Lessons from the Completion and Learning Review for the FY15-FY19 CPS}

40. The strategic objective of the CPS for FY15-20 was to support Bhutan's aspirations to achieve sustainable and inclusive growth. It focused on addressing the emerging challenges posed by short-term macroeconomic imbalances of hydropower-led growth and improving the business environment to diversify the economy. The CPS results areas were aligned with the government's $11^{\text {th }}$ FYP (2013-18), which was guided by the four pillars of GNH: good governance; sustainable socioeconomic development; preservation and promotion of culture; and environmental conservation. These pillars formed the basis for the three CPS results areas: improving fiscal and spending efficiency; increasing private sector growth and competitiveness; and supporting green development.

41. The CLR of FY15-19 CPF has been prepared and is attached to this CPF (Annex 2). Six of the seven development objectives were achieved, or mostly achieved, with notable development outcomes. Between 2015 and 2019, progress was made on fiscal efficiency, agriculture productivity, and management of natural resources. During the first half of the CPS period, the IDA program was strategically focused to make better use of resources. However, implementation of two investment 
projects was initially delayed, primarily because of insufficient government capacity, especially in procurement. During the Performance and Learning Review (PLR), the WBG program intensified support for fiscal management and private sector development. It explored possible engagement in the infrastructure and hydropower sectors through Investment Project Financing (IPF) and Program-forResults (PforR), but the government increasingly preferred budget support operation over IPF and PforR.

42. This CPF incorporates the lessons learned from the CLR, especially the need to diversify financing instruments to include IPF and/or PforR to allow more effective support for institutional capacity building. Under the $19^{\text {th }}$ IDA replenishment (IDA-19) cycle, this CPF introduces a new PforR on human capital that will contribute to building the government's institutional capacity to deliver services, including at the local level, where skills and human capacity are constrained.

Box 3. Summary of key lessons from the CLR

More diversified instrument to support institutional capacity building. The CLR notes that diversifying IDA financing instruments to include IPF and/or PforR would allow more effective support for institutional capacity building. Under IDA-19, this CPF introduces a new PforR on human capital as well as Development Policy Financing (DPF) operations on jobs and resilience. The human capital PforR will contribute to building the government institutional capacity in effectively delivering services, including at the local level where skills and human capacity are constrained.

Enhanced effectiveness of DPF to support implementation of reforms. While inter-ministerial coordination is important for effective implementation of reforms which often cut across sectors, such coordination has been weak as noted in the CLR. By introducing more sector-specific reforms in the new DPFs under IDA-19, the CPF will deepen its reform dialogue with specific sector ministries in addition to the Ministry of Finance thereby internalizing inter-ministerial coordination in the design of the DPC program.

Strategic use of trust fund (TF) resources for advisory services and analytics (ASAs). The CLR points to the need of making the ASA program more strategic and selective in using TF resources to better complement financing operations. Under this CPF, the ASA pipeline will be limited to core and extended-core diagnostics. Some core diagnostics can be more multi-sectoral. Stronger client ownership will be sought in implementing ASAs as well.

Technical Assistance (TA) has helped the government improve its implementation capacity. In view of this finding - as well as the SCD finding that gaps remain between policy making and policy implementation -TA will continue to be included in relevant operations as appropriate going forward, aiming to improve the capacity of implementation agencies.

Collaboration within WBG. Under the previous CPS, the collaboration between the Bank and the International Finance Corporation (IFC) were in the areas of business environment and financial sector though advisory and policy lending. The CLR suggests for further collaboration beyond those sectors given the challenges in expanding private sectors and promoting economic diversification in the country. This CPF will strengthen the synergy among the Bank, IFC, and the Multilateral Investment Guarantee Agency (MIGA). For example, new DPF operations will seek to support reforms in agriculture, forestry, and sustainable tourism which remove constraints in private investments in agribusiness and wood-based industries, including potential IFC investments and support by MIGA of cross-border investors. DPF operations can support reforms to allow more foreign investments by improving efficiency in FDI regulations or removing constraints in the external commercial borrowing (ECB) policy. They can also support improvements in efficiency and better targeting of public investments, which provide a more enabling environment for private investments.

Citizen engagements. The CLR notes the importance of citizen engagements in designing and implementing WBG operations. Citizen engagements have been well integrated in the preparation of this CPF, including a Country Opinion Survey in the design of the CPF and the strategic focus areas. The same tool will be used for the PLR and the CLR. Citizen engagements will be integrated into the design of new operations under the CPF. The CPF's cross-cutting emphasis on use of digital technology will also serve for increased citizens' engagement and participation. 
43. The WBG solicited the views of stakeholders in various ways. This included countrywide consultations on the CPF that were held between December 2019 and February 2020; and eight face-toface consultations with representatives of government, members of the Parliament, the private sector, youth groups, academia, the donor community, civil society organizations, and local communities. In parallel, online consultations were conducted (in both English and Dzongkha, the national language), using WeChat (through which the views of 2,900 online rural respondents were elicited) and other channels.

44. Stakeholders identified the following concerns: lack of job opportunities for youth; inconsistency between government policy and implementation; inadequate public-private dialogue; limited access to financial services and markets (particularly for CSIs and agriculture); poor transport and ICT connectivity; inadequate service delivery in remote rural areas; and a lack of sustainability of natural assets. Summaries of stakeholder consultations are available online. ${ }^{19}$

45. The FY19 Country Opinion Survey report suggested widespread support for the WBG's engagement in Bhutan, which views the WBG as a long-term partner that is respectful, open, and straightforward. Survey respondents wanted to see more collaboration with the private sector (to stimulate growth and job creation) and more engagement with civil society (see Box 4). Appreciation of traditional approaches to WBG support in sectors such as education and agriculture declined since the last survey conducted in 2016.

\section{Box 4. Summary of findings from the 2019 Bhutan Country Opinion Survey}

The Country Opinion Survey, administered to 122 stakeholders between February and May 2019, was designed to help the WBG understand how stakeholders in Bhutan perceive the WBG and its work in the country. It revealed that the institution is viewed as a long-term partner that is respectful, open, and straightforward. Collaboration with the government is perceived positively. Lower ratings relate to how the WBG engages with civil society and the private sector. Nearly half of respondents reported that the institution should collaborate more with the private sector.

More than a third of respondents identified jobs, growth, and private sector development, followed by agriculture (the perceived top contributor to poverty reduction) and governance as important areas for WBG engagement. Within the context of stakeholders' emphasis on jobs, private sector, and growth, the survey suggests that it might be valuable to consider building new relationships with targeted audiences in the private sector community. Respondents also viewed financial resources as the most important aspect of the Bank's work in Bhutan, although about 30 percent of respondents also pointed to the institution's technical assistance and policy advice.

\subsection{The Proposed Country Partnership Framework}

46. This CPF will help Bhutan promote inclusive and sustainable development through job creation and enhanced equity. It builds on the findings from the 2020 SCD, which points to the centrality of job creation to reduce poverty and improve shared propriety amid rising urban youth unemployment in cities and underemployment in rural areas. While hydropower generation continues to drive economic growth, equity remains an issue as the country faces persistent spatial and gender gaps in poverty reduction. This CPF focuses on reduction of such gaps as the country continues to grow.

19 World Bank (2019). World Bank Group Consultations in Bhutan. The World Bank. Washington, D.C. https://www.worldbank.org/en/country/bhutan/brief/world-bank-consultations-in-bhutan-country-partnership-framework. 
47. The CPF has two strategic focus areas-human capital and resilience-and focuses on both the supply and the demand sides of job creation. Investments in human capital and skills are needed to diversify and sustain Bhutan's sources of growth by increasing the productivity of the current and future workforce. The strategic focus area of resilience supports creation of labor demand through private sector growth, focusing on industries that promote inclusive and sustainable growth, including industries based on agriculture and environmental resources. By supporting environmental resilience, the CPF will help strengthen the livelihoods of low-income populations dependent on agriculture (who are highly vulnerable to natural disasters and climate change) and support the competitiveness of job-creating, nature-dependent sectors, such as agriculture. The CPF also supports the sustainability of job creation by safeguarding Bhutan from the risks of growth disruptions given its vulnerability to natural disasters and economic fluctuations. Figure 3 illustrates the architecture of the CPF.

Figure 3. Strategic focus areas, objectives, cross-cutting foundation, and implementation approach of the Country Partnership Framework for Bhutan

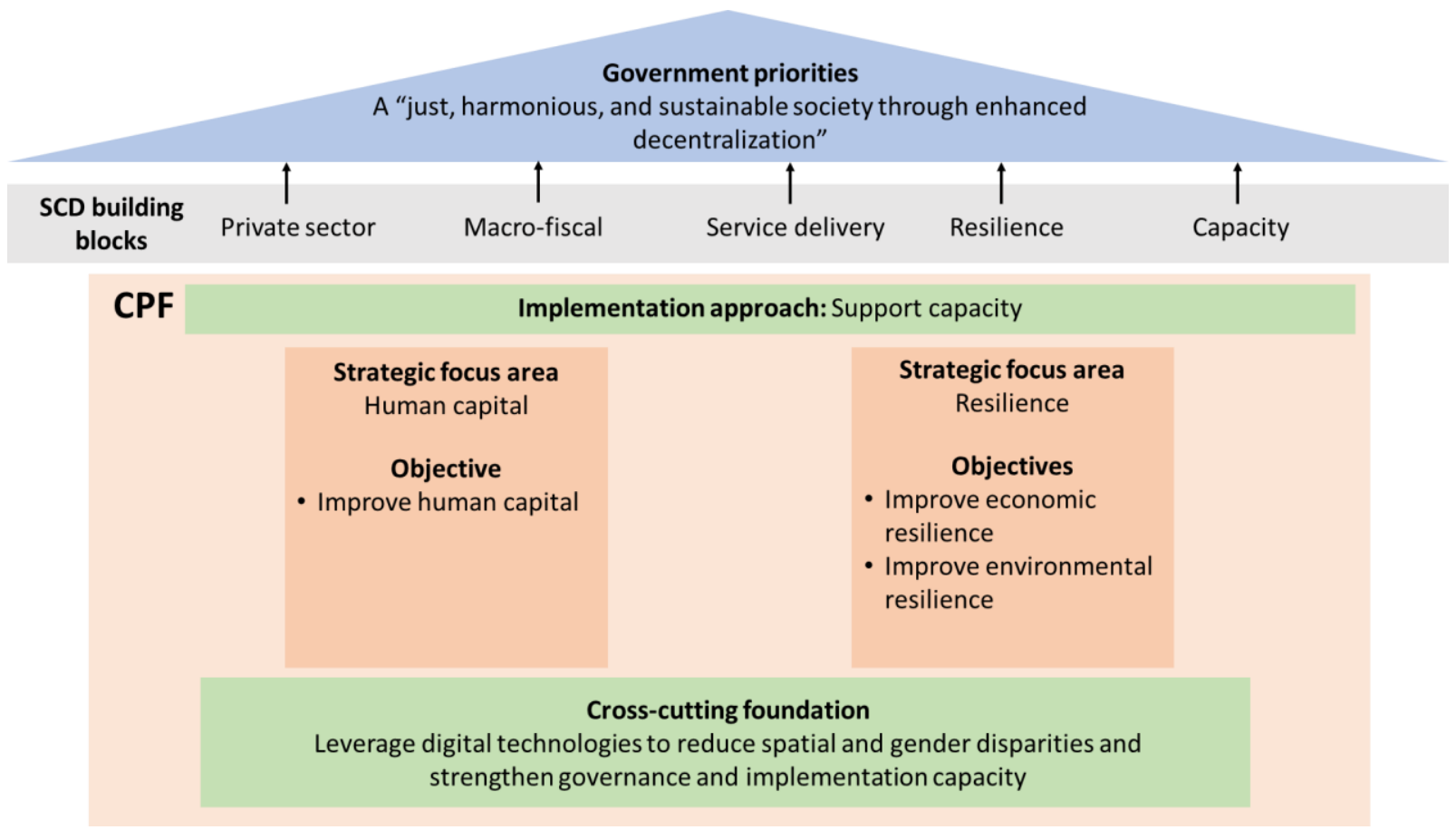

48. This CPF is fully aligned with the WBG COVID-19 Crisis Response Approach Paper "Saving Lives, Scaling-up Impact and Getting Back on Track" and its four thematic pillars. COVID-19 response interventions under the strategic focus area of human capital correspond to the "saving lives" pillar (pillar 1). Financing and analytical supports under the both strategic focus areas of human capital and resilience ensure that WBG supports to the country's response for "protecting poor and vulnerable people" from the impact of the crisis (pillar2). A set of interventions under the strategic focus area of resilience encompasses a variety of financing and advisory interventions from WBG to integrate longer-term development agenda of Bhutan in the context of responding to the COVID-19 crisis by addressing "saving livelihoods, preserving jobs, and ensuring more sustainable business growth and job creation" (pillar 3 ) and "strengthening policies, institutions and investments" (pillar 4). 
49. The CPF will leverage digital technologies across strategic focus areas. Digital technologies can yield enormous development benefits for small, landlocked, sparsely populated countries like Bhutan. They can help narrow spatial disparities by improving connectivity and reducing the costs of service delivery in remote areas and facilitating cross-border economic integration. With a view to strengthen the long-term sustainability and inclusiveness of Bhutan's growth, the CPF will seek opportunities under each strategic focus area to leverage digital technologies. The emphasis on digital technologies is also well aligned with the government's priority. Furthermore, the CPF will also strengthen governance and implementation capacity through data and statistics, addressing implementation gaps in policies, a priority identified by the SCD.

50. The CPF is well-aligned with the government's priorities. It considers the government's priorities, expressed through the 12th FYP, the ECP, and flagships as well as the main findings of the review of the government's 11th FYP and the 2015 GNH Index. The 2020 SCD, the International Finance Corporation's strategic approach in the country, lessons learned from the CLR and the 2019 Country Opinion Survey, and consultations with stakeholders also informed the preparation of the CPF.

\subsubsection{Selective filtering in the development of the CPF}

51. The strategic focus areas, objectives, and interventions of the CPF are developed based on a set of prioritization criteria. Specifically, the CPF: (a) prioritizes areas that are closely linked to the WBG's Twin Goals as well as the outcomes of the SCD, focusing on both the supply and demand sides of jobs and enhanced equity as the country develops; (b) aligns them with Bhutan's development priorities and input provided from the government on how to focus WBG support; and (c) focuses on areas in which the WBG has a comparative advantage, drawing lessons from past or existing engagements (Figure 4). The WBG reevaluated the focus areas, objectives, and interventions in the context of the COVID-19 pandemic and its effects on Bhutan and refocused to strengthen Bhutan's resilience to pandemic shocks.

52. Given the small size of the financing envelope available to Bhutan and the resulting need to focus the WBG's engagement in the country, further selectivity can be achieved by applying three engagement principles to maximize the impact of the CPF: (a) catalyzing existing government initiatives and the private sector; (b) creating sustainable impact through supporting programs with clear, measurable outcomes; and (c) optimizing WBG engagement by diversifying and targeting the instruments it uses to support Bhutan.

53. The WBG will catalyze existing government initiatives and the private sector by making use of programs, projects, or plans developed by the government. The planning capacity of the government is high, allowing for close collaboration on finalizing high-quality interventions. Working with the government, the WBG will help implementing agencies build their capacity. Catalyzing the private sector around the WBG program for Bhutan will help scale up efforts and maximize finance for development. 
Figure 4. The Country Partnership Framework at the intersection of selectivity criteria

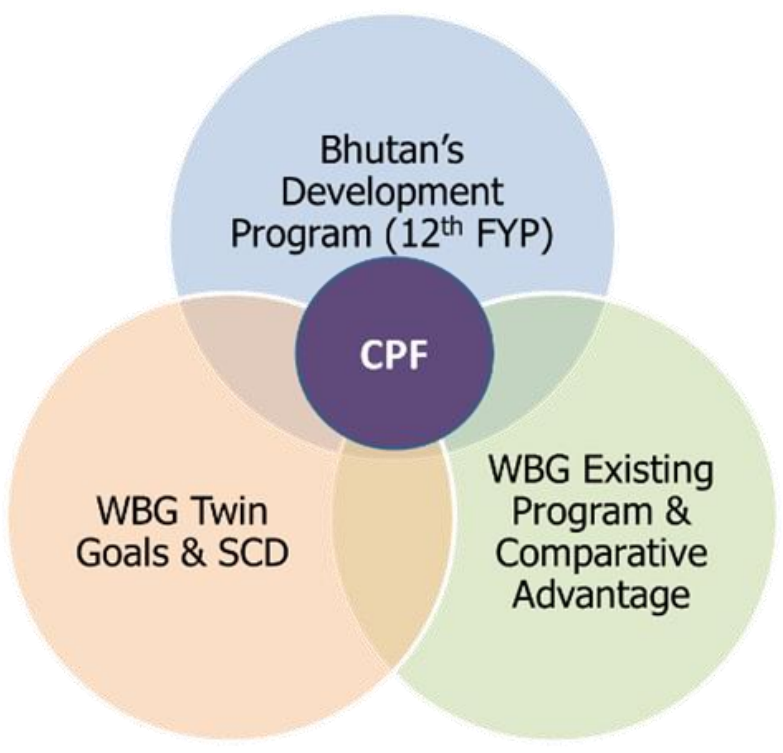

Figure 5. Linkage between the Country Partnership Framework, the Systematic Country Diagnostic, and government development priorities

\begin{tabular}{|c|c|c|}
\hline Government priorities & SCD priorities & CPF strategic focus areas and objectives \\
\hline $\begin{array}{l}\text { NKRAs: Economic Diversification; Food and } \\
\text { Nutrition Security; Infrastructure, } \\
\text { Communication and Public Services; Productive } \\
\text { and Gainful Employment } \\
\text { Flagships: Growing organic; Digitalizing Bhutan; } \\
\text { Redefining tourism; Economic diversification }\end{array}$ & $\begin{array}{l}\text { SCD Focus Area 1. Boosting Private Sector } \\
\text { Development } \\
\text { - Increasing access to finance } \\
\text { - Investing in connective transport } \\
\text { infrastructure and ICT } \\
\text { - Harnessing the potential of vast natural } \\
\text { resources }\end{array}$ & $\begin{array}{l}\text { CPF strategic focus area: Resilience } \\
\text { CPF objectives: Improve economic resilience } \\
\text { and environmental resilience } \\
\text { Cross-cutting foundation: Leverage digital } \\
\text { technologies to reduce disparities }\end{array}$ \\
\hline $\begin{array}{l}\text { NKRAs: Macroeconomic Stability } \\
\text { Flagship: Economic diversification }\end{array}$ & $\begin{array}{l}\text { SCD Focus Area } 2 \text {. Strengthening macro-fiscal } \\
\text { stability } \\
\text { - Strengthening domestic revenue mobilization } \\
\text { - Improving management of hydropower rents }\end{array}$ & $\begin{array}{l}\text { CPF strategic focus area: Resilience } \\
\text { CPF objective: Improve economic resilience } \\
\text { Cross-cutting foundation: Leverage digital } \\
\text { technologies to reduce disparities }\end{array}$ \\
\hline $\begin{array}{l}\text { NKRAs: Reducing Poverty and Inequality; } \\
\text { Quality Education and Skills; Gender Equality; } \\
\text { Health and Caring Society } \\
\text { Flagships: Health services through cancer } \\
\text { screening; Reliable drinking water and } \\
\text { irrigation water; ICT-izing schools }\end{array}$ & $\begin{array}{l}\text { SCD Focus Area 3. Investing further in human } \\
\text { capital and improved service delivery } \\
\text { - Improving access to and quality of basic } \\
\text { services and increasing investment in human } \\
\text { capital } \\
\text { - Strengthening the social protection system }\end{array}$ & $\begin{array}{l}\text { CPF strategic focus area: Human capital } \\
\text { CPF objective: Improve human capital to } \\
\text { increase productivity of current and future } \\
\text { workforce } \\
\text { Cross-cutting foundation: Leverage digital } \\
\text { technologies to reduce disparities }\end{array}$ \\
\hline $\begin{array}{l}\text { NKRAs: Carbon Neutrality, Climate and Disaster } \\
\text { Resilient; Sustainable Human Settlements; } \\
\text { Sustainable Water } \\
\text { Flagship: Growing organic }\end{array}$ & $\begin{array}{l}\text { SCD Cross-cutting Area } 1 \text {. Enhancing Disaster } \\
\text { and Climate Resilience } \\
\text { - Promoting sustainable management of water } \\
\text { resources } \\
\text { - Managing and mitigating climate-related } \\
\text { vulnerabilities }\end{array}$ & $\begin{array}{l}\text { CPF strategic focus area: Resilience } \\
\text { CPF objective: Improve environmental } \\
\text { resilience } \\
\text { Cross-cutting foundation: Leverage digital } \\
\text { technologies to reduce disparities, strengthen } \\
\text { governance and implementation capacity }\end{array}$ \\
\hline $\begin{array}{l}\text { 12th FYP. Plan Implementation, Monitoring and } \\
\text { Evaluation }\end{array}$ & $\begin{array}{l}\text { SCD Cross-cutting Area } 2 \text {. Addressing } \\
\text { Implementation Gap } \\
\text { - Improving coordination and addressing } \\
\text { capacity constraints } \\
\text { - Strengthening statistical capacity }\end{array}$ & $\begin{array}{l}\text { CPF implementation approach: Support } \\
\text { capacity through TA and DPC } \\
\text { Cross-cutting foundation: Leverage digital } \\
\text { technologies to strengthen governance and } \\
\text { implementation capacity }\end{array}$ \\
\hline
\end{tabular}


54. Several NKRAs are not standalone focus points of the CPF. ${ }^{20}$ However, some aspects of these areas are addressed as part of the WBG's efforts to strengthen human capital and resilience in Bhutan:

- Infrastructure is both a government and an SCD priority. Bhutan has significant connectivity challenges and transport infrastructure investments. Investing in connective infrastructure could pay high dividends in terms of market access and growth by connecting smaller places to large urban centers. The Asian Development Bank, the Japan International Cooperation Agency (JICA), and India have been active in financing infrastructure development. To avoid duplication with development partners and fragmentation of its program, the WBG will not focus on transport connectivity. Some transport-related aspects (such as road safety) are captured under the strategic focus on resilience.

- Reliable drinking water, irrigation water, and sustainable management of water resources are priorities for both the government and the SCD. Bhutan has abundant water resources but has faced challenges using them productively to sustain food production and address health concerns. The United Nations Children's Fund (UNICEF) and the SNV Netherlands Development Organization are actively involved in this area. Bhutan lacks an overarching integrated water resources management strategy, including policies on groundwater extraction to guide its use in line with GNH principles. Although the CPF does not include a strategic focus on water, the sustainable management of water resources may be addressed under the strategic focus on resilience, and the strategic focus on human capital captures the linkages among water, sanitation, and health.

- Preservation of culture is a cornerstone of Bhutan's development philosophy. Although the WBG has some expertise with cultural heritage, the focus in the 12th FYP is on intangible aspects of culture in which the WBG does not have comparative advantage.

- Effective justice services are a government priority. Strengthening institutions has been an integral part of the WBG's engagement in Bhutan and will remain one going forward. However, the WBG will focus on strengthening institutional implementation capacity in relation to Bank operations under the CPF, which do not include justice services.

- Health services through cancer screening is a planned government flagship program. The CPF strategic focus on human capital includes health services, particularly for mothers and children during the first 1,000 days of the child's life. Given the limited financing envelope, the WBG decided to support a government program on maternity and child health rather than cancer screening, bringing to the table its extensive experience with early childhood development.

- Managing waste and stray dogs is a planned government flagship program. As there has been little engagement on waste management between Bhutan and the WBG, a focus on this issue would not catalyze ongoing or previous work.

55. To optimize the WBG's engagement, the CPF seeks to diversify instruments and introduce more sector focuses in policy-based financing to support reforms for private sector growth and job creation. Although the WBG will continue to use DPF to facilitate policy dialogue and reform, the CPF will also use IPF (including in the format of Recipient-Executed Trust Fund, RETF) and PforR. Use of IPF and PforR responds to one of the key findings of the CLR: that diversification of financing instruments could have helped increase impact on institutional capacity for a small country such as Bhutan. The CPF will also use DPF to support sector reforms in areas such as agriculture, natural resource management, and tourism to unlock the potential for private sector growth and job creation.

56. In a small landlocked country, cross-border regional aspects are important for growth and poverty reduction. The South Asia region trails other regions with regard to regional integration. Barriers to

${ }^{20}$ Areas the CPF will not directly focus on will be reviewed and adjusted as necessary at the time of PLR of this CPF in FY22. 
promoting regional trade include border tax distortions, nontariff barriers, connectivity costs, and a trust deficit among the region's countries. There has been active dialogue at the regional level about facilitating cross-border electricity exports, from which Bhutan would gain significantly. This CPF will leverage WBG regional programs in addressing barriers in an effort to foster better integration with

\subsection{Focus Areas and Objectives of the Country Partnership Framework}

\subsubsection{Strategic focus area: Human capital}

57. Improved, sustainable human capital outcomes contribute to inclusion, productivity and overall economic growth. They require increased access to quality health and education services, especially among the poor and vulnerable, as well as improved employability of today's youth and adults. This, in turn, calls for both increased efforts on the demand side, supporting utilization of the most vulnerable, and improved access to services to promote human capital accumulation to accelerate economic growth and reduce poverty.

58. To achieve sustainable growth, Bhutan will require continued investment in the human capital of current and future generations. Human capital consists of the knowledge, skills, and health that people invest in and accumulate throughout their lives, enabling them to realize their potential as productive members of society. It begins accumulating even before birth, and continues increasing through investments in health care, nutrition, high-quality education, life-long learning, and acquisition of skills and jobs. Despite recent gains in terms of aggregate human capital, inequalities persist across urban/rural, economic and gender lines, hindering the effectiveness of interventions such as free health care and education. According to the 2020 Human Capital Index, a child born in Bhutan today will be only 48 percent as productive when she grows up as she could have been had she enjoyed complete education and full health. Some estimates show that GDP per worker could be as much as 2.2 times higher if the quantity and quality of human capital were improved.

Box 5. Potential benefits of regional cooperation for Bhutan

Greater regional cooperation has the potential to produce significant economic gains, accelerating shared growth and poverty reduction across all the countries of South Asia. Hitherto inadequately connected regions in the Himalayas spanning Afghanistan, Bhutan, India, Nepal, and Pakistan could benefit immensely-socially and economically-from increased intraregional trade and connectivity. Regional connectivity would be particularly beneficial for landlocked countries such as Bhutan.

Bhutan has been at the forefront of regional cooperation in South Asia. It is an integral part of several platforms (such as the BBIN [Bangladesh, Bhutan, India, Nepal] Initiative) and a signatory to key regional agreements. A pillar of the WBG's regional integration program in South Asia supports the formation of regional electricity markets, which would allow Bhutan to diversify its markets for hydropower. Similarly, the facilitation and adoption of regional approaches to management of transboundary river basins would improve water resources information systems, climate-resilient planning for hydropower sector, and enhanced water security. Analytical work at the regional level to support greater inclusion of women in economic activities such as tourism and agribusiness and the use of digital technologies and platforms to promote cross-border trade, especially for the benefit of women and micro-traders, can guide Bhutan's efforts toward more inclusive growth. Regional initiatives will be implemented at the country-level through investments and regional trust funds (set up by partners such as the [United Kingdom] Foreign, Commonwealth, and Development Office [FCDO] and the [Australian] Department of Foreign Affairs and Trade [DFAT]) that focus on increased regional cooperation, trade, connectivity and inclusive growth. 
59. The CPF will support Bhutan to protect existing human capital and improve human capital accumulation during early life, taking impacts of the COVID-19 pandemic into account and focusing on fast-disbursing support for relief. Interventions in this strategic focus area will support pillars 1 and 2 of the World Bank's COVID-19 Crisis Response Approach Paper.

\section{Objective 1: Improve human capital}

Key results:

- Increased participation in income support programs aimed at vulnerable households with young children

- Reduced stunting among children under five

- Improved antenatal care, increase in utilization of antenatal, maternal and early childhood health services

- Increased primary school readiness

60. Improving human capital requires a cross-sectoral approach to address demand, supply, and resilience aspects of the challenge, especially given the backdrop of the COVID-19 pandemic. Investments should include a suite of complementary interventions across sectors to address binding constraints such as access to and quality of foundational human capital services; opportunity and other hidden costs of utilization; household and community resilience that could allow for continued investment in human capital in the aftermath of the crisis; awareness and cultural norms; and access to opportunities for utilizing improved human capital (for example, inclusive employment support services, start-up and CSI support, and economic inclusion).

61. Through a human capital operation, the WBG will provide support to human capital development in Bhutan. The aim of this operation is to provide fast-disbursing support to existing government initiatives to help the government mitigate impacts of the COVID-19 crisis particularly on vulnerable households with small children. Interventions will seek to: increase access to and utilization of maternal and child health services and effect desirable behavior changes (through support to the Accelerating Mother and Child Health Program, AMCHP), and in particular, to expand coverage and increase utilization of early childhood care and development, and expand the share of families with children under age five. Interventions will help the following:

- Protecting existing human capital gains as the COVID-19 global pandemic remains a priority. Firstly, given the sub-optimal supply and demand of quality essential health services, and in an effort to improve human capital accumulation during early life, the CPF will support the implementation of the "Accelerated maternal and child health - 1000 Days Plus Program". The AMCHP aims to improve maternal, neonatal and child health outcomes including during periods of natural and health emergencies, thus the CPF support will ensure alignment with the "National Preparedness and Response Plan for Outbreak of Novel Coronavirus." To understand health sector readiness for maternal and child service delivery, including preparedness for emergencies, the CPF will support the Ministry of Health in conducting a health facility survey of relevant facilities in the country, to identify areas of strength, and opportunities for service delivery improvement.

- Addressing potential demand-side constraints to improvement in human capital pre- and postCOVID-19 pandemic. A decrease in income can impact investments that households are able to make into the health (especially nutrition) and education of their children. Hence, income support is necessary by offering a package of programs to families with young children to provide 
minimum income support and access to programs and services to improve child nutrition and development. WB can support the assessment, design and implementation of more regular income support to the most vulnerable (conditional on human capital investments) and community-level interventions aimed at behavioral change (around sanitation, nutrition, and investments into human capital of future generations). This effort can be aligned with and build on the roll-out of the $\mathrm{AMCH}$ program.

- Increasing access to and utilization of early childhood care and development (ECCD). Strengthening the resilience of Bhutanese citizens requires continual expansion of ECCD services including through community-based programs, which are particularly important for poorer and more vulnerable populations in rural areas that have limited access to quality services. A targeted approach to ECCD service expansion will enhance primary school readiness by promoting physical health and well-being, socio-emotional skills, language and cognitive development, and general knowledge of children.

- Achieving optimal returns on investments in programs mentioned above through the common platform to ensure programs' complementarities and convergence, avoiding duplication and wastage of resources for programs that aim to improve human capital.

\subsubsection{Strategic focus area: Resilience}

62. The CPF addresses resilience from a perspective of social and productive inclusion, economic growth and stability (economic resilience) and from an environmental and climate perspective (environmental resilience). This two-pronged approach acknowledges the interlinkages between the two types of resilience. Under the strategic focus area of resilience, the WBG supports economic recovery and resilience building. Interventions in this strategic focus area will support pillars 2, 3, and 4 of the World Bank's COVID-19 Crisis Response Approach Paper.

\section{Objective 2: Improve economic resilience}

\section{Key results:}

- Increased non-hydropower revenue

- Improved transparency in fiscal and debt management

- Increased investments and jobs created in CSIs and agribusinesses

- Improved access to finance through an enhanced credit information bureau system

63. The CPF will support Bhutan to accelerate its recovery from the COVID-19 economic shocks and help the country build economic resilience through developing a more inclusive and diversified economic basis for private sector job creation. The current lack of economic diversification limits the scope for job creation. Growth has been dependent on hydropower generation, which is not labor intensive. The public sector-Bhutan's largest formal sector-can no longer absorb new workers. Fostering private sector growth in non-hydropower sectors is therefore critical to job creation in Bhutan. Creating new jobs is also at the center of the government's efforts for economic recovery. Those efforts include both direct support for job creation in specific sectors and efforts to build a sound environment to accelerate job creation, including by maintaining macroeconomic stability and keeping the financial sector healthy.

64. The WBG continues to support the country to ensure macroeconomic and macro-financial stability, which is a foundation for economic resilience and creation of private sector jobs. Under the ECP, the government plans to undertake a set of policy measures to mitigate the impacts of COVID-19 while 
simultaneously initiating reforms and systemic changes that may trigger positive outcomes in the affected sectors in the medium to long term. Such economic recovery efforts need to be underpinned by reforms that strengthen macroeconomic fundamentals, including by diversifying domestic revenue sources beyond hydropower revenue while smoothing revenue flows from hydropower to safeguard against shocks. The hydropower sector itself needs to be better managed, so that it contributes more to the country's fiscal sustainability while expanding the regional market for its power sales. Maintaining financial sector stability is also crucial. A stable financial sector and efficient financial intermediation are important for promoting private investments, as are policies toward FDI and commercial borrowing. The financial sector in Bhutan is primarily state-owned and dominated by banks. It needs to evolve into a more diversified sector that is also led by the private sector to a larger degree. The CPF will support the government's efforts to respond to and recover from the COVID-19 economic challenges through reforms to strengthen fiscal stability and transparency through DPF operations during IDA-19, as well as through a Public Financial Management Multi-Donor Fund (PFM-MDF) project. The WBG will also provide advisory services and analytics, including a public expenditure review (PER), a country economic memorandum (CEM), and advisory services from the IFC. Reforms in the area of fiscal sustainability include the implementation of GST; adoption of fiscal stabilization measures; inclusion of hydropower investments in fiscal accounts; improvements in transparency in fiscal and debt management (such as publication of quarterly fiscal accounts and debt reports, debt management strategy); and better management of performance and contingent liabilities by SOEs. The PFM-MDF project will continue to support the government's strengthening of its public financial management (PFM) and procurement systems to enable sound fiscal policy implementation, including efficient public investments. ${ }^{21}$

65. The WBG will support Bhutan's efforts to create an enabling environment for private sector investments and job creation in key sectors such as agriculture, including high-value agribusiness, and tourism, as well as through CSIs. Investments to foster private sector growth in those sectors, in which the country has comparative advantage, can help create productive jobs in rural areas and for women. Removing investment constraints in those sectors, such as inadequate access to finance and markets, will contribute to their development, particularly CSIs. Strengthening the country's organic certification capabilities in order to develop organic agriculture-one of the government's flagship programs-may help Bhutan enter international niche markets. Expanding the range of safe and nutrition food for rapidly growing domestic urban markets also holds considerable potential. Through core analytical work and a new programmatic DPF series, the Bank will support reform actions that address sector-specific bottlenecks for private investments and productivity growth in sectors such as agriculture/agribusiness, including industries based on forestry resources, and tourism. Such reforms will complement the Bank's ongoing technical assistance in agriculture and food security. ${ }^{22}$ Through a combination of investments and advisory services, IFC plans to support the development of high-value agribusiness in the next three years, including certified organic products for potential exports, boosting productivity in the sector, creating jobs in rural areas and integrating farmers and MSMEs in their value chains. IFC is exploring investments in

\footnotetext{
21 The technical assistance under PFM-MDF project includes support to strengthen the integrated financial management information system (IFMIS), modernizing revenue administration and management including GST implementation, strengthening public procurement framework including implementation of electronic government procurement (eGP), improving financial reporting through IPSAS and BAS implementation, and others.

22 Food Security and Agricultural Productivity Project (FSAPP), financed from the Global Agriculture and Food Security Program (GAFSP) is strengthening the market-orientation of small farm households and piloting a reorientation of the state toward a more enabling function. The ongoing Japan Social Development Fund (JSDF)-funded Youth Employment and Rural Entrepreneurship project is piloting support for young entrepreneurs in rural areas. It is engaged predominantly in agriculturebased CSIs, lessons from which support a national reform agenda. The WBG is also providing technical assistance to Bhutan's food regulatory and organic certifying capabilities to support high-value agribusiness.
} 
niche, high-value agribusiness producers and providing thought leadership to encourage private agribusiness. Tangible progress in reforms in the tourism sector would help IFC scale up its investments in sustainable tourism in high-value tourism infrastructure, branding, and supply chain and waste management advisory.

66. Private sector-led job creation in turn requires growth in private investment, supported by a conducive business environment, including greater access to finance. Increasing private investment requires a combination of critical investments in public goods and an appropriate regulatory environment, including efficient regulatory systems. Despite growing rapidly in recent years, tourism in Bhutan ranked 78th out of 136 countries in the 2017 World Economic Forum Travel and Tourism Competitiveness Report. Current policies toward FDI and commercial borrowing need to be revised to remove excessive restrictions. Given the strong presence of SOEs in the economy, their competitive neutrality in the market needs to be addressed to provide space for the private sector to grow. Strengthening access to finance for CSIs is a key priority in Bhutan. IFC and the World Bank are working jointly to improve the regulatory framework, expand financial inclusion to underserved segments, support the development of microfinance and digital financial services, and promote entrepreneurship by providing more avenues for risk capital, incubation support, and capacity building. Enhanced support to startups and CSIs will not only help develop the much-needed entrepreneurship ecosystem and help their growth, but can also reduce defaulting on loans - thereby enhancing the impacts of increased access to finance.

67. In this context, the CPF will also support efforts to create a more conducive environment for private sector investments that will help build long-term resilience against shocks. The WBG will support business environment reforms by developing policies toward FDI, external commercial borrowing, ecommerce, and competition. Under the Third Strengthening Fiscal Management and Private Sector Employment Opportunities DPC, the government revised its 2010 policy to remove several restrictions on FDI. The WBG will support the implementation of those revisions, including revisions to FDI regulations and organizational reforms to strengthen the FDI Office in its role as an investment promotion agency. MIGA will continue to work to explore support for cross-border investments into Bhutan, especially in areas aligned with the CPF's objectives.

68. Improving financial inclusion by leveraging digital technology is another priority area for the WBG's support. Through advisory services and policy dialogue with the government, the WBG will support the expansion of financial services through a digital payment platform and mobile banking and the development of financial infrastructure to enhance credit information-sharing. This support will enable underserved CSIs to improve their access to finance and help them participate in value chains. Additionally, support to continued increase in digitization of government-to-people (G2P) payments can help improve access to financial services such as savings, insurance and credit in currently unbanked population in Bhutan. The WBG will continue to engage in policy dialogue on financial sector reforms to support further development of the financial sector in Bhutan.

69. In the medium term, the CPF will help the government build its social protection system. Building economic resilience at the household and community levels requires a robust social protection system to complement expanding economic opportunities, especially for subsistence households. Exogenous economic and natural shocks typically have a disproportionate impact on the poor and vulnerable, expanding and deepening poverty. They also have long-term effects on human capital among these households, especially among children, in terms of nutrition, education, and assets, because such households are more likely to use "negative coping mechanisms" by cutting consumption, selling productive assets, and removing children from school. An adaptive social protection system that will 
respond to shocks helps build household- and community-level resilience. Scaling up the social protection system is important for rapid response and recovery from the COVID-19 impact. The WBG could, for example, support the establishment of an integrated and interoperable social registry to support the design of adaptive elements in existing social programs, to promote household and community resilience. Additionally, existing social protection, employment, human capital and even entrepreneurship support programs could consider the inclusion of adaptive elements such as rapid expansion or mechanisms for timely adjustment of enrollment and service delivery in the event of natural and/or economic shocks.

70. The WBG will continue to engage in the sustainable development of hydropower. Bhutan recognizes the potential for substantial gains by achieving efficient connectivity to countries in the region and beyond. Confidence among India's eastern neighbors has gradually increased after India revised its crossborder electricity trade guidelines in December 2018, which opened a path to smoother and more diverse cross-border trading, including bidding into India's power exchanges. The WBG has supported Bhutan's efforts to strengthen its hydropower policy and regulatory framework. It will continue to support its implementation for the sustainable development of hydropower.

\section{Objective 3: Improve environmental resilience}

\section{Key results:}

- Maintenance of carbon-neutral status

- Approval of sustainable forest management plans

- Development of disaster management and contingency plan

- Establishment of a climate fund to aggregate emission reductions

- Achievement of climate co-benefits in line with IDA commitments

71. Bhutan's philosophy of GNH has promoted a development path that values natural resources and environmental quality. With its extensive forest cover and relatively low gross greenhouse gas emissions, Bhutan is the world's only net carbon sink country. Sectors other than forestry emit about 2.2 million tons of carbon dioxide $\left(\mathrm{CO}_{2}\right)$ equivalents a year but, because of its forests, Bhutan sequesters more than 6.3 million tons of $\mathrm{CO}_{2}$ annually. Consequently, Bhutan is internationally recognized as a leader in nature conservation. It has ratified major international conventions on the environment. In its Nationally Determined Contribution (NDC) submitted to the 21st Conference of the Parties (COP21) of the United Nations Framework Convention on Climate Change (UNFCCC) in December 2015 in Paris, Bhutan reaffirmed its commitment to remain carbon neutral and pursue a low-emission development path in support of the commitments of the Paris Agreement. ${ }^{23}$

72. The CPF supports Bhutan's approach to conserving the environment and will seek to maximize climate adaptation and mitigation co-benefits in the country program. At the same time, it will aim to reduce the country's vulnerability to climate change and natural disasters and to create new economic opportunities through a shift from conservation and subsistence use to conservation and the sustainable management of natural resources. Harnessing the economic potential of the country's natural resources will require intensive dialogue with the government on how this approach can create much-needed jobs and livelihoods while preserving the country's carbon-neutral status and commitment to conservation.

\footnotetext{
${ }^{23}$ National Environment Commission (2015). Kingdom of Bhutan Intended Nationally Determined Contribution. Royal Government of Bhutan. https://www4.unfccc.int/sites/ndcstaging/PublishedDocuments/Bhutan\%20First/Bhutan-INDC20150930.pdf
} 


\subsubsection{Natural resource management}

73. The WBG will help Bhutan unlock the untapped economic potential of its forests by promoting sustainable forest management and natural resources as contributors to the tourism sector. Under the $\mathrm{CPF}$, it will promote a shift from conservation and subsistence to sustainable forest management that enables job creation in the forestry and tourism sectors. This approach will stimulate economic opportunities without jeopardizing Bhutan's commitment to conservation.

74. According to Bhutan's national accounts, forestry contributed 2.4-2.9 percent of GDP between 2013 and 2017. From the early 2000s onward, the sector's contribution to real GDP declined and, since 2016, the growth rate of the sector has been negative. Recently, there has been a shift in government policy to create an enabling and business-friendly environment, but forest sector-specific interventions are needed. These policy changes have not yet resulted in the improvement of existing or the development of new forest-based small- and medium enterprises (SMEs). Bhutan's forestry sector can create jobs and contribute to economic development without jeopardizing the national goal of maintaining at least 60 percent of Bhutan's land under forest cover. Transforming the forestry sector by enhancing sustainable forest management has the potential to increase employment opportunities and promote small- and medium-size forest-based enterprises (including through public-private partnerships). Other countries have demonstrated that it is possible to maintain high forest cover while increasing forest productivity and supporting forest-based rural enterprises. Box 6 describes the experience of the Republic of Korea.

\section{Box 6. Developing a vibrant but sustainable forest sector in the Republic of Korea}

The Republic of Korea is forest-rich, with 63 percent of its land area under forest cover. With a forest policy that supports conservation and sustainable production, Korea's forests are also very productive. They are valued at more than US\$100 billion and contribute 9 percent of the country's GDP.

Korea's vibrant forest industry is known for innovation and the use of modern technology. To protect and maintain its extensive forest cover, it enforces the 2006 Act on Promotion and Management of Forest Resources based on criteria and indicators of sustainable forest management. A comprehensive legal framework is in place to implement Sustainable Forestry Management at all levels. The government intends to raise Korea's wood self-sufficiency rate from 16.7 percent in 2014 to 30.0 percent and to increase the number of high-quality jobs in the sector from 18,000 to 70,000 a year in the coming years.

75. Bhutan's natural wealth can be a key contributor to tourism. Bhutan's protected areas are extensive, but tourism offerings are concentrated around a few urban centers. Tourist services are lacking in the east and south, close to some of the more biologically rich protected areas, limiting the ability of protected areas to support tourism. Policies and investments that promote visitor experiences in protected areas without compromising the quality of the natural assets can increase the contribution of protected areas to development. The private sector can play a role in supporting high-value, low-impact tourism development through the diversification of products (such as ecotourism), services, amenities, and destinations.

76. To inform the proposed shift from sustainability and subsistence to sustainable natural resource management, the WBG will conduct a Country Environmental Assessment. IFC plans to promote financial inclusion and support economic diversification away from hydropower through agrobusiness, including forest-related business. Depending on government support to the private sector, IFC has the potential to help create markets in target sectors, which could include the forest sector. Building on the successful Reducing Emissions from Deforestation and Forest Degradation Readiness (REDD+) 
project $^{24}$ and the Bhutan Forest Note ${ }^{25}$, the WBG will work with the government on policy reforms that would allow Bhutan to unlock the job creation potential of sustainable natural resource management. Focus areas could include crafting forest management plans, enhancing technical and institutional capacities, introducing modern technology, strengthening forest-based SMEs, and developing publicprivate partnerships.

\subsubsection{Managing climate change and disaster risk}

77. Bhutan would benefit from being better prepared, financially, for disasters; this could be achieved through Disaster Risk Financing (DRF) instruments, such as the Bank's DPF with a Cat DDO. The WBG is currently using this instrument for the remaining IDA-18 funds, operationalizing the linkages between economic stability and resilience to natural disasters and climate change. Under this CPF, WBG investments will continue to support Bhutan's efforts to plan for climate change adaptation and disaster risk management.

78. The government understands the importance of integrating climate and disaster risk management (DRM) in development activities, but its practice and implementation are constrained by limited technical capacity and resources. The government has demonstrated its interest in enhancing the country's resilience by working with development partners on climate and disaster risk management initiatives. It has strengthened DRM capacity at the community level through community-based DRM approaches, prepared DRM and contingency plans for government ministries, implemented WBG emergency simulations to identify gaps, and strengthened aviation meteorological services, among other efforts. These initiatives are not always well linked or fully resourced, however, resulting in an ad hoc approach.

79. Digital technologies are critical to enhancing all aspects of DRM. Use of such technologies in Bhutan is growing but still limited. Advanced technologies available in the region need to be developed to support efforts to address climate and disaster risk. WBG support in this area will focus on enabling CSIs to anticipate and manage weather- and climate-related risks. Mobile dissemination of remote sensing data from satellites could be used to provide early warning alerts and weather advisories through mobile apps, text messaging, and other ICT-based technologies.

\subsubsection{Strengthening cross-cutting foundations}

80. With a view to strengthening the long-term sustainability and inclusiveness of Bhutan's growth model, the CPF will seek opportunities under each strategic focus area to leverage digital technologies to reduce spatial and gender disparities and strengthen governance and implementation capacity. Harnessing the potential of digital technologies is a priority of the government, as King Jigme Khesar Namgyel Wangchuck emphasized in his December 2019 National Day address, and has been envisioned in the Digital Drukyul Program. Given Bhutan's many remote areas and poor transport connectivity, digital technologies can be used to bridge gaps in access to information, services, and markets. They can also help reduce gender and spatial inequalities and help government authorities improve transparency,

24 REDD+ Secretariat (2020). Bhutan and REDD+. Ministry of Agriculture \& Forests. Royal Government of Bhutan. http://redd.dofps.gov.bt/?page_id=36

25 World Bank (2019). Bhutan Forest Note: Pathways for Sustainable Forest Management and Socio-equitable Economic Development. The World Bank. Washington, D.C. 
outreach, and statistical capacity; these outcomes are even more critical in the response to the COVID-19 pandemic, to support a resilient recovery and long-term economic competitiveness (see Box 7).

\section{Box 7. Digital development in Bhutan}

Bhutan needs to improve the accessibility and affordability of digital connectivity, a critical foundation for a digital economy and an increasingly critical infrastructure in the response to the COVID-19 pandemic. Access to high-speed Internet can help boost private sector investment and help create an inclusive digital economy. It can also support continuity of business and government operations and services at a time of social distancing and mobility restrictions, while also setting the stage for longer-term resilient and green recovery.

Bhutan's mobile market has shown steady growth in recent years. By 2019, 93 percent of the population subscribed to a mobile phone service. Bhutan is also reasonably well-placed within the region in terms of basic Internet use, with 48 percent using basic Internet services. However, penetration remains critically low, less than one percent, lagging behind neighboring countries such as Sri Lanka (29.3 percent), Nepal (12.8 percent), and India (6.5 percent). Most broadband subscribers are in urban centers, and Internet services are unaffordable for many. Average tariffs of even slower fixed broadband services ( 2 megabits per second/Mbps) are about 10 percent of GNI per capita, well above the global affordability target of 2 percent adopted by the United Nations Broadband Commission for Sustainable Development. This implies spatial divides in internet access and digitization, which could impede economic competitiveness and exacerbate other social or economic inequalities, especially as Bhutan might seek to use digital technologies more extensively in the response to the pandemic and other similar, future crises.

Several factors explain the underdevelopment of Bhutan's broadband market. They include the de facto monopoly of the fixed-line networks by Bhutan Telecom, the country's landlocked status and rugged mountain terrain, and its poor transport and energy infrastructure. Digital infrastructure needs to be widely accessible; affordable for all individuals, households, and businesses across the country; and be designed with resilience in mind.

Digital competencies and skills are lagging in Bhutan. In 2017 Bhutan ranked 133rd (out of 176 countries) on the skills sub-indices of the ICT Development Index of the International Telecommunication Union (ITU). A skills gap and misalignment exist with the rapidly evolving market needs of the global digital economy, resulting in limited growth of Bhutan's nascent IT and IT-Enabled Services (ITES) industry and limited availability of jobs in the private sector for the roughly 300 ICT graduates who enter the market every year. In 2018, ICT service exports represented 39 percent of service exports in South Asia. The figure for Bhutan was 0.25 percent.

Digital skills are also limited among the general population. In 2017, only a fifth of Bhutanese older than 15 had made or received a digital payment, compared with a third in Bangladesh and almost half in Sri Lanka. Digital competencies among the rural population and SMEs are also limited, hindering digital inclusion and the ability to access local and global markets. There is a need to develop a digitally enabled workforce, at all skills levels, to support increased technology adoption, innovation, and private sector growth in Bhutan.

81. Improving digital connectivity in a landlocked country like Bhutan would help create jobs. Benefits of improved digital connectivity include enhanced intraregional trade; improvements in the movement of information and knowledge, including by closing skills gaps by permitting trade in skills across borders; improved knowledge-sharing on issues of common concern, such as climate change and natural disasters; and increased inclusion, through online information and market initiatives that link women and young people to jobs and economic opportunities across borders and promote access to finance, for example.

82. The CPF will develop digital competencies and skills ranging from basic digital literacy to advanced IT skills. These skills will help bridge the skills gaps with industry, help workers access job marketplaces 
online, and facilitate CSIs' access to finance and markets. The CPF will also provide support to building emerging skills that have become increasingly high in demand, including skills in cybersecurity, data analytics, artificial intelligence, and skills for the deployment of new-generation networks such as 5G. These skills will become critical foundations for diversifying the local economy, promoting innovation and entrepreneurship, and building Bhutan's competitiveness in the global and regional digital market. They will also help Bhutan digitize key sectors of the economy, including agriculture, forestry, and tourism.

83. Policy formulation and implementation should be supported by high-quality data and statistics, but statistical capacity remains weak in Bhutan. There has been progress in establishing data standards and a wealth of data and statistics are now being produced. Some critical data gaps remain, however, and there are concerns about the quality and timeliness of data. Bhutan's score of 60 on the 2018 Statistics Capacity Index by the World Bank is lower than the South Asia average of 76.

84. Efforts to strengthen statistical capacity, including through more and better data and data literacy, will be critical to promoting evidence-based policy making. Better monitoring and evaluation, supported by good-quality data to measure results on the ground, will help determine whether policies are effective and public resources are allocated appropriately. Modernizing the statistical system to support such an initiative will require investments in human resources and technology as well as strong coordination and a clear vision toward a national system that integrates the production of statistics.

85. The WBG's approach to implementing operations under the CPF will address the SCD's cross-cutting area of "addressing implementation gaps" and its corresponding government priority ("plan implementation, monitoring, and evaluation." According to the CLR, TA has been particularly helpful in building implementation capacity of implementing agencies. Under this CPF, the WBG will focus Bank operational support through TFs target implementation capacity for specific operations.

\subsection{Implementing the Country Partnership Framework}

86. Bhutan's indicative IDA allocation under IDA-19 (FY21-23) is about $\mathbf{\$ 1 0 0}$ million, which will provide IDA financing under the three objectives through a mix of instruments. The WBG used DPF almost exclusively to support the previous CPF. The CLR evaluating the FY15-19 CPS strongly recommended that the WBG use of the entire range of instruments available. The CPF will include a PforR in the first year of its program. Two DPF operations in FY21 and in FY22 will help address impacts of the COVID-19 pandemic in a timely manner.

87. Table 3 shows the active and indicative pipeline of IDA financing.

88. This CPF also includes the delivery of core analytics and advisory work. Table 4 shows the pipeline of advisory services and analytics. Such analytics and advisory work, including PER and CEM will inform the reform dialogue through DPCs and others. A small number of trust fund activities, including regional programs funded by FCDO and DFAT, will support the strategic focus areas, which will be underpinned by core analytics. IFC can deploy its Creating Markets Advisory Window (CMAW) ${ }^{26}$ to enable de-risking and delivery of high-impact projects in Bhutan.

\footnotetext{
${ }^{26} \mathrm{CMAW}$ is a three-year funding window established to allow IFC to respond to increased demand for advisory services in IDA countries and fragile and conflict-affected situations (FCS).
} 
Table 3. Active and indicative pipeline of IDA financing

\begin{tabular}{lll} 
Objective & Active & Pipeline FY21-23 (IDA-19) \\
\hline Improve human capital & $\begin{array}{l}\text { COVID-19 Emergency Response and } \\
\text { Health Systems Preparedness Project } \\
\text { (US\$5 million, FY20) }\end{array}$ & $\begin{array}{l}\text { Human Capital PforR (US\$20 } \\
\text { million, FY21) }\end{array}$ \\
\hline Improve economic resilience & $\begin{array}{l}\text { Third Strengthening Fiscal Management } \\
\text { and Private Sector Employment } \\
\text { Opportunities DPC (US\$40 million, FY20) }\end{array}$ & $\begin{array}{l}\text { COVID-19 Crisis Response DPC } \\
\text { (US\$35 million, FY21)/1 } \\
\text { New Programmatic DPC (1) (US\$30 } \\
\text { million, FY22) (2) (US\$21 million, } \\
\text { FY23)/2 }\end{array}$ \\
& & \\
\hline Improve environmental resilience & DPF with Cat DDO (US\$14.8 million, & (Same Programmatic DPC (1) (2) as \\
& FY20) & above) \\
\hline
\end{tabular}

Note: /1 This DPC will include human capita-related policy measures. /2 The DPC series will also cover environmental resilience objective.

Table 4. Pipeline of World Bank Group advisory services and analytics

\begin{tabular}{ll} 
Objective & Output \\
\hline Improve human capital & Human Capital Review (FY22) \\
\hline $\begin{array}{l}\text { Improve economic } \\
\text { resilience }\end{array}$ & $\begin{array}{l}\text { Macroeconomic monitoring (continuous), including Bhutan Development Update } \\
\text { (annual), Debt Sustainability Analysis (FY21/FY22), and financial sector monitoring } \\
\text { Public Expenditure Review (FY22) } \\
\text { Country Economic Memorandum (FY22) }\end{array}$ \\
\hline $\begin{array}{l}\text { Improve environmental } \\
\text { resilience }\end{array}$ & Country Environmental Assessment (FY22) \\
\hline Cross-cutting & $\begin{array}{l}\text { Poverty monitoring (continuous) } \\
\text { Statistical capacity technical assistance } \\
\text { Fiduciary assessment (FY22) including Public Expenditure Fiduciary Assessment (PEFA) } \\
\text { and Methodology for Assessing Procurement System (MAPS) }\end{array}$ \\
\hline
\end{tabular}

89. Given that Bhutan is at moderate risk of debt distress, the World Bank's Sustainable Development Finance Policy (SDFP) requires the Bank to a set aside 10 percent of the annual country allocation. Setasides are released based on the findings of an annual exercise whereby IDA management systematically assesses the implementation of agreed performance and policy actions (PPAs) for enhancing fiscal sustainability and improving debt management. The Bank will assess performance of PPAs through macroeconomic monitoring and the new DPC series under IDA-19, supported by TA and advisory services in the areas of debt management and PFM If implementation of the PPA is considered satisfactory, Bhutan will have full access to its country allocation for the upcoming fiscal year.

90. IFC's investments are expected to be in the range of US\$6-US\$50 million. They will support microfinance, digital financial services, and high-value agribusiness producers. IFC plans to (a) provide advisory services to address microfinance institution regulations, risk assessments, and capacity building; (b) enhance credit information-sharing and digital financial services through financial infrastructure advisory; and (c) provide policy advice on FDI and ECBP advisory focusing on sector-specific investment 
promotion and upstream market development strategies. Analytical work has also been identified to explore opportunities in digital entrepreneurship and targeted agribusiness product development and market identification. The scope of IFC's engagement in Bhutan will depend largely on the government's receptivity and capacity to implement the reforms needed to create opportunities in the priority sectors. IFC remains ready to engage with clients in response to the COVID-19 crisis and is monitoring portfolio projections for its existing clients.

91. MIGA, working closely with the World Bank and IFC, will seek to actively explore opportunities to support cross-border investments into Bhutan. MIGA will monitor progress on the government's reform program to ensure that as opportunities arise MIGA can reach out to private sectors investors to seek to support their investment plans, as appropriate. MIGA also stands ready to support Bhutan's response to the COVID-19 crisis through the application of its political risk insurance.

\subsubsection{Financial management and procurement}

92. The government's PFM structures and processes have improved. Although challenges remain, the core elements of an adequate PFM system, including publication of the budget, are in place. Improvements in financial management stem from the government's commitment to (a) strengthening the legal framework; (b) enhancing institutional capacity and the internal control framework; (c) improving the financial management information system; and (d) strengthening the oversight of public finances. Together, these actions aim to increase accountability and improve the timeliness, quality, transparency, and reliability of the government's accounting and reporting functions.

93. Bhutan has prepared a PFM Reform Strategy and Action Plan that takes the reform agenda to the next phase. The 2016 Public Expenditure and Financial Accountability (PEFA) documents the progress made between 2010 and 2015. Based on its findings, in August 2017 the PFM Governance Group approved a comprehensive, sequenced, and time-bound PFM Reform Strategy and Action Plan.

94. Bhutan's public procurement system is open to competition, includes checks and balances, and is audited. Reforms to the public procurement system over the last decade are evident. The government demonstrated its commitment to further develop the procurement system by implementing Phase 1 of electronic government procurement (eGP), and Phase 2 is underway. In 2016, the World Bank conducted and approved the first Alternative Procurement Arrangements (APA) assessment of Thimphu Thromde (municipality). It observed several good international practices, such as a strong framework for control and audit, the use of quality/cost-rated criteria using a point-based system in works contracts, and the use of a conflict of interest declaration. Revised procurement rules and regulations, which were operationalized in October 2019, represent another effort to modernize the country's procurement framework.

\subsubsection{Citizen engagement}

95. This CPF includes a Citizen Engagement Country Roadmap. WBG efforts in ongoing and future engagements will include components that intensify and broaden outreach to citizens and all stakeholders, particularly the most vulnerable (such as women, youth, and seniors). The Citizen Engagement Country Roadmap (shown in Figure 6) sets out actions that will improve the quality of citizen engagement and create models for citizens to engage with a large number of stakeholders in development initiatives and country reforms to ensure good use of existing consultation and voice mechanisms. The CPF is committed to mainstreaming citizen engagement activities into the program, with TA and capacity 
building provided to project teams across all sectors to identify entry points and relevant citizen engagement mechanisms. In line with its cross-cutting foundations, this CPF will emphasize the use of digital technologies and data, including the introduction of data-driven feedback loops, in implementing citizen engagement.

Figure 6. Citizen Engagement Roadmap

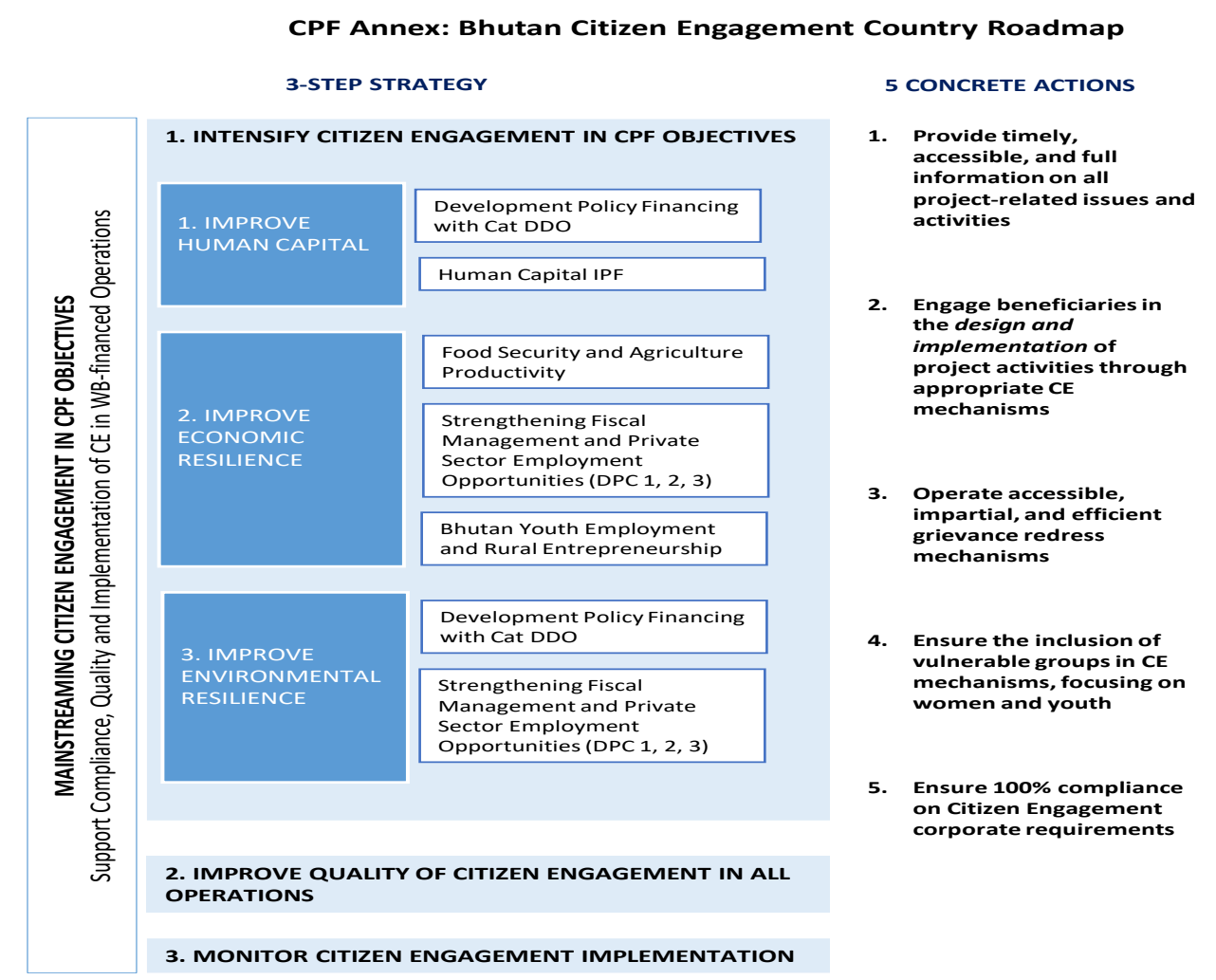

\subsubsection{Partnerships and donor coordination}

96. Because of Bhutan's strong economic growth and trajectory in social and human development, development partners are limiting their presence in and support to the country. Bhutan is eligible to graduate from the Least Developed Countries (LDC) category of the United Nations by 2023 (the end of the current FYP). The financing of the country's FYPs has been sourced mainly through Official Development Assistance (ODA) and domestic revenue. ODA has been decreasing and is expected to decrease further once Bhutan graduates from LDC status.

97. The government hosts a roundtable meeting once every two years. Since its inception in the early 1980 s, the roundtable has been the highest-level donor coordination forum with the government. The United Nations convenes bimonthly development partner group meetings to share information. The WBG will continue to explore partnerships in common areas of engagement to maximize impact and avoid aid fragmentation. 


\section{MANAGING RISKS TO THE COUNTRY PARTNERSHIP FRAMEWORK PROGRAM}

\section{The overall risk of this CPF is moderate (Table 5).}

99. Macroeconomic risks are substantial. The COVID-19 pandemic presents substantial economic risks, in the form of reduced demand for exports, including tourism. Import shortages and rising prices pose additional macroeconomic risks, as does a domestic outbreak of COVID-19 that is accompanied by lockdowns and social distancing measures.

100. The risk associated with inadequate institutional capacity for implementation and sustainability is substantial. Limited technical capacity, a complex organizational structure, and weak interagency coordination pose risks to the achievement of CPF's objectives. To mitigate this risk, the WBG's engagements focus on developing capacity and fostering coordination across implementing agencies.

Table 5. Evaluation of risks of the Country Partnership Framework

\begin{tabular}{l|l} 
Risk category & Risk rating \\
Political and governance & | Moderate \\
Macroeconomic & | Substantial \\
Sector strategies and policies & | Moderate \\
Technical design of project or program & | Moderate \\
Institutional capacity for implementation and sustainability & | Substantial \\
Fiduciary & | Moderate \\
Environment and social & | Low \\
Stakeholders & | Moderate \\
Other & \\
Overall & | Moderate
\end{tabular}




\section{ANNEX 1. BHUTAN CPF RESULTS MATRIX}

\section{FOCUS AREA 1: HUMAN CAPITAL}

Diversifying the source of growth and sustaining growth will require continued investment in the human capital of current and future generations. The Bhutan Human Capital Index is just 0.48 , implying that the country is failing to realize more than half of the potential it could reap if it provided full health and education. GDP growth in Bhutan would have been more than 2.2 times higher had its people enjoyed full health and education services.

\section{CPF Objective 1: Improve human capital}

Intervention logic: Improving human capital requires many interventions. Investment needs to be multisectoral and complementary to address the binding constraints to improving human capital outcomes.

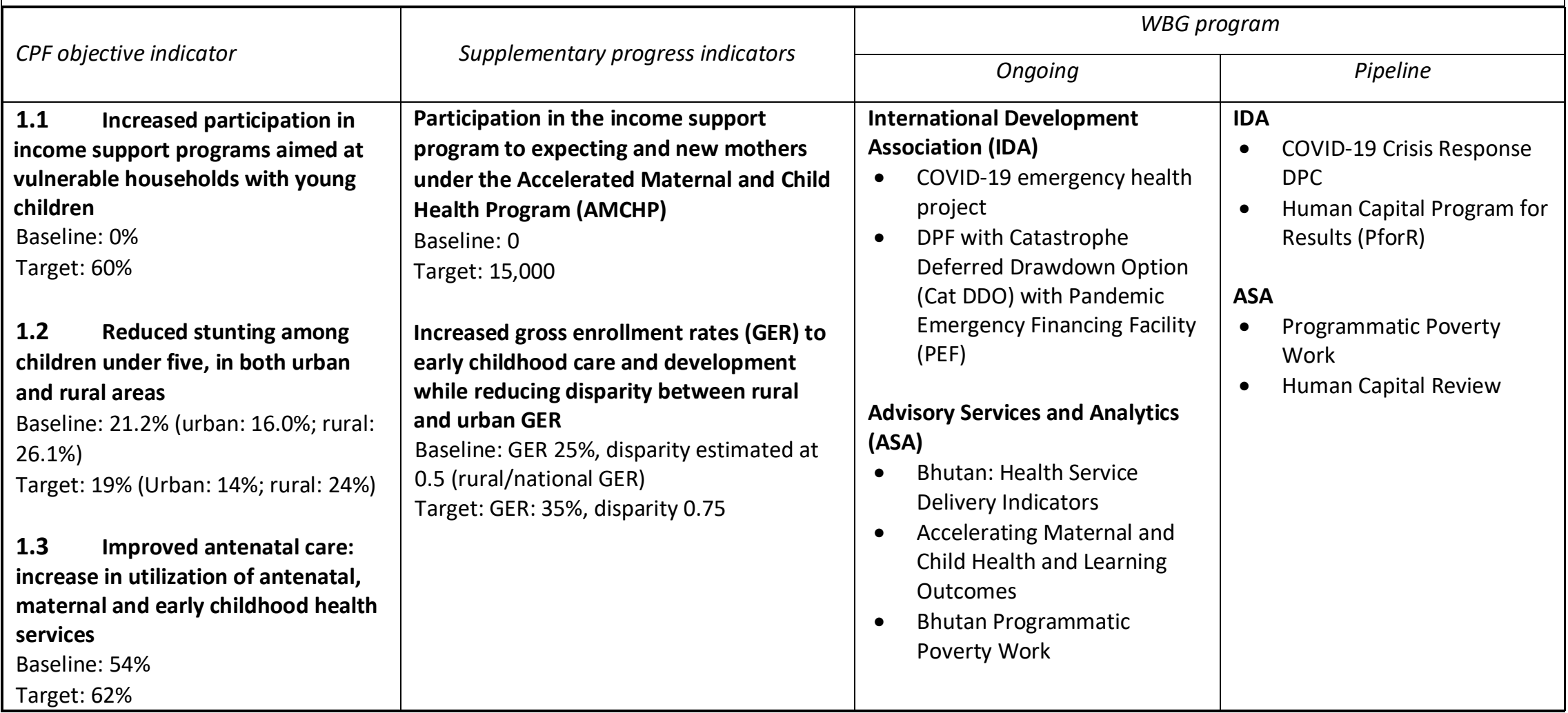




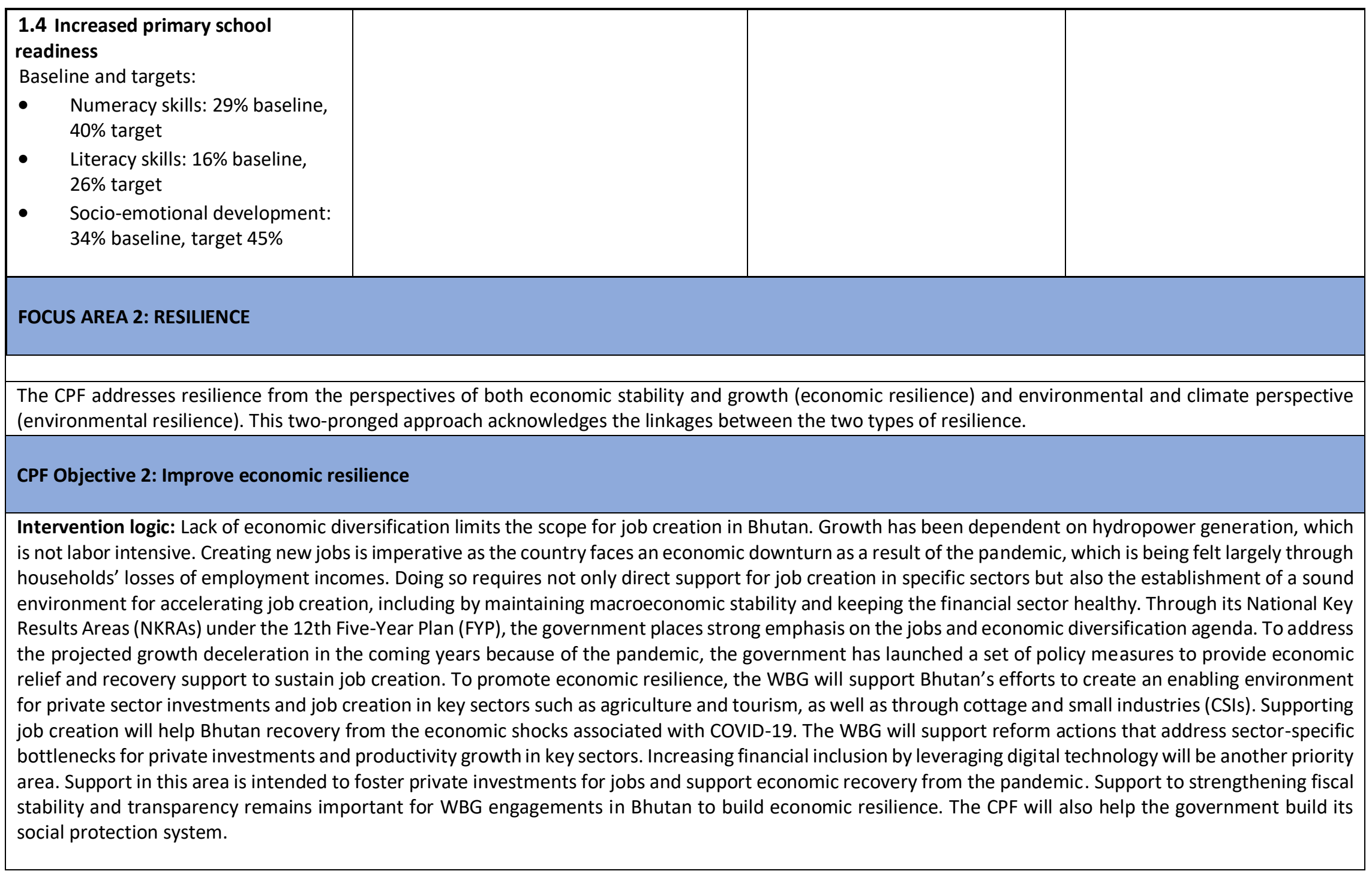




\begin{tabular}{|c|c|c|c|}
\hline \multirow[b]{2}{*}{ CPF objective indicator } & \multirow[b]{2}{*}{ Supplementary progress indicators } & \multicolumn{2}{|c|}{ WBG program } \\
\hline & & Ongoing & Pipeline \\
\hline $\begin{array}{l}\text { 2.1 Number of cottage and small } \\
\text { industries (CSIs) } \\
\text { Baseline: } 18,032 \text { (2018) } \\
\text { Target: } 25,000 \text { (2025) } \\
\text { 2.2 Total new private investments in } \\
\text { high-value agribusiness } \\
\text { Baseline: } 0 \text { (2020) } \\
\text { Target: } \$ 10 \text { million (2025) } \\
\text { 2.3 Number of entities reporting to credit } \\
\text { information bureau } \\
\text { Baseline: } 998 \text { (2016) } \\
\text { Target: At least } 20 \text { percent increase by } \\
\text { 2025 } \\
\text { 2.4 Non-hydropower revenue (as percent } \\
\text { of GDP) } \\
\text { Baseline: } 12.8 \text { (2019/20) } \\
\text { Target: } 15.0(2024 / 25)\end{array}$ & $\begin{array}{l}\text { Increase in outstanding loans to CSIs } \\
\text { Baseline: Ngultrum 18,976 million (2018) } \\
\text { Target: Ngultrum 26,557 million (2025) } \\
\text { Updating of foreign direct investment (FDI) } \\
\text { regulations/revisions of external } \\
\text { commercial borrowing (ECB) policies } \\
\text { revised } \\
\text { Baseline: No } \\
\text { Target: Yes (2025) } \\
\text { Revenues collected under the goods and } \\
\text { services tax (GST) } \\
\text { Baseline: } 0 \\
\text { Target: } 20 \text { percent of FY2016 revenue } \\
\text { (2024) } \\
\text { Publication of quarterly fiscal and debt } \\
\text { reports } \\
\text { Baseline: No (2020) } \\
\text { Target: Yes (2025) } \\
\text { Publication of quarterly aggregated SOE } \\
\text { reports with financial and operational } \\
\text { performance indicators } \\
\text { Baseline: No (2020) } \\
\text { Target: Yes (2025) }\end{array}$ & $\begin{array}{l}\text { IDA } \\
\text { - Third Strengthening Fiscal } \\
\text { Management and Private } \\
\text { Sector Employment } \\
\text { Opportunities } \\
\text { Development Policy } \\
\text { Credit (DPC) } \\
\text { Recipient-Executed Trust Fund } \\
\text { (RETF) } \\
\text { - Public Financial } \\
\text { Management- Multi- } \\
\text { Donor Fund (PFM-MDF)- } \\
\text { Financed Strengthening } \\
\text { Public Financial } \\
\text { Management (P162196) } \\
\text { (US\$4 million, FY2018, } \\
\text { closing FY2021) } \\
\text { Food Security and } \\
\text { Agriculture Productivity } \\
\text { Project (US\$8 million; } \\
\text { FY2017, closing FY2023) } \\
\text { Bhutan Youth } \\
\text { Employment and Rural } \\
\text { Entrepreneurship Project } \\
\text { (US\$1.25 million, FY2017, } \\
\text { closing FY2021) }\end{array}$ & $\begin{array}{l}\text { IDA } \\
\text { - } \text { COVID-19 Crisis Response } \\
\text { DPC } \\
\text { - } \quad \text { Programmatic DPC-1 } \\
\text { (the programmatic DPC series } \\
\text { will also address } \\
\text { environmental resilience } \\
\text { objectives) } \\
\text { Advisory Services and } \\
\text { Analytics (ASA) } \\
\text { - Public Expenditure Review } \\
\text { (PER) } \\
\text { - Country Economic } \\
\text { Memorandum (CEM) } \\
\text { - monitoring } \\
\text { - Macroeconomic } \\
\text { monitoring, including } \\
\text { Bhutan Development } \\
\text { Updates and financial } \\
\text { sector monitoring } \\
\text { - Programmatic poverty } \\
\text { work } \\
\text { - Statistical capacity TA } \\
\text { Fiduciary Assessment } \\
\text { including Public } \\
\text { Expenditure Fiduciary } \\
\text { Assessment (PEFA) and } \\
\text { Methodology for Assessing } \\
\text { Procurement System } \\
\text { (MAPS) }\end{array}$ \\
\hline
\end{tabular}




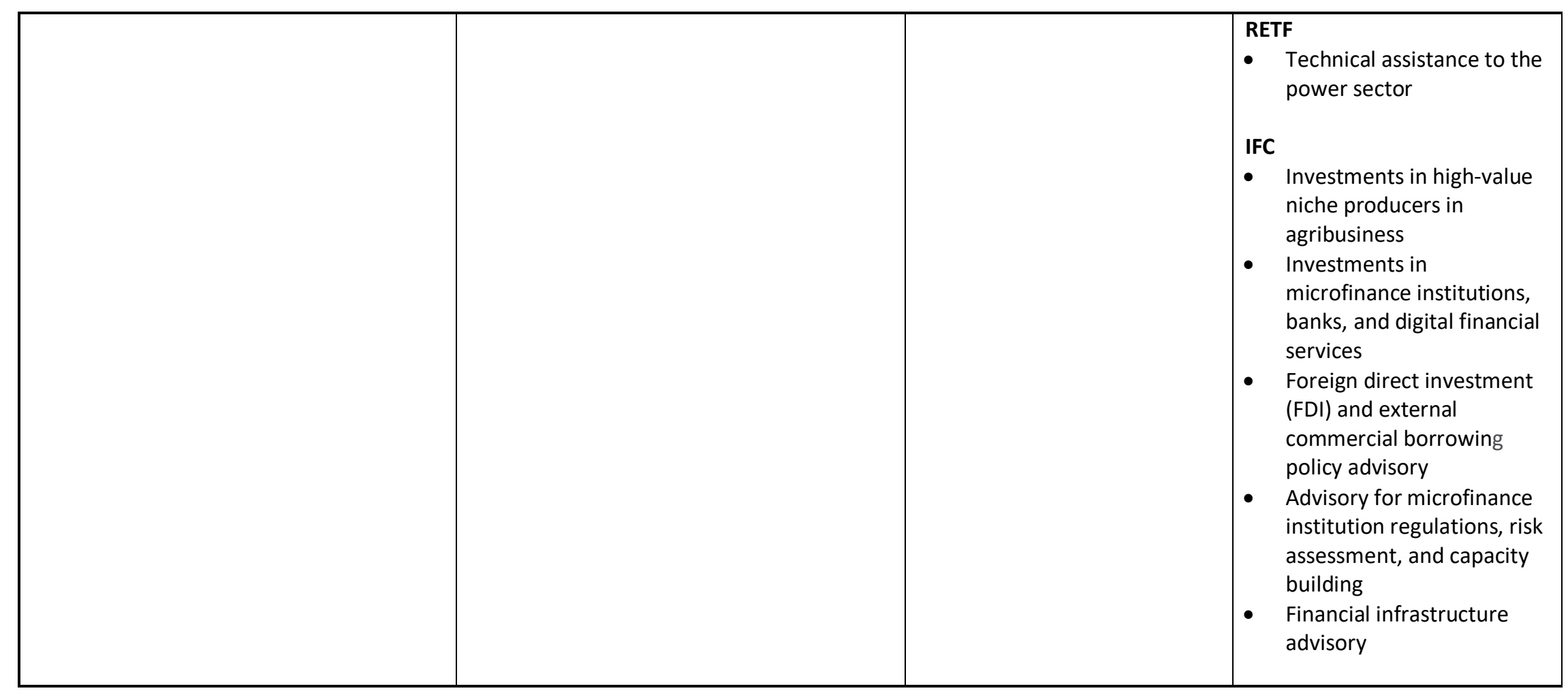

CPF Objective 3: Improve environmental resilience

Intervention logic: Natural resources continue to provide unique opportunities for Bhutan's growth. Their preservation is an integral aspect of the country's development philosophy. Natural resources are also a foundation of economic opportunities, including for underserved populations. The CPF supports Bhutan's approach to conserving the environment while at the same time opening new economic opportunities through a shift from conservation and subsistence use to conservation and sustainable management of natural resources.

\begin{tabular}{|c|c|c|c|}
\hline \multirow[b]{2}{*}{ CPF objective indicator } & \multirow[b]{2}{*}{ Supplementary progress indicators } & \multicolumn{2}{|c|}{ WBG program } \\
\hline & & Ongoing & Pipeline \\
\hline $\begin{array}{l}\text { 3.1 Maintenance of carbon-neutral status } \\
\text { Baseline: } 1: 3 \text { (tons of }\left(\mathrm{CO}_{2} \text { ) }\right. \\
\text { Target: } 1: 3\end{array}$ & $\begin{array}{l}\text { Increase in investments in modern forest } \\
\text { technology in Forest Management Units } \\
\text { and Community Forests (in US\$) }\end{array}$ & $\begin{array}{ll}\text { IDA } & \\
\text { - DPF with Catastrophe } & \text { Deferred Drawdown } \\
& \text { Option (Cat DDO) }\end{array}$ & $\begin{array}{l}\text { IDA } \\
\text { - Programmatic DPC-1 } \\
\text { - } \quad \text { Programmatic DPC-2 }\end{array}$ \\
\hline
\end{tabular}




\begin{tabular}{|c|c|c|c|}
\hline $\begin{array}{l}\text { 3.2 Approvable of sustainable forest } \\
\text { management plans } \\
\text { Baseline: No } \\
\text { Target: Yes } \\
\text { 3.3 Development of disaster } \\
\text { management and contingency plan } \\
\text { Baseline: Two agencies } \\
\text { Target: All agencies } \\
\text { 3.4 Establishment of a climate fund to } \\
\text { aggregate emission reductions } \\
\text { Baseline: No } \\
\text { Target: Yes } \\
\text { 3.5 Climate co-benefits total IDA } \\
\text { commitments FY2018-21 }\end{array}$ & $\begin{array}{l}\text { FMU and CF forest area managed under } \\
\text { revised forest management plans } \\
\text { (hectares) } \\
\text { Increase in investments in early warning } \\
\text { systems (US\$) } \\
\text { Reduction in carbon emissions through } \\
\text { WBG-supported interventions }\end{array}$ & $\begin{array}{l}\text { with Pandemic } \\
\text { Emergency Financing } \\
\text { Facility (PEF) } \\
\text { RETF } \\
\text { - } \quad \text { Forest Carbon } \\
\text { Partnership Facility } \\
\text { Reducing Emissions } \\
\text { from Deforestation } \\
\text { and Forest } \\
\text { Degradation } \\
\text { Readiness grant } \\
\text { - Preparation Support } \\
\text { Program } \\
\text { Bhutan Weather and } \\
\text { Disaster Resilience } \\
\text { Project } \\
\text { Preparation of } \\
\text { Strategic Program for } \\
\text { Climate Resilience }\end{array}$ & $\begin{array}{l}\text { RETF } \\
\text { - Bhutan Climate Fund } \\
\text { ASA } \\
\text { - Country Environmental } \\
\text { Assessment }\end{array}$ \\
\hline
\end{tabular}




\section{ANNEX 2. COMPLETION AND LEARNING REPORT}

The Kingdom of Bhutan FY2015-19 CPS Completion and Learning Review

Date of Country Partnership Strategy: September 23, 2014 (Report No. 88507BT)

Date of Performance and Learning Review: May 8, 2017 (Report No. 110736-BT)

Period covered by the Completion and Learning Review: FY2015-19

I. Introduction and Key Findings

\section{Introduction}

1. This Completion and Learning Review (CLR) provides an evaluation of the development outcomes and implementation of Bhutan's Country Partnership Strategy (CPS) for FY2015-19. The CLR evaluates the achievements of the CPS program outcomes and World Bank Group (WBG) performance in designing and implementing the CPS program. The CLR draws lessons from implementation that will inform the forthcoming Country Partnership Framework (CPF).

2. The strategic objective of the CPS was to support Bhutan's aspirations to achieve sustainable and inclusive growth. The CPS focused on emerging challenges of the country's short-term macroeconomic imbalances of hydro-led growth and improving the business environment to diversify the economy. The CPS results areas are aligned with the government's 11th Five-Year Plan (FYP) for 201318 that was guided by the four pillars of Gross National Happiness $(\mathrm{GNH})$ : good governance, sustainable socioeconomic development, preservation and promotion of culture, and environmental conservation. These four pillars form the basis for the three CPS results areas: (a) improving fiscal and spending efficiency, (b) increasing private sector growth and competitiveness, and (c) supporting green development. A Performance and Learning Review (PLR), prepared on May 8, 2017, confirmed the broad relevance of the CPS.

\section{Summary of Key Findings}

3. The development outcome rating of the CPS is Moderately Satisfactory.27 This rating is based on an aggregate assessment of the achievements under the seven outcome objectives in the results matrix revised through the PLR. All seven objectives were either Achieved or Mostly Achieved with notable progress under all three results areas. Table 1 summarizes the CPS development outcome ratings and Section II provides more detailed assessment of the achievement of the CPS objectives.

4. The WBG's performance in designing and implementing the CPS is rated Good.28 The selectivity of the CPS program was driven by the client's development aspiration described in the 11th FYP, the WBG's comparative advantage, and portfolio consolidation. The CPS engagement areas were selective and effectively supported government reform programs through a series of Development Policy Credits (DPC) and limited number of investment lending operations. The lending program was complemented with Advisory Services and Analytics (ASA) services and trust fund (TF) activities, although a proliferation of

\footnotetext{
27 The overall outcome is rated either Highly Satisfactory; Satisfactory; Moderately Satisfactory; Moderately Unsatisfactory; Unsatisfactory; and Highly Unsatisfactory based on the ratings of the individual objectives. The rating scale for Moderately Satisfactory is the program Achieved or Mostly Achieved the objectives; or the program either partially achieved most the objectives. No major shortcomings were identified.

28 WBG Performance rating scale includes Superior; Good; Fair and Poor. The Good rating requires that design and implementation of the program successfully contributed to pursuit of key CPS objectives and timely adaptation to changing circumstances and priorities.
} 
ASA and trust-funded activities made it challenging for the WBG to be selective for the entire CPS program. The results matrix could have been further streamlined with fewer indicators to show maximum impact. Activities of the International Finance Corporation (IFC) were relevant and focused mostly on business environment and financial inclusion. There were no opportunities for utilizing the Multilateral Investment Guarantee Agency's (MIGA) political risk insurance instrument to support cross-border private investments. The CPS program Implementation was moderately affected by the 2018 elections. The implementation of the reform programs supported by DPC was delayed, although policy reform directions remained unchanged. During the first half of the CPS period, the IDA program was strategically focused to make better use of available resources. However, the implementation of two investment projects was initially delayed primarily due to insufficient government capacity, especially in the area of procurement. During the PLR stage, the WBG program intensified support for fiscal management and private sector development. Although the World Bank explored possible engagement in the infrastructure and hydropower sectors through Investment Project Financing (IPF) and Program-for-Results (PforR),29 the government increasingly preferred budget support operation over IPF and PforR. The IDA delivered a modest lending program of US $\$ 104$ million against US $\$ 162$ million to Bhutan,30 covering both the IDA17 and IDA18 cycles.

\section{PROGRESS TOWARD CPS DEVELOPMENT OUTCOMES}

5. Bhutan's economic growth remained robust during the CPS period. A combination of prudent fiscal and monetary policy contributed to the acceleration of gross domestic growth (GDP) growth at an average of 6 percent during FY2015-19. Hydropower has contributed to rapid GDP growth through increased investment and export earnings. Tourism has contributed to solid growth of the services sector. The national poverty headcount declined from 23.2 percent in 2007 to 8.2 percent in 2017. An estimated 145,000 people (almost a quarter of the population) were lifted out of poverty during that period. Poverty reduction was likely driven by agricultural productivity and better prices for cash crops. However, poverty remains a challenge in rural areas where poverty headcount ratio is still high. the Gini Index, which measures inequality, remains almost the same at the national level (0.36 in 2012 and 0.38 in 2017). The country's private sector remains underdeveloped, facing constraints due to a small domestic market with low connectivity, lack of access to finance, shortage of skilled labor, large state footprint, and regulatory challenges.

6. This section evaluates the CPS program performance based on specific outcomes laid out in the revised Results Matrix during the PLR. It is an assessment of program achievements directly linked to WBG supported activities. Table 1 summarizes the development outcome indicator ratings while Attachment 1 contains the assessment details of the outcome indicators.

Table 1. Summary of CPS outcome ratings

\begin{tabular}{|c|c|c|c|c|c|}
\hline \multirow[b]{2}{*}{ CPS results areas and outcomes } & Overall & \multicolumn{4}{|c|}{ Outcome indicator ratings } \\
\hline & $\begin{array}{l}\text { outcome } \\
\text { rating 1/ }\end{array}$ & Achieved & $\begin{array}{l}\text { Mostly } \\
\text { achieved }\end{array}$ & $\begin{array}{l}\text { Partially } \\
\text { achieved }\end{array}$ & $\begin{array}{c}\text { Not } \\
\text { achieved }\end{array}$ \\
\hline \multicolumn{6}{|c|}{ Results Area 1: Improving fiscal and spending efficiency - Moderately Satisfactory } \\
\hline 1. Strengthened fiscal efficiency & Achieved & 2 & & & \\
\hline $\begin{array}{l}\text { 2. Strengthened system for public financial } \\
\text { management and procurement performance }\end{array}$ & $\begin{array}{l}\text { Mostly } \\
\text { achieved }\end{array}$ & 1 & 1 & & \\
\hline
\end{tabular}

29 PforR links disbursement of funds directly to the delivery of defined results, helping countries improve the design and implementation of their own development programs and achieve lasting results by strengthening institutions and building capacity.

30 This includes US\$47 million country allocation in FY2020, outside of the CPS cycle. 


\section{Results Area 2: Increasing private sector growth and competitiveness - Moderately Satisfactory}

3. Improved regulatory framework for Mostly

1 1 business environment Achieved

4. Increased efficiency and access to financial Achieved 2 services

Results Area 3: Supporting green development - Satisfactory

5. Increased agricultural productivity in Achieved 2 targeted remote areas

6. Improved urban infrastructure management Achieved 2

7. Improved management of the natural Achieved 3 capital and strengthened resilience to climate change/disaster risks

Total

1/ Outcome rating builds on outcome of indicator ratings.

\section{Results Area 1: Improving fiscal and spending efficiency - Moderately Satisfactory}

7. For this results area, The CPS program made good progress in supporting government reforms to increase revenues, lower deficit, and strengthen public financial management and procurement systems. The Adoption of the 2016 debt policy has been instrumental in strengthening debt management to ensure fiscal sustainability.

\section{Outcome 1: Strengthened fiscal efficiency - Achieved}

8. Fiscal management improved during the CPS period. The CPS programs contributed to deepening WBG engagement in this outcome area through a series of DPCs and ASAs to promote policy measures that enabled the government to improve revenue and expenditure performance. Examples are (a) an increase in tax rates of custom duties and sales taxes and green taxes on selected goods, (b) strengthening of debt management functions, and (c) the revision of rules and regulations of fiscal incentives. Implementation of these reforms helped increase tax revenues from $\mathrm{Nu} 18.4$ billion in 2014/15 to $\mathrm{Nu} 27.1$ billion in 2017/18. In addition, the share of domestic revenue to total expenditure exceeded the CPS target, reaching 65 percent from the baseline of 60 percent. The fiscal balance improved from a deficit of 4.2 percent of GDP in FY2013 to a surplus of 0.8 percent of GDP in FY2019 due to a large decline in capital expenditure. The 2018 Debt Sustainability Analysis (DSA) confirmed that Bhutan's risk of debt distress remained moderate and all debt indicators have been below the threshold defined in the 2016 debt policy. For example, the non-hydropower debt to GDP ratio at 22.3 percent in 2017/18 was lower than the threshold in the debt policy. The Debt Management Division was formally transferred to the Department of Macroeconomic Affairs, which ensures that public debt is sustainable and contracted at low costs with minimum risk.

Outcome 2: Strengthened system for public financial management and procurement performance - Mostly Achieved

9. Progress was made in improving public financial management (PFM) and procurement systems for enhanced public service delivery. The 2016 Public Expenditures and Financial Accountability (PEFA) assessment confirmed that Bhutan has good fiscal discipline through comprehensive coverage of budget execution, good control of expenditure commitments and oversight 
aggregate fiscal risk31, and the quality and timeliness of budget reports32. As a result, two out of three CPF indicator 3 (e.g. PI-9, PI-24) achieved its target while the third indicator related to legislative scrutiny of the annual budget law (PI-27) remained at the baseline status with no progress. The government, with the support from the World Bank's technical assistance, developed a PFM Reform Strategy and Action Plan and The Multi-Donor Fund (PFM MDF) has been supporting the implementation of key reform activities. several key policy reforms either have already been implemented or are in an advanced stage of implementation: improving budget documentation, analyzing and classifying through enhanced focus on gender and climate change, strengthening public procurement systems, and integrating for moving toward Integrated Financial Management Information System (IFMIS) and ePayments initiative (ePEMS). These initiatives are expected to contribute toward efficient, accountable, and transparent PFM systems. For example, budget execution and key fiscal information of all the agencies are now published and available in the public domain. The first phase of the electronic government procurement (e-GP) system is being used by 10 ministries, 11 autonomous agencies, 20 districts, and 4 municipalities. Thimphu municipality became the first government counterpart to qualify for use of its own procurement system-Alternative Procurement Arrangement — under the World Bank-financed projects.33

\section{Results Area 2: Increasing private sector growth and competitiveness - Moderately Satisfactory}

10. The WBG's active engagement influenced government policies in improving efficiency of financial services and streamlining institutional process for improved business environment. Domestic investment also increased, creating further employment opportunities. The revised 2019 foreign direct investment (FDI) policy is expected to enable investors to have faster approvals and will allow a minimum investment size. However, progress in these areas has not yet been fully translated into increased private sector development.

\section{Outcome 3: Improved regulatory framework for business environment - Mostly Achieved}

\section{CPS target in streamlining business regulations was Mostly Achieved, but challenges remain.} The programmatic DPC series and ASA supported various reforms and systems enhancement to simplify business procedures. These included the amendment of the Companies Act, the establishment of an online property and land registration system in Thimphu in addition to other three municipalities, and the introduction of an electronic tax payment system. These system enhancements made positive contributions in increasing the ease of doing business. For example, currently 64 percent of the taxpayers use the Revenue Administration Management Information System (RAMIS). In addition, Online property and land registration became fully functional and the system is used in all 20 districts and 4 municipalities with 1,415 transactions and 1,940 registered users. Technical assistance, both at the design and implementation of land registration and transfer reforms, led to a significant reduction in the number of days taken to register and transfer a property, as reflected in the Doing Business report. The CPS program supported the government's reform efforts to facilitate domestic investment and FDI. Bhutan's cumulative FDI increased from US\$21 million in 2014 to US\$146 million in 2017 with a total of 73 FDI projects. The number of jobs in FDIrelated companies increased from 2,849 in 2013 to 5,30734 in 2018. However, FDI flows remain relatively small (about 1.3 percent of GDP in 2010-17) and the lowest across the South Asia region. While these achievements are encouraging, the private sector continues to be constrained by the small market size, skill shortages, insufficient business promotion, a large state footprint in commercially viable sectors, and an underdeveloped financial market. Further effort is needed in improving the investment climate, given that

31 PEFA indicator PI-9.

32 PEFA indicator PI-24.

33 https://www.worldbank.org/en/news/press-release/2016/11/16/bhutan-agency-approved-for-alternative-procurementarrangement

34 Implementation Completion and Results Report “Bhutan Programmatic Development Policy Operations I and II” (P157469). 
Bhutan's ranking fell from 73 to 89 (out of 190 countries) in the 2020 Ease of Doing Business where resolving insolvency, protecting a minority investors and ease of trading across borders are key constraints to businesses in Bhutan.

\section{Outcome 4: Increased efficiency and access to financial services - Achieved}

12. Bhutan's financial system has been strengthened and access to financial services has improved. The programmatic DPC and ASA supported the government in key financial sector reforms such as strengthening of the Credit Information Bureau (CIB) and the formulation of the Financial Sector Development Action Plan (FSDAP). Bhutan also maintained financial sector stability during the CPS. The Royal Monetary Authority (RMA), has strengthened prudential regulations and stress-testing exercises, introduced limits to consumption credit, incentivized productive sector lending and effective monitoring of $\mathrm{CIB}$, and adjusted risk weights and capital requirements. Bhutan's access to Financial inclusion increased through the strengthening of the functions of CIB, registration of movable assets as collaterals in the Central Registry for Secured transactions (CRST), and implementation of FSDAP. For example, CIB coverage of individuals and firms increased from 15.9 percent in 2014 to 35.9 percent in 2018, exceeding the CPS target. The share of micro, small, and medium enterprise loans to the CRST also increased by 487 percent during the same period. However, the 2017 Investment Climate Assessment identified lack of access to finance as a constraint that firms face while doing business since the procedures for acquiring loan are complex, collateral requirements are high, and regulations for the use of funds are restrictive. For example, Progress in improving legal framework for getting credit is limited such as the amendment of The Movable and Immovable Property Act and a new insolvency bill have not yet been submitted to parliament due to the delay in internal consultation. Finally, through IFC's support to the RMA of Bhutan and the Royal Institute of Governance and Strategic Study, Bhutan's Economic Forum for Innovative Transformation (BEFIT) was arranged. The BEFIT conference promoted equitable growth through financial inclusion and focused on micro finance, small and medium enterprises, agri-finance, and digital financial services. The Recommendations from the conference have guided Bhutan's National Financial Inclusion Strategy.

\section{Results Area 3: Supporting green development - Satisfactory}

13. The WBG's program supported the promotion of improved irrigation and agroeconomic practices and rehabilitation of productive assets. Despite implementation challenges, the program helped increase agriculture productivity in key commodities such as paddy. Access to urban infrastructure improved through the successful use of land pooling as the instrument to implement the Thimphu Structure Plan (TSP) in providing this infrastructure. IFC's first public-private partnership (PPP) concession for Thimphu City parking facilities is a significant milestone for Bhutan's further engagement with the private sector. The World Bank's strong partnership through various grant mechanisms enabled the government to mainstream biodiversity conservation into national planning, which is highly relevant for improving the management of natural capital and resilience to the impacts of climate change.

\section{Outcome 5: Increased agriculture productivity in targeted remote areas - Achieved}

14. Agriculture productivity in selected remote rural areas improved. The World Bank's investment lending project35 supported rural communities through improved irrigation, community-led investment in infrastructure, and agricultural technologies. Rehabilitation of irrigation schemes led to intensification and diversification of irrigated crop production. About 41 irrigation schemes with 795 ha36

35 Remote Rural Community Development Project (P123820).

36 About 59.5 ha was equipped with high-efficiency irrigation schemes, nine schemes covering 72.1 ha were equipped with water storage tanks, and three high-efficiency irrigation schemes covering 102.3 ha were established. 
of command area were rehabilitated. Improved water supply, combined with adoption of better watersaving practices and improved agricultural technologies, increased productivity of most crops. For example, Paddy productivity increased from $1,700 \mathrm{~kg} / \mathrm{ha}$ to $2,400 \mathrm{~kg} / \mathrm{ha}$ (in 13 selected schemes), a 38 percent increase in productivity. While there is tangible progress, the IPF also faced implementation bottlenecks. Progress was also observed in improving 41 community-led productive, post-harvest, and marketing infrastructures benefiting 27,696 people. In addition, IFC's investment in hazelnut plantation is expected to increase the incomes of 12,000 farm households, which is equivalent to 14 percent of Bhutan's population in the eastern part. As a result of the project, about 7.1 million trees have been planted and an estimated 16,900 tons of $\mathrm{CO}_{2}$ were reduced in 2019, while 2,000 direct and indirect jobs were created. The World Bank's recent Agriculture Sector Policy Notes emphasized that the agriculture sector is not homogeneous. One part consists of a commercially oriented subsector, in which production decisions are dynamically and strategically responding to market incentives, while the other part consists of a more subsistence-oriented subsector focused on food production for own consumption. Moving forward, this is an important policy discourse for the WBG's future engagement.

\section{Outcome 6: Improved urban infrastructure management - Achieved}

15. The CPS program achieved the targets for increased access to urban infrastructure and planning. The World Bank project37 contributed to improving basic infrastructure services and urban management systems in Thimphu and Phuntsholing municipalities. Access to piped water supply and sewerage connections increased, benefiting a total of 1,24238 households. In addition, 33,309 people were provided with access to all-season road within 500 meter. The government's use of land pooling mechanism in Local Area Plans (LAPs) reduced the incidence of unplanned and poorly serviced areas in the city. Municipal financial management services improved through the digitization of property tax records that has enabled municipalities to increase their property tax collections and other revenues significantly. For example, Thimphu municipality increased its annual revenue collection from $\mathrm{Nu} 7.58$ million in 2009 to $\mathrm{Nu} 236$ million when the project was closed in mid-2019. While no new investment under IDA is envisaged in the short term, the potential for long-term sustainability of operations and maintenance arrangements for improvements in infrastructure and the lack of staff training and capacity to carry forward the municipal finance activities raise concerns. IFC, In parallel, supported Thimphu municipality in designing and signing its first PPP concession agreement with a private developer to design, build, and operate two multilevel parking facilities to accommodate 550 cars and operate parking in the central business area of Thimphu municipality.

\section{Outcome 7: Improved management of natural capital and strengthened resilience to climate change/disasters risks - Achieved}

16. The CPS target to improve natural resource management was achieved. The World Bank administered several TF activities, which provided technical assistance and capacity-building support for biodiversity conservation, sustainable forest management, carbon trading, and wildlife conservation. The Sustainable Biodiversity Conservation and Natural Resource Management TF helped improve the operational effectiveness of Bhutan Trust Fund for Environmental Conservation (BTFEC) to adopt modern governance and business practices to implement a new strategic plan for environment conservation in Bhutan. Conservation management of high-altitude northern areas landscape at the community and farm levels improved in addition to increased financial resources for conservation activities. Consequently, it has helped bring 1.3 million ha area under enhanced biodiversity protection and adopt sustainable land management practices for over 114,821 ha of land area. Sustainable forest and natural resource management has been rolled out at the national level through the Surveillance Monitoring and Reporting Tool (SMART),

37 Second Urban Development Project (P090157) and Additional Financing (P145392).

38 About 732 households water and 510 households sewerage. 
which is an efficient way to contribute to the reduction of human-wildlife conflict, forestry management, and conservation. The World Bank has been supporting the government to build national capacity to engage in Reduced Emissions from Deforestation and Forest Degradation, Sustainable Management of Forests, and Enhancement of Forest Carbon Stocks (REDD+) efforts at the national and international levels through strengthened policies, increased knowledge on REDD+, and enhanced data availability on forests and forest management. Transforming the forestry sector by further enhancing sustainable forest management has the potential to increase employment opportunities and forest productivity.

17. The World Bank financed initiatives to strengthen Bhutan's climate and disaster risk management have made solid progress. At the national level, the government has taken initiatives to improve weather and climate services and strengthen disaster early warning systems and response capacity. The World Bank's program facilitated strengthening the capacity of the National Center for Hydrology and Meteorology to improve hydromet monitoring, forecasting, and services. The weather forecasting services have been enhanced through the operationalization of the SMART-met system that has enabled efficient access to all available weather forecasting inputs. An agromet decision support system is also being developed to provide agro-advisories to farmers to help make farm level decisions, which is one of the first initiatives of delivering hydromet services to users. To enhance the information base for disaster management, the government is preparing a Disaster Management Information System, which will improve preparedness and response capacity of the Department of Disaster Management under the Ministry of Home and Cultural Affairs. Capacity building opportunities provided to the National Center for Hydrology and Meteorology to develop climate projections in house for the first time.

\section{WORLD BANK GROUP PERFORMANCE}

18. Overall, the WBG's performance during the CPS was Good. The assessment is based on the arguments elaborated in the following sections.

\section{Design}

19. The CPS addressed Bhutan's development challenges and covered priority areas of support as laid out in the 11th FYP and the principles of Bhutan's development philosophy of GNH. Lessons learned and feedback from stakeholder consultations from the previous CPS were incorporated in the design of the strategy. The design focused on unique emerging challenges for a small state like Bhutan, of increasing competitiveness to help the government with macroeconomic stability and an inclusive business environment to diversify the economy while continuing to focus on improving rural livelihoods, managing urbanization, and protecting its natural resources. During the PLR, the WBG adjusted the design reflecting priorities of the government. for example, the WBG decided to reengage in human development.

20. While The CPS Results Matrix was aligned with the government's development goals, there is room for further improvement. For example, the CPS Outcomes 2 and 5 had three sub-indicators to measure progress. While these indicators were directly linked to the program, Having Multiple subindicators made it difficult to measure and rate the overall outcome. In addition, Outcome 7 (improved management of the natural capital and resilience to climate change/disaster risks) was formulated broadly with multidimensional objectives. There was a disconnect between the broad scope of the objective, which served two goals, and the narrow set of indicators. Overall, there were too many outcomes and supporting indicators for Bhutan's small program, which could have been further simplified during the PLR.

21. Selectivity/instruments. The strategic program of the CPS was selective and leveraged IDA resources with TFs and complemented IFC investments. The CPS applied selectivity for a mix of financing instruments with a limited number of investment projects, complemented by the programmatic DPC and 
ASA, given the limited implementation capacity and constraints of the government and World Bank's resources. IDA's DPC supported the government on key policy reforms to address development challenges such as competitiveness, fiscal management, and private sector development. The DPC series was complemented by key analytical work and technical assistance to strengthen the government's capacity. In addition, The IDA program along with TF resources continued to support rural livelihood, urbanization, disaster risk management, and natural resource management. IFC's program remains committed to financial inclusion, business climate enhancement, and SME development through investment and advisory services. The CPS program attempted to explore diversification of IDA instruments, such as a PforR and IPF operation. However, this did not materialize as the government preferred budget support operations and changed its direction to PforR and IPF.

22. Risks. Risks were identified correctly and remained relevant throughout the CPS period. The macroeconomic and political governance risks continued to be moderate despite the elections in 2018. However, reform implementation was initially delayed due to the 2018 election and subsequent change in the government. The Political risk was mitigated through peaceful transition of power, government's commitment to reform and macroeconomic stability. The risk to institutional capacity for implementation and sustainability remained substantial. It was moderately mitigated through the World Bank's continued work with the government through the DPC series and investment operations that provided technical assistance for capacity-building support and coordination across various implementing agencies.

\section{Implementation}

23. The CPS IDA lending delivery for FY2015-19 reached US\$104 million, covering both IDA1739 (FY2015-17) and IDA1840 (FY2018-19) replenishment periods totaling US\$162 million. Four programmatic DPCs were approved and supported policy reforms in the areas of fiscal management, competitiveness, job creation, and PFM. During the PLR, the World Bank program aimed to intensify its support to existing areas and reengage in new areas such as infrastructure, hydropower, and human capital in view of key development challenges. While the World Bank has been engaged in policy dialogue in these areas and encouraged the government to utilize existing IDA country allocations, 41 the government's commitment to investment lending, particularly in the areas of infrastructure and hydropower, was limited. Despite the initial official requests from the government, the anticipated regional connectivity project and hydropower project did not materialize. On the former, The previous government postponed it due to slow progress of a political agreement on information and communication technology connectivity between Bhutan, Bangladesh, and India. The hydropower project was canceled as the previous government decided to conduct an overall review of development of the hydropower sector.

24. Portfolio performance during the CPS has been modest. The two investment operations, Remote Rural Community Development Project and Bhutan Urban Development Project, faced implementation challenges including changes in project management, shortage of qualified engineers, lack of coordination among implementing agencies, delays in procurement decision, and human capacity constraints. The World Bank team recognized associated risks of implementation delays and proposed reasonable mitigation measures such as strengthening local capacity-building support of technical staff in procurement, financial management, and community infrastructure. In addition, Enhanced supervision mission through hands on support in procurement also improved implementation bottlenecks. While the World Bank's proactive support helped improve portfolio performance, the sustainability of the program

39 IDA17 allocation was US\$56 million, of which only US\$44 million for two DPC operations was utilized.

40 IDA18 allocation was US\$104 million, of which US\$60 million for two DPC operations was utilized as of July 2019.

41 Under IDA18, Bhutan's country allocation doubled to US\$100 million at concessional rate. Bhutan is likely to graduate from United Nations Least Developed Country status. 
after project closing raises a concern since the government is reluctant to use credit resources for capacitybuilding support.

25. IFC's investment during the CPS has been modest with a total committed portfolio of US\$20.5 million as of June 30, 2019. While the investment volumes have been small, IFC engagements have been impactful. The portfolio consists of three projects: (a) an equity participation in Bhutan National Bank (BNB), (b) external commercial borrowing to Zhiwa Ling Hotel, and (c) an equity investment to support a greenfield hazelnut plantation. IFC reduced its equity stake in BNB by half in 2016 in the first major equity buyback in Bhutan's corporate sector. IFC's investment in Zhiwa Ling Hotel in 2015 marks the first crossborder commercial loan from a fully private Bhutanese company. IFC maintains trade finance facility lines with Bhutan's two largest banks42 supporting access to markets for small and medium enterprises and trade competitiveness. Going forward, IFC's potential to grow its investment program will largely depend on government support to the private sector in general.

26. MIGA does not have an outstanding exposure in Bhutan.

27. TF activities expanded substantially for a small program like in Bhutan. A total of 32 trustfunded operations totaling US\$31.7 million supported technical assistance and analytical work in the areas of natural resource management, climate and disaster risk management, PFM, intergovernmental fiscal relations, urban transport, financial sector, health, social protection, and statistical capacity. Some of these activities were relevant in strengthening policies and institutional capacity. For example, technical assistance helped improve government statistical capacity to measure and monitor several national surveys which are vital for welfare conditions of the poor. Similarly, Technical support in the 2016 Debt Policy, FSDAP, and investment climate made positive impact on institutional development. While some of these activities were vital for CPS implementation and complemented IDA lending operations, overall, they were not selective enough to reduce the fragmentation of the World Bank's support and deliver results where counterpart capacities were limited.

28. The ASA program provided policy advice, sectoral diagnostics, and technical assistance across multiple sectors that are relevant to Bhutan's development challenges. For policy dialogue, a comprehensive set of Policy Notes was prepared for the new government in late 2018, which provided challenges and opportunities across various sectors with actionable policy recommendations. Key analytical pieces included the Public Finance Think Piece, the semiannual Bhutan Economic Updates, DSA, PEFA, and the Investment Climate Assessment, all of which informed the design of the programmatic DPC and the preparation of the 12th FYP for 2018-23. The World Bank also supported sector-specific analytical pieces such as weather and climate services, sustainable forest management, agricultural productivity, rural growth, and urbanization that promote rural-urban links and resilient poverty reduction. Public Expenditure Review for nutrition has informed government for evidence-based cost-effective interventions. However, More selectivity of these activities could have led to stronger impact. It is not evident whether these ASA recommendations informed or influenced any evidence-based policy making.

29. IFC provided key advisory support during the CPS through a number of interventions. Advisory support to reform Bhutan's licensing regime for businesses resulted in passing a licensing policy, setting up an e-portal for all license-related information, and streamlining the priority areas for FDI project approval. IFC's technical assistance to Thimphu municipality led to the first PPP concession in the key sector of urban infrastructure to help reduce traffic congestion in a central business area in Thimphu. IFC's technical assistance was prominent in helping BNB introduce global best practices in risk management, environmental and social policy, and corporate governance. It also supported RMA to host international

42 BNB and Bank of Bhutan. 
summit on financial inclusion and corporate governance. IFC delivered a feasibility study to the government to explore viability of setting up a Bhutanese-owned power trading company in India and remains ready to engage in the hydropower sector if the opportunity arises. Leveraging its convening power and thought leadership, IFC also sponsored a private sector-led conference focusing on energy, economy, and the environment in Bhutan.

30. The WBG coordinated with other development partners in leveraging financial and technical assistance. The World Bank has been working closely with the International Monetary Fund (IMF) on macroeconomic, debt management, and financial issues. The World Bank actively contributed to the IMF Article IV reviews and coordinated closely with a number of technical assistance programs supported through the DPC series. The World Bank coordinated with the Asian Development Bank (ADB) in hydropower, financial, and private sector development where the ADB is providing technical assistance. IFC partnered with the ADB on the hazelnut plantation project and the CIB. The World Bank has been working with the European Union and the Australian Development Agency through the implementation of the PFM MDF. The World Bank's work in the agriculture sector in the southern provinces of the country complemented the International Fund for Agricultural Development work that concentrated in the eastern provinces. The World Bank also participated in a donor roundtable meeting hosted by the government.

31. Safeguard/fiduciary. There were no significant safeguard or fiduciary issues during the CPS. Internal audit remains an area of improvement. Both Bhutan Remote Rural Communities Development and Bhutan Urban Development Project complied with the environmental and social management framework requirements for all community infrastructures with Satisfactory or Moderately Satisfactory ratings.

\section{ALIGNMENT WITH CORPORATE GOALS}

32. The CPS program maintained a strong focus on the WBG's Twin Goals. Results Area 1 on improving fiscal management helped strengthen public service delivery that primarily benefited the bottom 40 percent of the income distribution. Policies and reforms to improve investment climate under Results Area 2 helped develop the private sector to create more jobs. Improved access to finance particularly though CIB supported gender equality through increased availability of credit history. Results Area 3 supported targeted rural areas with the highest poverty incidence through various community infrastructure projects targeting the poorest subdistricts through selection criteria that factored various aspects of poverty. Improving access to irrigation, farm roads, and community assets had a positive effect on shared prosperity.

33. Efforts were made in mainstreaming gender into World Bank's portfolio. The recently concluded investment projects (Remote Rural Communities Development Project and Bhutan Urban Development Project) did not consider gender in project design. However, the outcomes of these projects, such as improved road accessibility to market and access to services and farming practices, had positive economic and social impacts for women and children. The DPC series supported the government's efforts to ensure a sustainable economic growth model by promoting gender equality policies and genderdisaggregated result indicators.

34. The CPS program also addressed climate change adaptation through various activities. Particularly, The World Bank has supported the government in preparing a Strategic Framework for Climate Resilience (SPCR) that integrates a multisector climate-resilient investment plan into Bhutan's national development plan and is in line with the Intended Nationally Determined Contributions' priorities. On the DPC operations, climate co-benefits were applied for selected prior actions. 


\section{LESSONS LEARNED}

35. The implementation experience of the CPS provides important lessons to be reflected in the design of the next CPF.

36. Diversification of the financial instruments could have helped achieve greater impact on institutional capacity for a small country such as Bhutan. During the CPS implementation period, the government requested DPCs to utilize all new commitments (US\$104 million). At the PLR, the World Bank explored opportunities to apply IPF and PforR for new projects to contribute more through bringing technical expertise such as project management. For example, PforR instruments can be relevant for a small state like Bhutan because of its focus on capacity building and the ability to link financing directly to the achievement of strengthened institutional capacity, a paramount need in small states.43 However, the government was not able to utilize the instruments partly due to political considerations. Going forward, the government and the World Bank need to deepen the dialogue beyond the Ministry of Finance covering other government agencies that oversee complex reform programs requiring stronger technical and institutional capacities to best utilize different instruments.

37. effectiveness and efficiency of the DPC instrument need to be constantly reviewed. DPC is the only instrument committed during the CPS period. While the use of DPC contributed significantly to accelerate policy and institutional reforms, the implementation was not properly followed in some areas (for example, parliament approval on the Bankruptcy Act). Going forward, the World Bank should consider the effectiveness of the DPC instrument for not only policy and institutional reforms but also implementation and results.

38. Capacity development and coordination across the implementing agencies can help improve implementation bottlenecks of DPC. Despite its smallness Coordination across ministries and agencies remains a concern in Bhutan. Lessons from the implementation of the DPC series showed that due to the cross-cutting nature of the program, many ministries and agencies are involved in the implementation of the policy and institutional reforms. Most of the agencies face limited technical capacity and weak coordination. Tailored technical assistance for building capacity among technical staff should be considered in the DPC program. The WBG's future program, therefore, needs to provide enhanced supervision to improve technical capacity of institutions and internal coordination. In addition, The CPF program could strengthen collaboration with other development partners to leverage capacity development.

39. Technical assistance for IPF is important to improve project implementation, particularly where skills and human capacity are insufficient at the local level. Technical capacity of implementing agencies is one of key binding constraints for project implementation. Lessons from the Remote Rural Communities Development Project show that lack of timely technical assistance hampered the development outcome and efficiency of the project. The project had limited scope for investing in technical assistance as the government was reluctant to use credit resources for the activity. Therefore, It is crucial for future projects to accommodate the institutional strengthening of the implementing agency and capacity building of technical staff at the local level at a much earlier stage.

40. Close engagement with the client has been effective in involving the government to support reform agenda. The WBG's policy recommendation and technical assistance to the RMA and the Ministry of Finance influenced policy reforms in areas such as secured transactions registry reform, credit information reporting, and insolvency regime as identified in the FSDAP. The Extensive consultations ensured smooth implementation of reforms along with buy in from the senior management which ensured

43 World Bank. 2017. "Small State: A Roadmap for World Bank Group Engagement." 
required support at each level. While the World Bank Group has been closely engaged with the client, there is room for improvement.

41. The World Bank's knowledge program could have been more strategic and selective in the use of TF resources. In Bhutan, the Stakeholders are interested in tapping World Bank's knowledge and experience. Technical assistance and analytical work through TF resources complemented lending operations. However, some activities were driven largely by the availability of TF resources and had limited government ownership. In addition, Proliferation of TF activities may have led to the increase in transaction costs for both the client and the World Bank. Going forward, ASA portfolio program needs to be coordinated by their strategic relevance (including link to a project and core analytical works) with fewer and larger TF program that are highly selective with stronger client ownership.

42. Further Collaboration between the World Bank and IFC is needed. The World Bank and IFC complemented their work in business environment and financial sector through advisory and policy lending operations. This was appropriately captured in the CPS Results Matrix. next CPF could explore partnership beyond those sectors Given that Bhutan has some persistent challenges in expanding private sectors, improving productivity, diversification of the economy and developing the domestic markets. For example, looking into improving the quality of both demand of skills and technology supply, thought leadership, advisory support and a joint dialogue to encourage and expedite necessary reforms in key sectors for maximum impact. MIGA could leverage this work for supporting cross-border investment and lending in Bhutan.

43. Engaging citizen at the project design stage to allocate land for infrastructure and community facilities proved to be an effective way of building consensus in urban development. For example, the Preparation of the Second Urban Development Project included the introduction of land pooling, an alternative planning mechanism that offered a more inclusive land assembly approach to reduce the cost of land assembly to manage urban growth and enable service provision. The World Bank and the client provided extensive stakeholder consultations with land owners and the public to resolve the potential for any conflicts or resettlement concerns based on the 2009 land pooling policy. While this lengthened the project preparation period considerably, it also ensured strong ownership at the local level during the planning process. Over the course of the project, land pooling has been used successfully and The Thimphu experience stands as a strong example of using land pooling in the World Bank's operation. In future operations, it will be important to sustain this effort by strengthening citizen engagement and building trust between the government and its citizens. 
CLR Attachment 1: Summary of Results Matrix evaluation

\begin{tabular}{|c|c|c|c|}
\hline CPS outcomes and indicators & Summary of progress at CLR & $\begin{array}{l}\text { Lessons learned and suggestions for } \\
\text { the new CPF }\end{array}$ & $\begin{array}{c}\text { Ongoing and indicative World } \\
\text { Bank Group program }\end{array}$ \\
\hline \multicolumn{4}{|c|}{ Results Area 1: Improving fiscal and spending efficiency } \\
\hline \multicolumn{4}{|c|}{ Outcome 1: Strengthened fiscal efficiency - Achieved } \\
\hline $\begin{array}{l}\text { Indicator 1: Ratio of domestic } \\
\text { revenues to total expenditure } \\
\text { Baseline: } 60 \text { percent (FY2013) } \\
\text { Target: } 62 \text { percent (FY2019) } \\
\text { Indicator 2: Fiscal deficit } \\
\text { Baseline: Below } 4.2 \text { percent } \\
\text { (FY2013) } \\
\text { Target: Below } 6.0 \text { percent } \\
\text { (FY2019) }\end{array}$ & $\begin{array}{l}\text { Achieved. Domestic revenue to total } \\
\text { expenditure is } 65 \text { percent (as of } \\
\text { 2017/18). } \\
\text { Achieved. Fiscal surplus to GDP is at } \\
0.8 \text { percent in FY2019. }\end{array}$ & $\begin{array}{l}\text { Technical assistance is crucial for } \\
\text { reform implementation and } \\
\text { sustainability. Greater focus on } \\
\text { building capacity in the context of } \\
\text { budget support operation will help } \\
\text { strengthen program performance. } \\
\text { Future operations need to be } \\
\text { tailored to existing capacity and will } \\
\text { require focus on institutional } \\
\text { strengthening. }\end{array}$ & $\begin{array}{l}\text { Financing: Closed/Ongoing } \\
\text { Fiscal Sustainability and } \\
\text { Investment Climate DPC I } \\
\text { (P147806); Fiscal Sustainability } \\
\text { and Investment Climate DPC II } \\
\text { (P157469); Strengthening Fiscal } \\
\text { Management and Private Sector } \\
\text { Employment Opportunities DPC } \\
\text { II (P164290) } \\
\text { Ongoing: Strengthening Fiscal } \\
\text { Management and Private Sector } \\
\text { Employment Opportunities DPC } \\
\text { II (P168166) } \\
\text { ASA: Delivered/Ongoing } \\
\text { delivered: Public Finance Think } \\
\text { Piece (P152382); Debt } \\
\text { Management Reform Plan } \\
\text { (P166637); Macro-Fiscal } \\
\text { Monitoring, Analysis and } \\
\text { Management Program } \\
\text { (P152381); Tax Rationalization } \\
\text { TA (P156989); Bhutan } \\
\text { Economic Update (P163844) } \\
\text { (P164960); Macro Monitoring } \\
\text { and Analysis Program } \\
\text { (P165006); Debt Management } \\
\text { Reform Plan (P166637); } \\
\text { Improving Capacity of the } \\
\text { Government to Implement } \\
\text { Infrastructure PPPs (P150701) }\end{array}$ \\
\hline
\end{tabular}




\begin{tabular}{|c|c|c|c|}
\hline $\begin{array}{l}\text { Indicator 3: PEFA } \\
\text { PI-9. Oversight of aggregate fiscal } \\
\text { risk from other public sector entities } \\
\text { D+ (2010) to C+ (2019) } \\
\text { PI-24. Quality and timeliness of in- } \\
\text { year budget reports D+ (2010) to } \\
\text { C+ (2019) } \\
\text { PI-27 Legislative scrutiny of the } \\
\text { annual budget law D+ (2010) to C+ } \\
\text { (2019) }\end{array}$ & $\begin{array}{l}\text { Mostly achieved. Three out of two sub- } \\
\text { indicators achieved, and one not } \\
\text { achieved. } \\
\text { P1-9: Oversight of aggrege fiscal risk } \\
\text { from other public sector entities } \\
\text { improved from D+ to B. } \\
\text { PI -24: Quality and timeliness of in- } \\
\text { year budget to C+. } \\
\text { PI- 27: The status is D+ while there is } \\
\text { progress at the dimension level where } \\
\text { the score for dimensions I and II has } \\
\text { improved but the overall indicator } \\
\text { remained the same as baseline. } \\
\text { Achieved. On average, it takes } 60 \text { days } \\
\text { through e-GP system. }\end{array}$ & $\begin{array}{l}\text { - Deeper the Ownership of the } \\
\text { reforms by the government, better } \\
\text { the results. } \\
\text { Where the capacity of the } \\
\text { implementing agency is limited, } \\
\text { reforms should be phased in } \\
\text { gradually. } \\
\text { Bhutan needs to Continue to } \\
\text { implement several of its Key } \\
\text { ongoing PFM reforms both on the } \\
\text { revenue and expenditure side. These } \\
\text { reforms are primary or fundamental. } \\
\text { Once these reforms are } \\
\text { consolidated, the government } \\
\text { should move on to the next levels of } \\
\text { reforms covering public investment } \\
\text { management and so on. }\end{array}$ & $\begin{array}{l}\text { Financing: Ongoing/Closed } \\
\text { closed: } \\
\text { - PFM IDF } \\
\text { - } \quad \text { PFM MDF } \\
\text { ASA: Delivered/Ongoing } \\
\text { delivered: Public Financial } \\
\text { Management Report (PEFA -II) } \\
\text { (P153989); BT PFM Reform } \\
\text { Strategy and Action Plan } \\
\text { (P165361); } \\
\text { APA assessment of Thimphu } \\
\text { Thromde }\end{array}$ \\
\hline \multicolumn{4}{|c|}{ Results Area 2: Increasing private sector growth and competitiveness } \\
\hline \multicolumn{4}{|c|}{ Outcome 3: Improved regulatory framework for business environment - Mostly achieved } \\
\hline $\begin{array}{l}\text { Indicator 6: Foreign direct private } \\
\text { investment } \\
\text { Baseline: US } \$ 21 \text { million }(2014) \\
\text { Target: US } \$ 50 \text { million (2019) }\end{array}$ & $\begin{array}{l}\text { Mostly achieved. According to the } \\
\text { Doing Business report } 2019 \text {, it takes } 12 \\
\text { days to start a business. Bhutan made it } \\
\text { easier by reducing the time for } \\
\text { obtaining a security clearance } \\
\text { certificate, registering at the Office } \\
\text { of the Registrar, and registering for } \\
\text { taxes. (Source: DPC series } \\
\text { Implementation Completion and } \\
\text { Results Review) }\end{array}$ & $\begin{array}{l}\text { Bhutan needs to implement Doing } \\
\text { Business reforms and ensure that } \\
\text { there is a consistent government } \\
\text { policy that can help improve } \\
\text { investment climate with a well- } \\
\text { organized team from the } \\
\text { government that can spearhead the } \\
\text { reforms. In addition to } \\
\text { strengthening the regulatory } \\
\text { environment it is important to } \\
\text { stimulate the growth of CSIs and } \\
\text { start-ups through the development } \\
\text { of a robust entrepreneurship/CSI } \\
\text { ecosystem. }\end{array}$ & $\begin{array}{l}\text { Financing: Ongoing/closed } \\
\text { Closed: Fiscal Sustainability } \\
\text { and Investment Climate DPC I } \\
\text { (P147806); Fiscal Sustainability } \\
\text { and Investment Climate DPC II } \\
\text { (P157469); Strengthening Fiscal } \\
\text { Management and Private Sector } \\
\text { Employment Opportunities DPC } \\
\text { II (P164290) } \\
\text { Ongoing: Strengthening Fiscal } \\
\text { Management and Private Sector } \\
\text { Employment Opportunities DPC } \\
\text { II (P168166) } \\
\text { ASA: Delivered/Ongoing } \\
\text { Delivered: Trade and Transport } \\
\text { Facilitation (P149065); } \\
\text { Improving Bhutan Investment } \\
\text { Climate (P153221); }\end{array}$ \\
\hline
\end{tabular}




\begin{tabular}{|c|c|c|c|}
\hline & $\begin{array}{l}\text { information and communication } \\
\text { technologies. }\end{array}$ & & $\begin{array}{l}\text { Programmatic TA for Private } \\
\text { Sector Competitiveness and } \\
\text { Investment Climate Reform } \\
\text { (P165685) } \\
\text { Ongoing: PPP TA; A Job } \\
\text { Platform; Hotel Expansion to } \\
\text { Promote Tourism (IFC) }\end{array}$ \\
\hline \multicolumn{4}{|c|}{ Outcome 4: Increased efficiency and access to financial services - Achieved } \\
\hline $\begin{array}{l}\text { Indicator 7: Increase in the share } \\
\text { of credit to manufacturing, } \\
\text { agriculture, service and tourism, } \\
\text { trade and commerce } \\
\text { Baseline (2013): } 45 \text { percent } \\
\text { Target: } 50 \text { percent (2019) } \\
\\
\text { Indicator 8: Increased coverage of } \\
\text { credit information bureau } \\
\text { Baseline: } 0 \text { percent (2014) } \\
\text { Target: } 35 \text { percent (2019) }\end{array}$ & $\begin{array}{l}\text { Achieved. As of March } 2019 \text {, the total } \\
\text { loan portfolio size is Nu } 112.25 \text { billion } \\
\text { and the share of credit to } \\
\text { manufacturing, agriculture, services and } \\
\text { tourism, and trade and commerce is } \\
53.3 \text { percent of the total portfolio. } \\
\text { Achieved. As of } 2018,35.9 \text { percent } \\
\text { (male: } 22.7 \text { percent and female } \\
\text { 13.2percent) of adult population has } \\
\text { access to CIB. The credit report shows } \\
\text { the demographic details of the borrower } \\
\text { and the detailed history of his/her credit } \\
\text { status. The commercial report contains } \\
\text { the details of the credit facility granted } \\
\text { to the commercial entities. }\end{array}$ & $\begin{array}{l}\text { - Close engagement with the } \\
\text { government through technical } \\
\text { assistance proved to be an effective } \\
\text { way to achieve the intended results } \\
\text { as well as support government } \\
\text { reforms in the areas related to } \\
\text { secured transactions registry, credit } \\
\text { information reporting, and } \\
\text { insolvency regime. }\end{array}$ & $\begin{array}{l}\text { Financing: Closed/Ongoing } \\
\text { Closed: Fiscal Sustainability } \\
\text { and Investment Climate DPC I } \\
\text { (P147806); Fiscal Sustainability } \\
\text { and Investment Climate DPC II } \\
\text { (P157469); Strengthening Fiscal } \\
\text { Management and Private Sector } \\
\text { Employment Opportunities DPC } \\
\text { II (P164290) } \\
\text { Ongoing: Strengthening Fiscal } \\
\text { Management and Private Sector } \\
\text { Employment Opportunities DPC } \\
\text { II (P168166) } \\
\text { ASA: Delivered/Ongoing } \\
\text { Delivered: Financial Sector } \\
\text { Strategy (P147461); Bhutan } \\
\text { Institutional and Organization } \\
\text { Review of the RMA (P159068); } \\
\text { Implementation of Financial } \\
\text { Sector Development Action Plan } \\
\text { (P161711); Off-load half of IFC } \\
\text { ownership in BNB- increase } \\
\text { efficiency } \\
\text { Ongoing: Monitor and support } \\
\text { existing portfolio: BNB and } \\
\text { ESM (IFC); Financial } \\
\text { Infrastructure TA (IFC); } \\
\text { supporting RMA for financial } \\
\text { inclusion workshop (IFC); }\end{array}$ \\
\hline
\end{tabular}




\begin{tabular}{|c|c|c|c|}
\hline & & & $\begin{array}{l}\text { support to credit bureau } \\
\text { (IFC); RMA on corporate } \\
\text { governance (IFC); assisting } \\
\text { SME Fund for Bhutan (IFC) }\end{array}$ \\
\hline \multicolumn{4}{|c|}{ Results Area 3: Supporting green development } \\
\hline \multicolumn{4}{|c|}{ Outcome 5: Increased agricultural productivity in targeted remote areas - Achieved } \\
\hline $\begin{array}{l}\text { Indicator 9: Cereal yields in } \\
\text { targeted irrigation system } \\
\text { (MT/acre) } \\
\text { Paddy: Baseline: } 1.1 \text { (2012) } \\
\text { Target: } 1.32 \text { (2019). } \\
\text { Indicator 10: Number of female } \\
\text { clients who adopted an improved } \\
\text { agriculture technology } \\
\text { Baseline: } 0(2012) \\
\text { Target: } 190(2017)\end{array}$ & $\begin{array}{l}\text { Achieved. } 189 \text { female farmers (out of } \\
450 \text { total farmers) adopted improved } \\
\text { technology promoted through the } \\
\text { project. The Shortfall of } 0.5 \text { percent is } \\
\text { well within the margin of error. }\end{array}$ & $\begin{array}{l}\text { - Complementing technical assistance } \\
\text { with investing financing is critical } \\
\text { for achieving desired outcomes. } \\
\text { Lack of soft investments in } \\
\text { technical assistance hampered the } \\
\text { development outcome and } \\
\text { efficiency of the Remote Rural } \\
\text { Community Development Project. It } \\
\text { is critical for future projects to } \\
\text { accommodate the institutional } \\
\text { strengthening of the implementing } \\
\text { agency and the capacity building of } \\
\text { technical field implementers at early } \\
\text { stages. }\end{array}$ & $\begin{array}{l}\text { Financing: Ongoing/Closed } \\
\text { Closed: Remote Rural } \\
\text { Community Development } \\
\text { Project (P123820) } \\
\text { Ongoing: Food Security and } \\
\text { Agriculture Productivity (TF); } \\
\text { Generating Youth Employment } \\
\text { and Community Based } \\
\text { Enterprise Development (TF) } \\
\text { ASA: Delivered/Closed } \\
\text { delivered: Supporting Bhutan's } \\
\text { Social Protection and Labor } \\
\text { Strategy; Poverty and Shared } \\
\text { Prosperity NLTA (P152474); } \\
\text { Bhutan PA on Poverty and } \\
\text { Social Protection (P158583); } \\
\text { Targeted Household Poverty } \\
\text { Program (P159525); Strategic } \\
\text { Agriculture Sector Review for } \\
\text { Job Creation and Sustainable } \\
\text { Rural Livelihood in Bhutan } \\
\text { (P165766); A Job Platform }\end{array}$ \\
\hline \multicolumn{4}{|c|}{ Outcome 6: Improved urban infrastructure management - Achieved. } \\
\hline $\begin{array}{l}\text { Indicator 11: Number of new } \\
\text { households with piped water and } \\
\text { sewage connections and kilometers } \\
\text { of internal roads constructed in the } \\
\text { targeted cities } \\
\text { Water: Baseline: } 20,000(2014) \\
\text { Target: } 20,500(2019) \\
\text { Sewage: Baseline: } 0 \text { (2010) } \\
\text { Target: } 250\end{array}$ & $\begin{array}{l}\text { Achieved. } \\
\text { Water: } 732 \text { additional households have } \\
\text { access to new piped water connections. } \\
\text { Sewerage: } 510 \text { households with new } \\
\text { sewerage connections. } \\
\text { Roads: } 10.5 \mathrm{~km} \text { of internal roads } \\
\text { constructed. }\end{array}$ & $\begin{array}{l}\text { Good progress was made in terms of } \\
\text { civil works and improvements in } \\
\text { municipal revenue management. } \\
\text { However, training and capacity } \\
\text { building for Thromde staff and } \\
\text { defining long-term operation and } \\
\text { maintenance arrangements for } \\
\text { capital investments raise concerns } \\
\text { about the longer-term sustainability. }\end{array}$ & $\begin{array}{l}\text { Financing: Ongoing/Closed } \\
\text { Closed: Strengthening } \\
\text { intergovernmental systems } \\
\text { (IDF); Second Urban } \\
\text { Development Project (P090157) } \\
\text { and Additional Financing } \\
\text { (P145392) } \\
\text { ASA: Delivered/Ongoing }\end{array}$ \\
\hline
\end{tabular}




\begin{tabular}{|c|c|c|c|}
\hline $\begin{array}{l}\text { Roads: Baseline: } 0 \mathrm{~km} \mathrm{(2010)} \\
\text { Target: } 8.34 \mathrm{~km}(2019) \\
\text { Indicator 12: Upgraded municipal } \\
\text { finance systems in four city } \\
\text { corporations } \\
\text { Building permits for service plots } \\
\text { Baseline: } 115 \text { (2010) } \\
\text { Target: } 200 \text { (2019) }\end{array}$ & $\begin{array}{l}\text { Achieved. } 221 \text { building permits have } \\
\text { been issued for local area planning. }\end{array}$ & $\begin{array}{l}\text { Land pooling as a planning } \\
\text { mechanism for three local area } \\
\text { plan is a successful example of } \\
\text { managing urban expansion for new } \\
\text { growth. }\end{array}$ & $\begin{array}{l}\text { Delivered: Stewardship } \\
\text { Planning for Bhutan's Cultural } \\
\text { Heritage Bill Implementation } \\
\text { and Review of Bhutan's Tourism } \\
\text { Policy (P152108); Public } \\
\text { Transport Access TA for } \\
\text { Thimphu (P156611); Monitor } \\
\text { Progress of PPP Parking Project } \\
\text { (IFC); } \\
\text { Bhutan Urban Policy Notes } \\
\text { (P165222); Affordable Housing } \\
\text { Options (IFC) }\end{array}$ \\
\hline \multicolumn{4}{|c|}{ Outcome 7: Improved management of the natural capital and resilience to climate change/disaster risks - Achieved } \\
\hline $\begin{array}{l}\text { Indicator 14: Improved disaster } \\
\text { preparedness and delivery of } \\
\text { weather and climate services } \\
\text { Baseline: 1-day subjective weather } \\
\text { forecasting (2014) } \\
\text { Target: 3-day weather forecasting } \\
\text { with verification system (2019) } \\
\\
\text { Indicator 15: The Number of } \\
\text { hydromet services developed } \\
\text { Baseline: } 0 \\
\text { Target: } 2(2019)\end{array}$ & $\begin{array}{l}\text { Achieved. As of December } 31,2018 \text {, } \\
1,327,462 \text { ha was brought under } \\
\text { enhanced biodiversity protection } \\
\text { through demarcation and expansion, } \\
\text { development and repair of trails and } \\
\text { bridges for effective mobility of park } \\
\text { officials and biodiversity. } \\
\text { Achieved. 3-day weather forecasting is } \\
\text { being provided. }\end{array}$ & $\begin{array}{l}\text { Biodiversity conservation and } \\
\text { natural resource management is } \\
\text { highly relevant to improving the } \\
\text { management of Bhutan's natural } \\
\text { capital and enhancing sustainable } \\
\text { growth and resilience to the impacts } \\
\text { of climate change. } \\
\text { BTFEC is now a national partner } \\
\text { with institutional capacity and } \\
\text { sustainability for successfully } \\
\text { mainstreaming biodiversity } \\
\text { conservation into national planning. }\end{array}$ & $\begin{array}{l}\text { Financing: Ongoing/Closed } \\
\text { Strengthening Regional } \\
\text { Cooperation for Wildlife } \\
\text { Protection in Asia (closed); } \\
\text { Sustainable Financing for } \\
\text { Biodiversity Conservation and } \\
\text { Natural Resource Management } \\
\text { (TF014705); Bhutan Hydromet } \\
\text { Services and Disaster Resilience } \\
\text { (TF0A3513); Hydromet Services } \\
\text { and Disaster Resilience Regional } \\
\text { Project (P154477); Bhutan } \\
\text { Weather and Disaster } \\
\text { Improvement Regional Project } \\
\text { (TF0A3511); Strategic Program } \\
\text { for Climate Resilience } \\
\text { (TF0A4475); PHRD for } \\
\text { Improving Resilience to Seismic } \\
\text { Risk (TF) } \\
\text { Bhutan REDD+ Readiness } \\
\text { Preparation Support Program } \\
\text { (TF0A6108); Bhutan FCPF } \\
\text { Readiness Grant (TF019030); } \\
\text { Hydropower TA } \\
\text { ASA: Delivered/Ongoing }\end{array}$ \\
\hline
\end{tabular}




\begin{tabular}{|l|l|l|}
\hline & & Delivered: Bhutan Forest Note; \\
& Hydromet Modernization and \\
Resilience TA; Minerals for & \\
Development Bhutan (P158727); \\
Green Growth Policy Note; \\
Disaster and Climate Resilience \\
TA; Sustainable Development of \\
Hydropower (P156263) \\
Ongoing: Cryosphere \\
Monitoring and Capacity \\
Development; Formulation of \\
Strategic Roadmap for \\
Remaining Untapped \\
Hydropower Potential in Bhutan
\end{tabular}




\section{CLR Attachment 2: Planed and actual lending}

\begin{tabular}{|c|l|c|l|c|}
\hline FY & \multicolumn{1}{|c|}{ Planned } & $\begin{array}{c}\text { Amount(US\$, } \\
\text { million) }\end{array}$ & \multicolumn{1}{|c|}{ Actual } & $\begin{array}{c}\text { Amount(US\$, } \\
\text { million) }\end{array}$ \\
\hline FY15 & Development Policy Credit & 20 & & 20 \\
\hline FY16 & Regional Connectivity & 13 & $\begin{array}{l}\text { Fiscal Sustainability and } \\
\text { Investment Climate Development } \\
\text { Policy Credit (I) (P147806) }\end{array}$ & $\begin{array}{l}\text { Fiscal Sustainability and } \\
\text { Investment Climate Development } \\
\text { Policy Credit (II) (P157469) }\end{array}$ \\
\hline FY17 & Development Policy Credit 2 & 20 & $\begin{array}{l}\text { Strengthening Fiscal Management } \\
\text { and Private Sector Employment } \\
\text { DPC (I) (P164290) }\end{array}$ & 30 \\
\hline FY18 & $\begin{array}{l}\text { New Development Policy } \\
\text { Credit }\end{array}$ & 30 & Dropped & 30 \\
\cline { 2 - 5 } & \begin{tabular}{l} 
Hydropower TA \\
\cline { 2 - 5 } \\
Regional Connectivity Project \\
including regional IDA)
\end{tabular} & 25 & Dropped & \\
\hline FY19 & $\begin{array}{l}\text { New Development Policy } \\
\text { Credit Series }\end{array}$ & 30 & $\begin{array}{l}\text { Strengthening Fiscal Management } \\
\text { and Private Sector Employment } \\
\text { Opportunities (II) (P168166) }\end{array}$ & \\
\cline { 2 - 5 } & $\begin{array}{l}\text { A PforR Operation in the } \\
\text { Financial Sector }\end{array}$ & & & $\mathbf{1 0 4}$ \\
\hline & $\begin{array}{l}\text { Total (including regional } \\
\text { IDA) }\end{array}$ & $\mathbf{1 4 2}$ & & \\
\hline
\end{tabular}




\begin{tabular}{|c|c|}
\hline \multicolumn{2}{|c|}{ CLR Attachment 3: Planned and actual ASA activities } \\
\hline CPS Planned & CPS Actual \\
\hline Bi Annual Economic Update & Bhutan Financial Sector Strategy (P147461) \\
\hline Public Finance Think Piece & $\begin{array}{l}\text { Disaster Risk Management and Climate Resilience in } \\
\text { Bhutan (P148430) }\end{array}$ \\
\hline PEFA Update & Bhutan Trade and Transport Facilitation (P149065) \\
\hline Labor Market and Skills Assessment & $\begin{array}{l}\text { Bhutan \#A060 Financial Sector Development } \\
\text { Implementation Plan (P150078) }\end{array}$ \\
\hline Investment Climate Assessment & $\begin{array}{l}\text { Bhutan Improving Capacity of the Government to } \\
\text { Implement Infrastructure PPPs (Phase II) (P150701) }\end{array}$ \\
\hline Public Finance Management MDTF & $\begin{array}{l}\text { Stewardship Planning for Bhutan's Cultural Heritage } \\
\text { Bill Implementation and Review of Bhutan's Tourism } \\
\text { Policy (P152108) }\end{array}$ \\
\hline Statistical Capacity Building - TFSCB & $\begin{array}{l}\text { Bhutan Macro-Fiscal Monitoring, Analysis and } \\
\text { Management Program (P152381) }\end{array}$ \\
\hline Financial Sector (FIRST) & Public Finance Think Piece (P152382) \\
\hline BNB Risk Management Advisory (IFC) & $\begin{array}{l}\text { Bhutan Poverty and Shared Prosperity NLTA } \\
\text { (P152474) }\end{array}$ \\
\hline Corporate Governance RMA (IFC) & Roads and Bridges Asset Management TA (P152774) \\
\hline Business Climate TA (World Bank + IFC) & In Depth Labor Market Analysis (P153004) \\
\hline Rural Youth Employment (JSDF) & Improving Bhutan Investment Climate (P153221) \\
\hline Social Protection TA & $\begin{array}{l}\text { BT: Public Financial Management Report (PEFA II) } \\
\text { (P153989) }\end{array}$ \\
\hline Inland Water Transport & Sustainable Development of Hydropower (P156263) \\
\hline Feasibility SEW Highway ICD & Public Transport Access TA for Thimphu (P156611) \\
\hline Cultural Heritage TA & $\begin{array}{l}\text { Bhutan Tax Rationalization Technical Assistance } \\
\text { (P156989) }\end{array}$ \\
\hline REDD+ (FCPF) & $\begin{array}{l}\text { Bhutan PA on Poverty and Social Protection } \\
\text { (P158583) }\end{array}$ \\
\hline Disaster and Climate Resilience TA & BT: Green Data Center Strategy (P158584) \\
\hline Green Urban Transport & Minerals for Development in Bhutan (P158727) \\
\hline Green Growth TA (including mining) & $\begin{array}{l}\text { Bhutan Institutional and organization review of the } \\
\text { RMA (P159068) }\end{array}$ \\
\hline Tourism Strategy (IFC) & $\begin{array}{l}\text { TA Targeted Household Poverty Programme } \\
\text { (P159525) }\end{array}$ \\
\hline Bhutan Development Report & BH: Hydropower Sustainability Support (P159917) \\
\hline Poverty Assessment & Property Registration (P160388) \\
\hline APA assessment of Thimphu Thormode & Bhutan Development Report (P161253) \\
\hline Financial Infrastructure Bhutan (with IFC) & $\begin{array}{l}\text { Bhutan Implementation of Financial Sector } \\
\text { Development Action Plan (P161711) }\end{array}$ \\
\hline A Job Platform & Bhutan Economic Update (P164960) \\
\hline $\begin{array}{l}\text { Formulation of Strategic Roadmap for Remaining } \\
\text { Untapped Hydropower Potential in Bhutan }\end{array}$ & $\begin{array}{l}\text { Bhutan Macro Monitoring and Analysis Program } \\
\text { (P165006) }\end{array}$ \\
\hline Hydropower Sustainability Support & Bhutan Urban Policy Notes (P165222) \\
\hline Cryosphere & $\begin{array}{l}\text { Bhutan PFM Reform Strategy and Action Plan } \\
\text { (P165361) }\end{array}$ \\
\hline & $\begin{array}{l}\text { Bhutan Programmatic TA for Private Sector } \\
\text { Competitiveness and Investment Climate Reform } \\
(\mathrm{P} 165685)\end{array}$ \\
\hline
\end{tabular}


Strategic Agricultural Sector Review for Job Creation and Sustainable Rural Livelihood in Bhutan (P165766)

Bhutan Health Sector Support Program (P166520)

Bhutan Debt Management Reform Plan (P166637)

Improving Employment and Inclusion Impacts of Entrepreneurship Interventions in Bhutan

(P168206)

Encouraging Private Sector Youth Employment (P165569)

Bhutan Jobs Platform (P165860)

Creation of a Functional Labor Market Information

System (LMIS) (P170574)

BT: Accelerating MCH \& Learning Outcomes (P170787)

Bhutan: Health Service Delivery Indicators (P170544)

Updating the ICT Roadmap (P154673)

Green Data Center Strategy (P158584) 


\section{ANNEX 3. SELECTED INDICATORS OF BANK PORTFOLIO PERFORMANCE AND MANAGEMENT}

As of December 1, 2020

\section{$\underline{\mathrm{IBRD} / \mathrm{IDA}} *$}

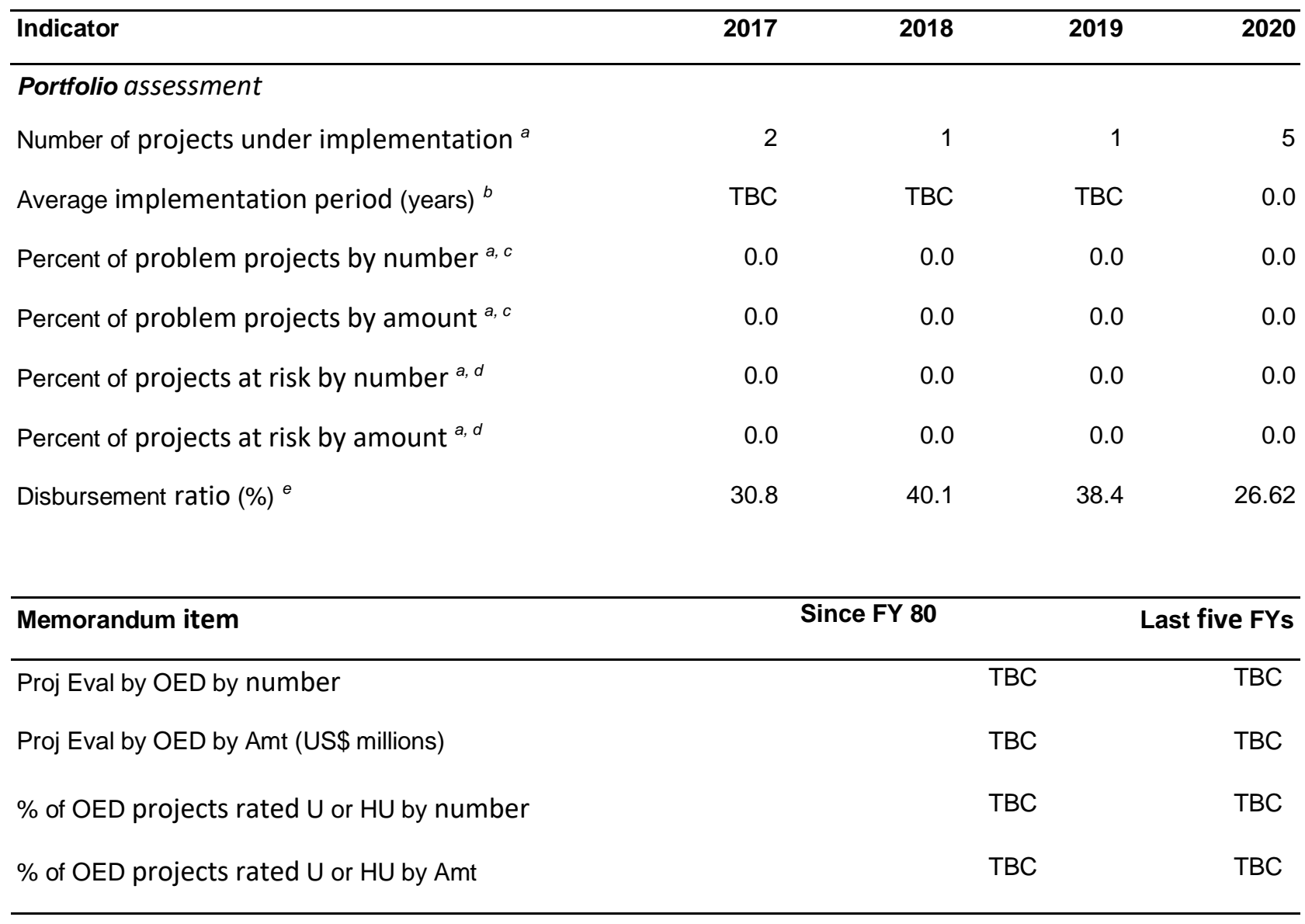

a. As shown in the Annual Report on Portfolio Performance (except for current FY).

b. Average age of projects in the Bank's country portfolio.

c. Percent of projects rated $\mathrm{U}$ or $\mathrm{HU}$ on development objectives (DO) and/or implementation progress (IP).

d. As defined under the Portfolio Improvement Program.

e. Ratio of disbursements during the year to the undisbursed balance of the Bank's portfolio at the beginning of the year: Investment projects only.

* All indicators are for projects active in the Portfolio, with the exception of Disbursement Ratio, which includes all active projects as well as projects which exited during the fiscal year. 


\section{ANNEX 4. OPERATIONS PORTFOLIO (IBRD/IDA AND GRANTS)}

\section{$\underline{\text { IBRD/IDA }}$ *}

Total disbursed (active)

of which has been repaid

0.00

Total disbursed (closed)

0.00

of which has been repaid

0.00

Total disbursed (active + closed)

0.00

of which has been repaid

0.00

Total undisbursed (active)

Total undisbursed (closed)

Total undisbursed (active + closed)

0.00

active projects

Implementation

\begin{tabular}{|c|c|c|c|c|c|c|}
\hline $\begin{array}{l}\text { Project } \\
\text { ID }\end{array}$ & Project name & Progress & Fiscal year & IDA & Grant & UNdisb. \\
\hline P155513 & $\begin{array}{l}\text { Food Security and } \\
\text { Agriculture Productivity } \\
\text { Project Employment }\end{array}$ & $\mathrm{S}$ & 2017 & & 8.00 & 1.25 \\
\hline $\mathrm{P} 171780$ & $\begin{array}{l}\text { Strengthening Fiscal } \\
\text { Management and Private } \\
\text { Sector Employment } \\
\text { Opportunities } \\
\text { Development Policy } \\
\text { Credit }\end{array}$ & & 2020 & 40.00 & & 0.00 \\
\hline P150177 & Bhutan REDD Readiness & & 2015 & & 4.8 & 0.00 \\
\hline P173008 & $\begin{array}{l}\text { Bhutan Development } \\
\text { Policy Financing with Cat } \\
\text { DDO }\end{array}$ & $\mathrm{S}$ & 2020 & 14.8 & & 0.00 \\
\hline P173787 & $\begin{array}{l}\text { Bhutan: COVID-19 } \\
\text { Emergency Response and } \\
\text { Health Systems } \\
\text { Preparedness Project }\end{array}$ & $\mathrm{S}$ & 2020 & 5 & & 2.16 \\
\hline \multicolumn{4}{|c|}{ Overall results } & 59.8 & 12.8 & 3.41 \\
\hline
\end{tabular}




\section{ANNEX 5. STATEMENT OF IFC'S HELD AND DISBURSED PORTFOLIO}

B8 (IFC) For Bhutan

Committed and Disbursed Outstanding Investment Portfolio

As of 10/31/2020

(In USD Millions)

\begin{tabular}{|c|c|c|c|c|c|c|c|c|c|c|c|}
\hline \multirow[b]{2}{*}{ FY Approval } & \multirow[b]{2}{*}{ Company } & \multicolumn{5}{|c|}{ Committed } & \multicolumn{5}{|c|}{ Disbursed Outstanding } \\
\hline & & Loan & Equity & $\begin{array}{l}\text { *Quasi } \\
\text { Equity }\end{array}$ & ${ }^{*} \mathrm{GT} / \mathrm{RM}$ & Participant & Loan & Equity & $\begin{array}{l}\text { "*Quasi } \\
\text { Equity }\end{array}$ & ${ }^{*} \mathrm{GT} / \mathrm{RM}$ & Participant \\
\hline FY13 & BHUTAN NATIONAL & 0.00 & 14.22 & 0.00 & 0.00 & 0.00 & 0.00 & 14.22 & 0.00 & 0.00 & 0.00 \\
\hline Total Portfolic & & 0.00 & 14.22 & 0.00 & 0.00 & 0.00 & 0.00 & 14.22 & 0.00 & 0.00 & 0.00 \\
\hline
\end{tabular}

